Prepared in cooperation with National Park Service

\title{
Predicting the Vulnerability of Streams to Episodic Acidification and Potential Effects on Aquatic Biota in Shenandoah National Park, Virginia
}

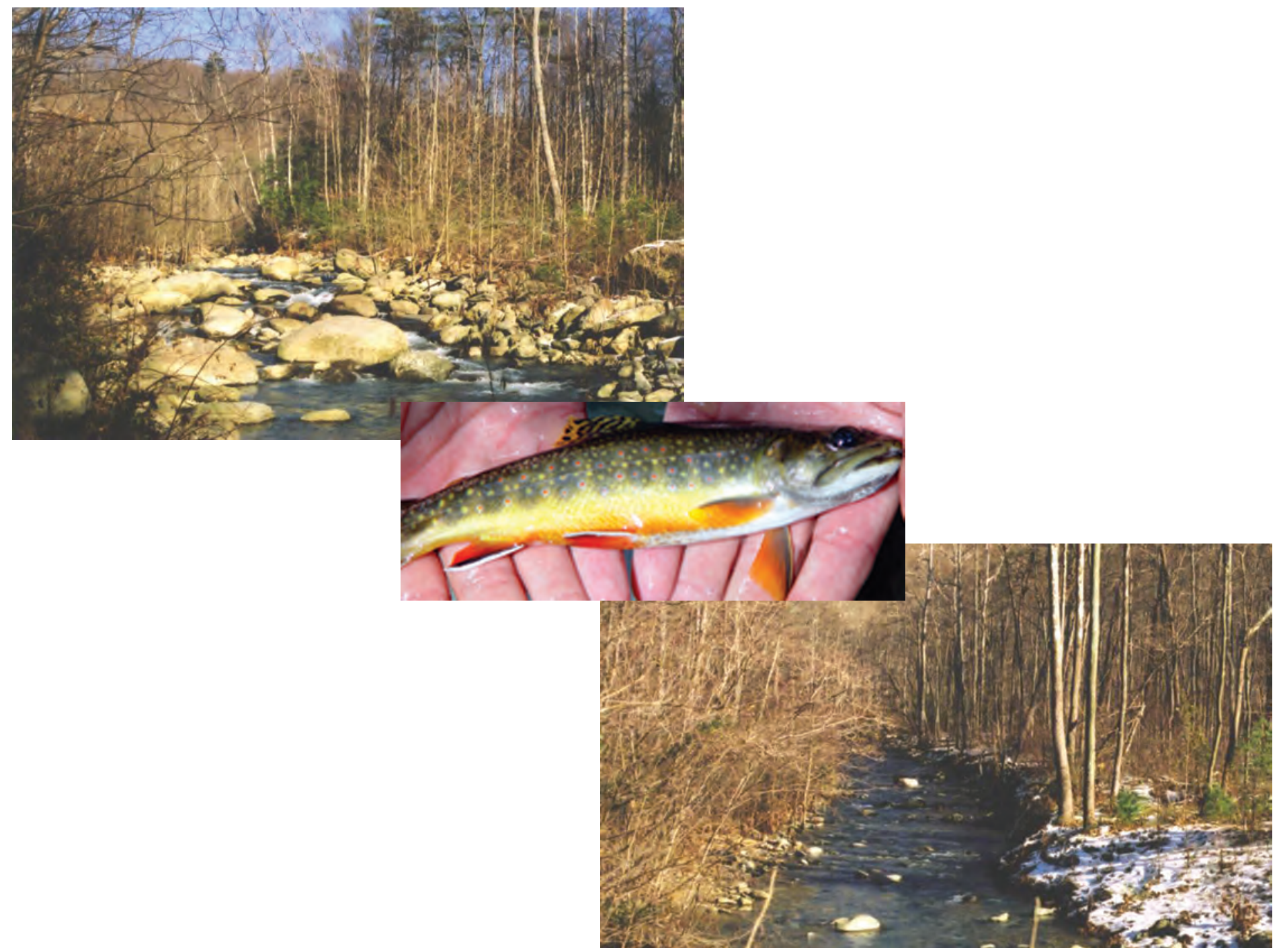

Scientific Investigations Report 2005-5259 


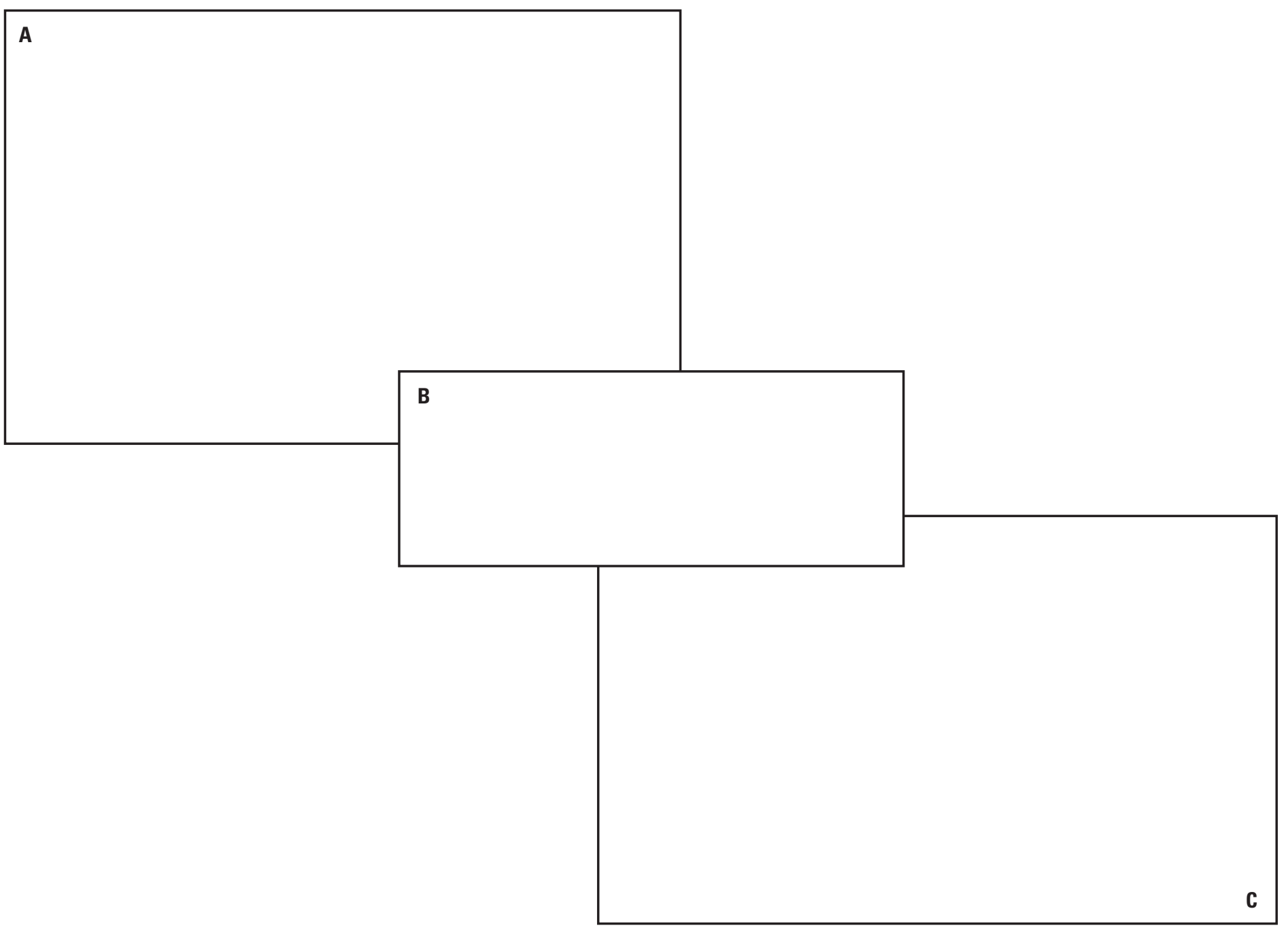

\section{Front Cover:}

A. Photograph of Rapidan River in the Shenandoah National Park, near Graves Mill, Virginia, by Karen C. Rice, U.S. Geological Survey

B. Photograph of brook trout by James R. Webb, University of Virginia

C. Photograph of Rapidan River in the Shenandoah National Park, near Graves Mill, Virginia, by Karen C. Rice, U.S. Geological Survey 


\section{Predicting the Vulnerability of Streams to Episodic Acidification and Potential Effects on Aquatic Biota in Shenandoah National Park, Virginia}

By Karen C. Rice, ${ }^{1}$ Frank A. Deviney, Jr., ${ }^{2}$ George M. Hornberger, ${ }^{2}$ and James R. Webb ${ }^{2}$

${ }^{1}$ U.S. Geological Survey

${ }^{2}$ University of Virginia

Prepared in cooperation with National Park Service

Scientific Investigations Report 2005-5259 


\title{
U.S. Department of the Interior \\ Gale A. Norton, Secretary
}

\section{U.S. Geological Survey \\ P. Patrick Leahy, Acting Director}

\section{U.S. Geological Survey, Reston, Virginia: 2006}

\author{
For sale by U.S. Geological Survey, Information Services \\ Box 25286, Denver Federal Center \\ Denver, CO 80225 \\ For product and ordering information: \\ World Wide Web: http://www.usgs.gov/pubprod \\ Telephone: 1-888-ASK-USGS
}

Any use of trade, product, or firm names is for descriptive purposes only and does not imply endorsement by the U.S. Government.

Although this report is in the public domain, permission must be secured from the individual copyright owners to reproduce any copyrighted materials contained within this report.

For additional information, contact:

Director

USGS Virginia Water Science Center

1730 E. Parham Rd.

Richmond, VA 23228

dc_va@usgs.gov

Information about water resources in Virginia is available online at http://va.water.usgs.gov 


\section{Contents}

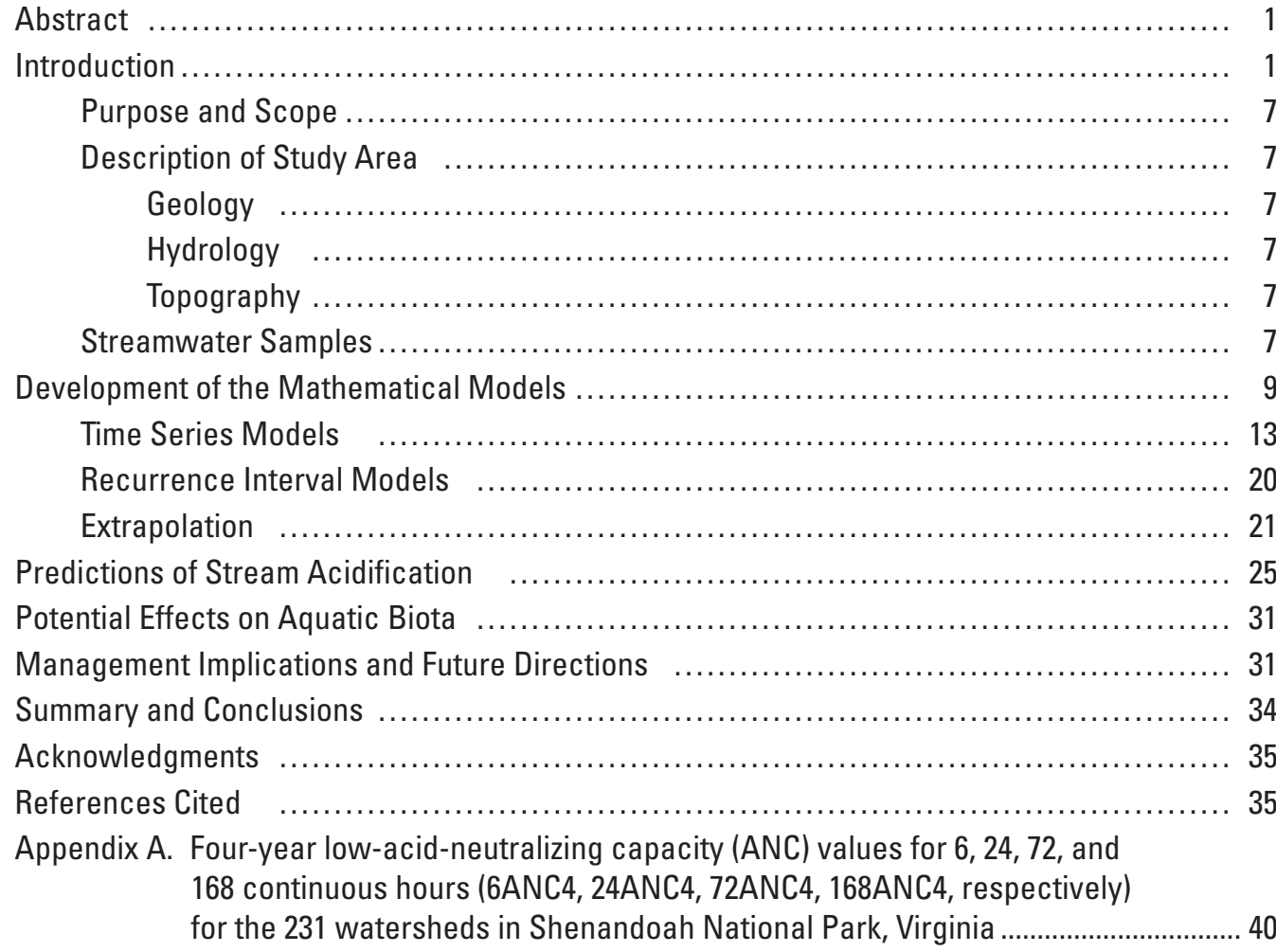

Appendix B. Streamgaging techniques used by the Shenandoah Watershed Study (SWAS), Virginia.

\section{Figures}

1. Location of Shenandoah National Park, Virginia .............................................................. 3

2. Relations among $\mathrm{pH}$, acid-neutralizing capacity, and associated bedrock type in streams in Shenandoah National Park, Virginia..................................................... 4

3. Relation between acid-neutralizing capacity and discharge in Staunton River in Shenandoah National Park, Virginia.................................................. 5

4. Generalized geology and location of the 5 Shenandoah Watershed Study (SWAS) watersheds and the 231 watersheds in Shenandoah National Park, Virginia ................. 8

5-10. Graphs showing:

5. Distribution of watershed area among the Shenandoah Watershed Study (SWAS) and Shenandoah National Park (SNP) watersheds, Virginia

6. Distribution of geologic metrics among the Shenandoah Watershed Study (SWAS) and Shenandoah National Park (SNP) watersheds, Virginia 
7. Distribution of topographic metrics among the Shenandoah Watershed Study (SWAS) and Shenandoah National Park (SNP)

watersheds, Virginia . 12

8. Distribution of streamwater acid-neutralizing capacity among the Shenandoah Watershed Study (SWAS) watersheds, Virginia 14

9. Distribution of natural logarithms of hourly discharge among the Shenandoah Watershed Study (SWAS) watersheds, Virginia 15

10. Distribution of natural logarithms of hourly runoff among the Shenandoah Watershed Study (SWAS) watersheds, Virginia 16

11. Flowchart showing three major steps in development of models used to predict the vulnerability of streams to episodic acidification in Shenandoah National Park, Virginia .

12. Rank of annual acid-neutralizing capacity minimum values for the Shenandoah Watershed Study (SWAS) watersheds, Virginia for 6-hour (A), 24-hour (B), 72-hour (C), and 168-hour (D) duration periods

13. Estimated recurrence intervals for the Shenandoah Watershed Study (SWAS) watersheds, Virginia for 6-hour (A), 24-hour (B), 72-hour (C), and 168-hour (D) duration periods predicted by annual minimum acid-neutralizingcapacity values.

14-17. Maps showing:

14. Predicted range of minimum values of acid-neutralizing capacity (ANC) on a 4-year recurrence interval for 6-hour duration periods (6ANC4) in watersheds in Shenandoah National Park, Virginia .

15. Predicted range of minimum values of acid-neutralizing capacity (ANC) on a 4-year recurrence interval for 24-hour duration periods (24ANC4) in watersheds in Shenandoah National Park, Virginia.

16. Predicted range of minimum values of acid-neutralizing capacity (ANC) on a 4-year recurrence interval for 72-hour duration periods (72ANC4) in watersheds in Shenandoah National Park, Virginia .

17. Predicted range of minimum values of acid-neutralizing capacity (ANC) on a 4-year recurrence interval for 168-hour duration periods (168ANC4) in watersheds in Shenandoah National Park, Virginia.

18-20. Graphs showing:

18. Estimated recurrence interval distributions for the Shenandoah Watershed Study (SWAS) watersheds, Virginia for 6-hour (A), 24-hour $(B)$, 72-hour (C), and 168-hour (D) duration periods predicted by regression of parameters against watershed characteristics.

19. Relations between minimum and mean elevations and corresponding values for 72ANC4 for watersheds underlain by $0(A), 20(B), 80(C)$, and $100(D)$ percent basaltic/carbonate bedrock, with the remainder of the watershed underlain by siliciclastic bedrock, in Shenandoah National Park, Virginia

20. Distribution of Shenandoah National Park, Virginia watersheds that are predicted to have 72-hour low-acid-neutralizing capacity periods of less than -20, 0,20 , and 50 microequivalents per liter, at least once every 6 years 


\section{Tables}

1. Response of brook trout to the average acid-neutralizing capacity of a stream ............. 6

2. Geologic formations in Shenandoah National Park, Virginia and associated Shenandoah Watershed Study (SWAS) class

3. Percentage of Shenandoah Watershed Study (SWAS) and Shenandoah National Park (SNP) watersheds, Virginia underlain by the three SWAS classes of bedrock...

4. Transfer function parameter values for the Shenandoah Watershed Study (SWAS) watersheds, Virginia 19

5. Mean Square Error for Model 1, Model 2, and the transfer function model for the Shenandoah Watershed Study (SWAS) watersheds, Virginia.

6. Analysis of variance of regression model for distributional parameters scale and threshold for the Shenandoah Watershed Study (SWAS) watersheds, Virginia

7. Fit statistics of regression model for distributional parameters scale and threshold for the Shenandoah Watershed Study (SWAS) watersheds, Virginia

8. Parameter estimates of regression model for distributional parameters scale and threshold for the Shenandoah Watershed Study (SWAS) watersheds, Virginia

9. Percentage of land area in Shenandoah National Park, Virginia subject to defined levels of episodic acidification on a 4-year recurrence interval 


\section{Conversion Factors and Abbreviated Water-Quality Units}

\begin{tabular}{|c|c|c|}
\hline Multiply & By & To obtain \\
\hline \multicolumn{3}{|c|}{ Length } \\
\hline centimeter $(\mathrm{cm})$ & 0.3937 & inch (in.) \\
\hline millimeter (mm) & 0.03937 & inch (in.) \\
\hline meter $(\mathrm{m})$ & 3.281 & foot $(\mathrm{ft})$ \\
\hline kilometer $(\mathrm{km})$ & 0.6214 & mile (mi) \\
\hline \multicolumn{3}{|c|}{ Area } \\
\hline square meter $\left(\mathrm{m}^{2}\right)$ & 0.0002471 & acre \\
\hline hectare (ha) & 2.471 & acre \\
\hline square kilometer $\left(\mathrm{km}^{2}\right)$ & 247.1 & acre \\
\hline hectare (ha) & 0.003861 & square mile $\left(\mathrm{mi}^{2}\right)$ \\
\hline square kilometer $\left(\mathrm{km}^{2}\right)$ & 0.3861 & square mile $\left(\mathrm{mi}^{2}\right)$ \\
\hline \multicolumn{3}{|c|}{ Volume } \\
\hline liter $(\mathrm{L})$ & 0.2642 & gallon (gal) \\
\hline cubic meter $\left(\mathrm{m}^{3}\right)$ & 264.2 & gallon (gal) \\
\hline \multicolumn{3}{|c|}{ Flow rate } \\
\hline liter per second $(\mathrm{L} / \mathrm{s})$ & 15.85 & gallon per minute (gal/min) \\
\hline liter per second $(\mathrm{L} / \mathrm{s})$ & 0.03531 & cubic foot per second $\left(\mathrm{ft}^{3} / \mathrm{s}\right)$ \\
\hline
\end{tabular}

Temperature in degrees Celsius $\left({ }^{\circ} \mathrm{C}\right)$ may be converted to degrees Fahrenheit $\left({ }^{\circ} \mathrm{F}\right)$ as follows:

$$
{ }^{\circ} \mathrm{F}=\left(1.8 \times{ }^{\circ} \mathrm{C}\right)+32
$$

Vertical coordinate information is referenced to the North Geodetic Vertical Datum of 1929 (NGVD 29).

Horizontal coordinate information is referenced to the North American Datum of 1983 (NAD 83).

Altitude, as used in this report, refers to distance above the vertical datum.

Abbreviated water-quality units: Chemical concentration is reported in micrograms per liter $(\mu \mathrm{g} / \mathrm{L})$ or microequivalents per liter $(\mu \mathrm{eq} / \mathrm{L})$. Microequivalents per liter is a unit expressing the concentration of chemical constituents in solution as equivalent charges (equivalents) of solute per unit volume (liter) of water. One-thousand microequivalents per liter is equal to one milliequivalent per liter. 
Abbreviations:

ANC, acid-neutralizing capacity

CDF, cumulative distribution function

DEM, digital elevation model

MSE, mean square error

NFDR, North Fork of Dry Run watershed

PAIN, Paine Run watershed

PINE, Piney River watershed

SNP, Shenandoah National Park

SSE, sum of squares for error

STAN, Staunton River watershed

SWAS, Shenandoah Watershed Study

WOR1, White Oak Run watershed

UVA, University of Virginia

6ANC4, low 6-hour mean acid-neutralizing capacity (ANC) predicted to occur on average once every 4 years

24ANC4, low 24-hour mean acid-neutralizing capacity (ANC) predicted to occur on average once every 4 years

72ANC4, low 72-hour mean acid-neutralizing capacity (ANC) predicted to occur on average once every 4 years

168ANC4, low 168-hour mean acid-neutralizing capacity (ANC) predicted to occur on average once every 4 years

$\mu \mathrm{eq} / \mathrm{L}$, microequivalents per liter 



\title{
Predicting the Vulnerability of Streams to Episodic Acidification and Potential Effects on Aquatic Biota in Shenandoah National Park, Virginia
}

\author{
By Karen C. Rice, ${ }^{1}$ Frank A. Deviney, Jr., ${ }^{2}$ George M. Hornberger, ${ }^{2}$ and James R. Webb²
}

\section{Abstract}

Acidic deposition is one of the most serious environmental problems affecting Shenandoah National Park in north-central Virginia. The park is the third most contaminated park in the National Park System because of the deposition of acid rain. Acid rain affects headwater streams in the park by temporarily reducing the acid-neutralizing capacity (ANC) of the water, a process termed episodic acidification. In turn, the increase in acidic components in streamwater can have deleterious effects on the aquatic biota.

Although acidic deposition to the park is relatively uniform across its land area, the water-quality response of streamwater during rain events varies substantially. This response is a function of the underlying geology and topographic attributes of watersheds.

Geologic and topographic data for the park's 231 watersheds are readily available; however, long-term (years and tens of years) measurements of streamwater ANC and accompanying discharge are not and would be prohibitively expensive to collect. Modeled predictions of the vulnerability of the park's streams to episodic acidification are an alternative to longterm water-quality monitoring. These predictions can aid park officials in making management decisions.

In an attempt to model the magnitude, frequency, and duration of a water-quality parameter, transfer function time series models were developed to predict hourly ANC from discharge for five watersheds in the park that have long-term records of water quality and discharge. Hourly ANC predictions over short time periods were averaged and distributions of the recurrence intervals of annual minimum ANC values were modeled for periods of $6,24,72$, and 168 hours. The distributions were extrapolated to the rest of the watersheds in the park on the basis of watershed geology and topography.

\footnotetext{
${ }^{1}$ U.S. Geological Survey

${ }^{2}$ University of Virginia
}

These distributions allow quantitative assessments to be made of watershed vulnerability in the park, thereby providing better information to decision makers than the qualitative assessments that can be made on the basis of geology alone.

On the basis of the models, large numbers of park streams have 6- to 168-hour (1-week) periods of low-ANC values, which may stress resident brook trout and other fish populations. The results indicate that smaller watersheds are more vulnerable to episodic acidification than larger watersheds on the same bedrock. Watersheds with similar topography and area are more vulnerable if they are underlain by less basaltic/carbonate bedrock. Additional model results indicate that substantial areas of the park are vulnerable to successive annual episodic ANC decreases in streamwater that could cause mortality of some fish species. For example, approximately 14 percent of the park watersheds are predicted to have 72-hour periods of average ANC less than 0 microequivalents per liter ( $\mu$ eq/L) at least once every 2 years. At this frequency, these watersheds can be expected, with a probability greater than 90 percent, to have 4 continuous years of these conditions at least once in the next $40-100$ years.

\section{Introduction}

Acidic deposition is a worldwide problem. During the mid-1800's, a British chemist, Robert Angus Smith, made the first extensive scientific studies of acid rain and its effects (Bricker and Rice, 1993). For the next 20 years, Smith continued to research the chemistry of precipitation in England, Scotland, and Germany; when he published his findings, the term "acid rain" was coined (Smith, 1872). Acid rain is caused primarily by sulfur and nitrogen emissions from the combustion of fossil fuels (by electric utilities, motor vehicles, industrial facilities, and residences). Once airborne, sulfur and nitrogen are oxidized and combine with other compounds to form sulfuric and nitric acids - the acids are returned to the Earth's surface through all forms of wet (precipitation and aerosol) and dry (gaseous and particulate) deposition. Con- 
taminants from power-plant emissions are primarily sulfuric acid, whereas contaminants from motor-vehicle emissions are primarily nitric acid.

The components of acid rain can harm the environment and its inhabitants in various ways, including damage to buildings and structures (Baadeker and others, 1990), human health (Graham and others, 1990; Grant and others, 1990), and natural ecological systems. Damages to natural systems include acidification of surface waters (Baker and others, 1991); loss of aquatic biota (Baker and Christensen, 1991); depletion of soil nutrients, for example, calcium (Huntington, 2000); and impairment of forest health (Driscoll and others, 2001). The most affected parts of North America are the Northeast and Mid-Atlantic regions because of the downwind drift of contaminants from coal-fired power plants in the Ohio River Valley (Driscoll and others, 2001).

Shenandoah National Park (SNP) in Virginia (fig. 1) is the third-most contaminated national park in the Nation because of this downwind drift of airborne contaminants (Appalachian Voices and National Parks Conservation Association, 2004). Because the park is situated along the crest of the Blue Ridge Mountains, it hosts multiple headwater streams with relatively small watersheds (generally less than $25 \mathrm{~km}^{2}$ ). In general, atmospheric water is more acidic than ground water because ground water has had contact with earth-surface materials (for example, soils and bedrock) and, therefore, has undergone some neutralization of the acidity. Because the streams in the park originate at the top of the mountains, however, runoff supplying streamflow is primarily of atmospheric origin; the streamwater, therefore, is acidic and is susceptible to episodic acidification. Such streams are considered to be sensitive to acidic deposition.

In natural waters, the primary measure used to characterize acidity (or the lack thereof) is acid-neutralizing capacity (ANC). ANC is the capacity of a solution to neutralize strong acids and is defined as the equivalent sum of all bases or baseproducing materials, solutes plus particulates, in an aqueous system that can be titrated with acid to an equivalence point. This term designates titration of an "unfiltered" sample. A low ANC indicates little capacity to neutralize acidity, whereas a high ANC indicates a greater capacity to neutralize acidity.

The ANC of streamwater at base flow is related to the type of bedrock underlying the watershed (for example, Lynch and Dise, 1985; Bricker and Rice, 1989; Webb and others, 1994; Webb, 1999; Webb and others, 2001). Rocks that weather easily (for example, limestone) yield streams with higher ANC relative to rocks that are resistant to weathering (for example, quartzite). In general, streams with low ANC have a correspondingly low $\mathrm{pH}$, and streams with higher ANC have near-neutral $\mathrm{pH}$. The more acidic the streamwater, the less likely it will be able to support a diversity of aquatic life. Research indicates that fish, aquatic insects, and amphibians are sensitive to $\mathrm{pH}$ and ANC values (for example, Bulger and others, 2000; Grant and others, 2005; Baldigo and Murdoch, 1997; Baldigo and Lawrence, 2000). The three major types of bedrock in the park - siliciclastic, granitic, and basaltic/car- bonate-yield streams with low, moderate, and high ANC and $\mathrm{pH}$, respectively (fig. 2).

Research in small watersheds throughout the world indicates that for a given stream, ANC and streamwater discharge are inversely correlated in a curvilinear fashion (see Pinol and Avila, 1992, and references therein; fig. 3, $r=0.64$ ). In general, the higher the ANC at base flow, the more pronounced the decrease in ANC with increased discharge. During stormflow, short-term variability in ANC values is related to hydrology (Wigington and others, 1990) and hydrologic variability is related to topography (for example, Pinol and Avila, 1992).

Davies and others (1992) define "episodic acidification" as

... the process by which lakes and streams experience a short-term decrease of ANC, usually during hydrological events (transient increases in discharge) and over time-scales of hours to weeks. An 'episode,' then, is any short-term decrease of ANC, and an 'acidic episode' is an episode in which ANC falls below zero microequivalents per liter ( $\mu$ eq $\mathrm{L}^{-1}$ ).

Episodic acidification of streamwater is a concern because it can cause deleterious effects on aquatic organisms. If episodic acidification of a stream occurs during a critical life stage of a fish, such as spawning, the hatched fry can die, because they cannot tolerate high acidity. From the perspective of water-quality management objectives, characterizing streamwater vulnerability to episodic acidification is a first step towards being able to predict the effect of episodes on streamwater biota. In addition, such a characterization can help managers assess the potential effect of strategies for mitigating episodic acidification that results from anthropogenic causes.

Researchers in the Department of Environmental Sciences at the University of Virginia (UVA) have conducted the Shenandoah Watershed Study (SWAS) in the park for more than 25 years (http://swas.evsc.virginia.edu/). Begun in 1979 , SWAS is the longest continuously conducted watershed research and monitoring program in the National Park System, and the researchers have compiled the most extensive streamwater quality database in the National Park System. The initial focus of SWAS was on the effects of acidic deposition on the park's sensitive streams. Although the program has evolved to address additional issues that challenge watershed ecosystems in the park, the effects of acidic deposition remain a primary focus.

Bulger and others (1995) established a system to classify the response of brook trout (Salvelinus fontinalis) to the average ANC of a stream (table 1). Temporary decreases in streamwater ANC values are not the same as being in these ranges on the average. The ranges associated with the brook trout response classes nonetheless provide a frame of reference for comparing the results of this study with those of other studies.

There are 27 other species of fish identified as permanent residents of the park (James Atkinson, Shenandoah National Park, written commun., 2004), including bass, chub, dace, 


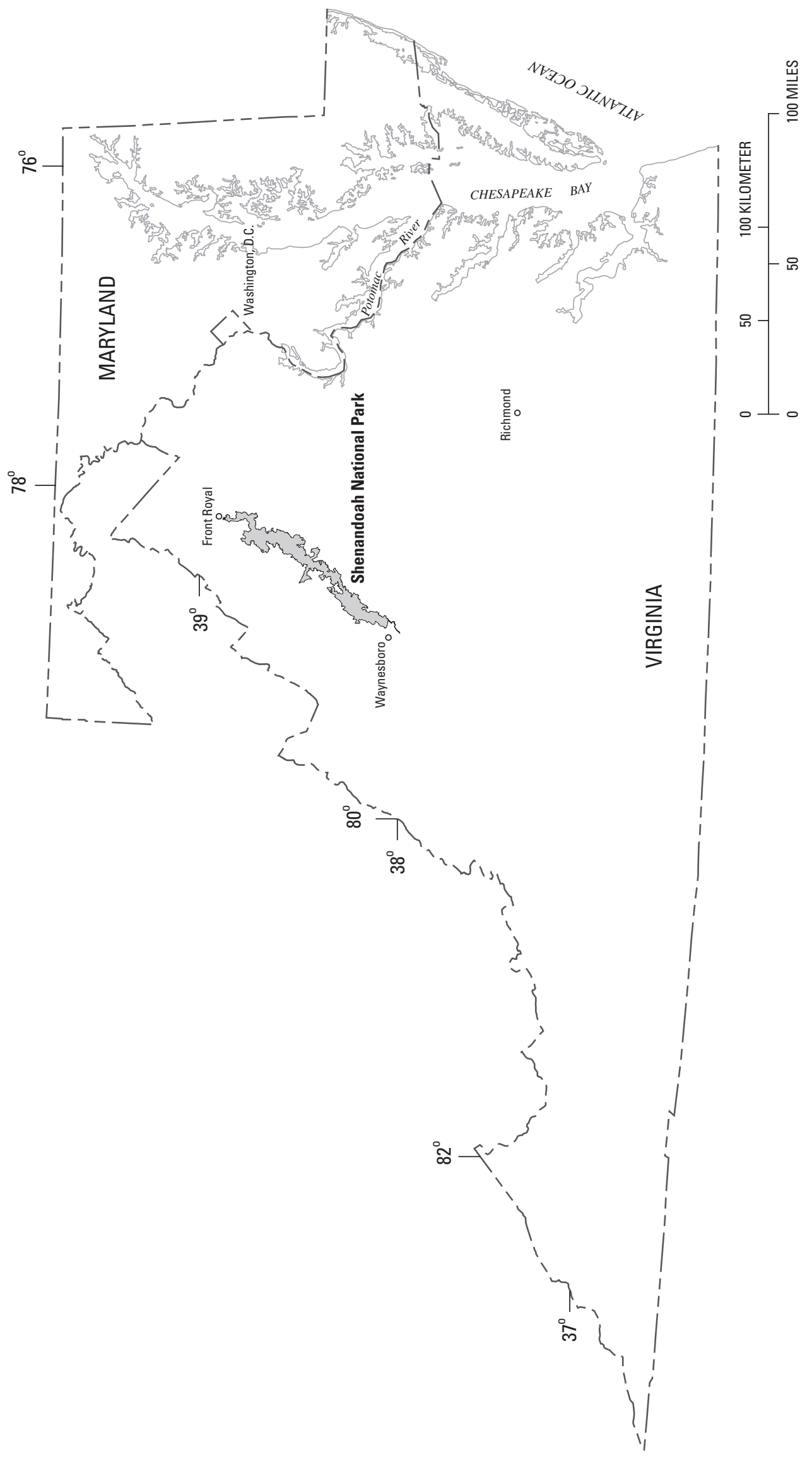

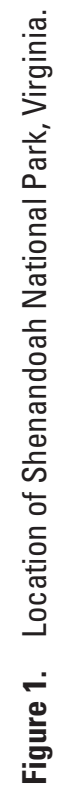




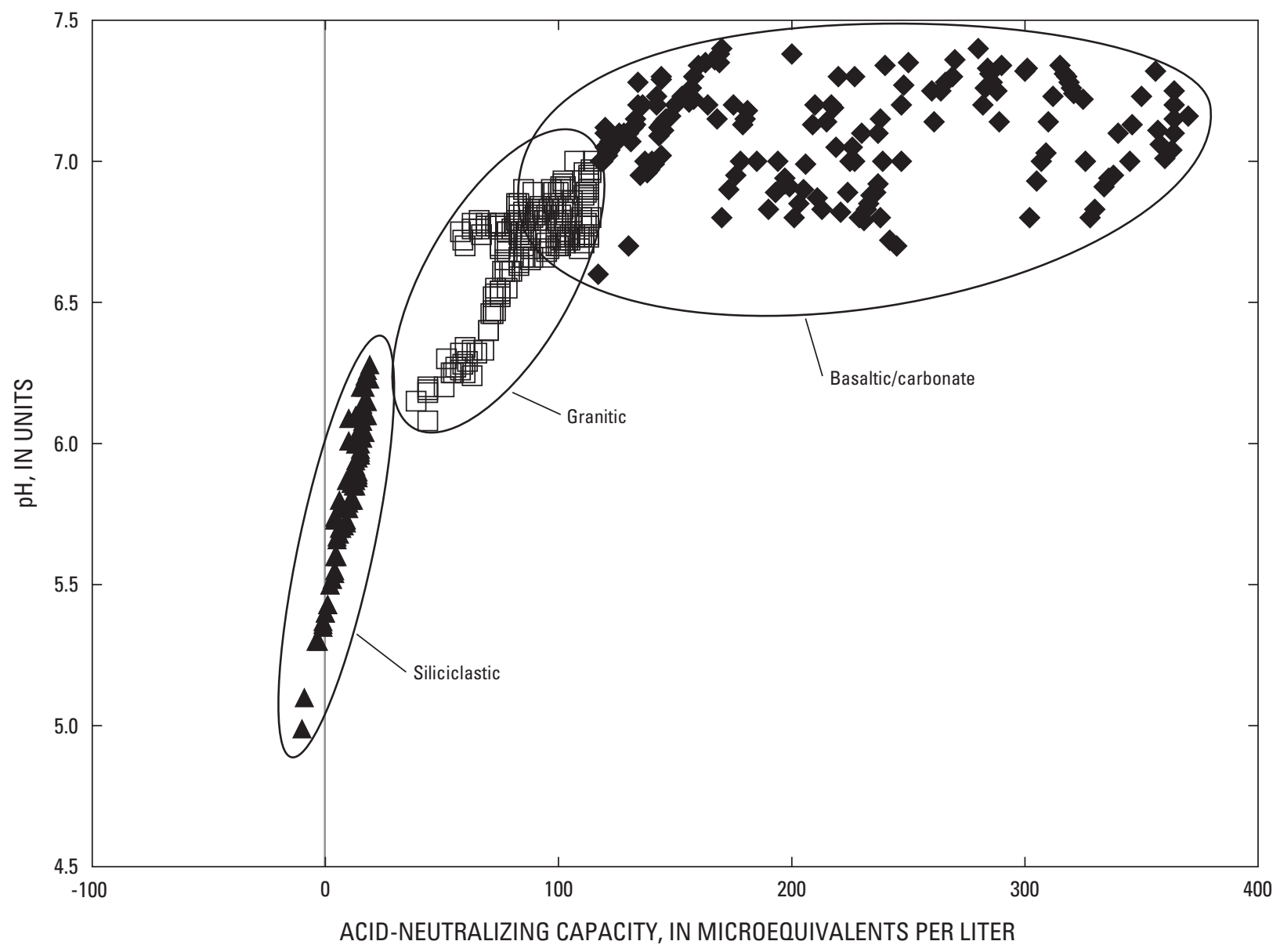

Figure 2. Relations among $\mathrm{pH}$, acid-neutralizing capacity, and associated bedrock type in streams in Shenandoah National Park, Virginia. 


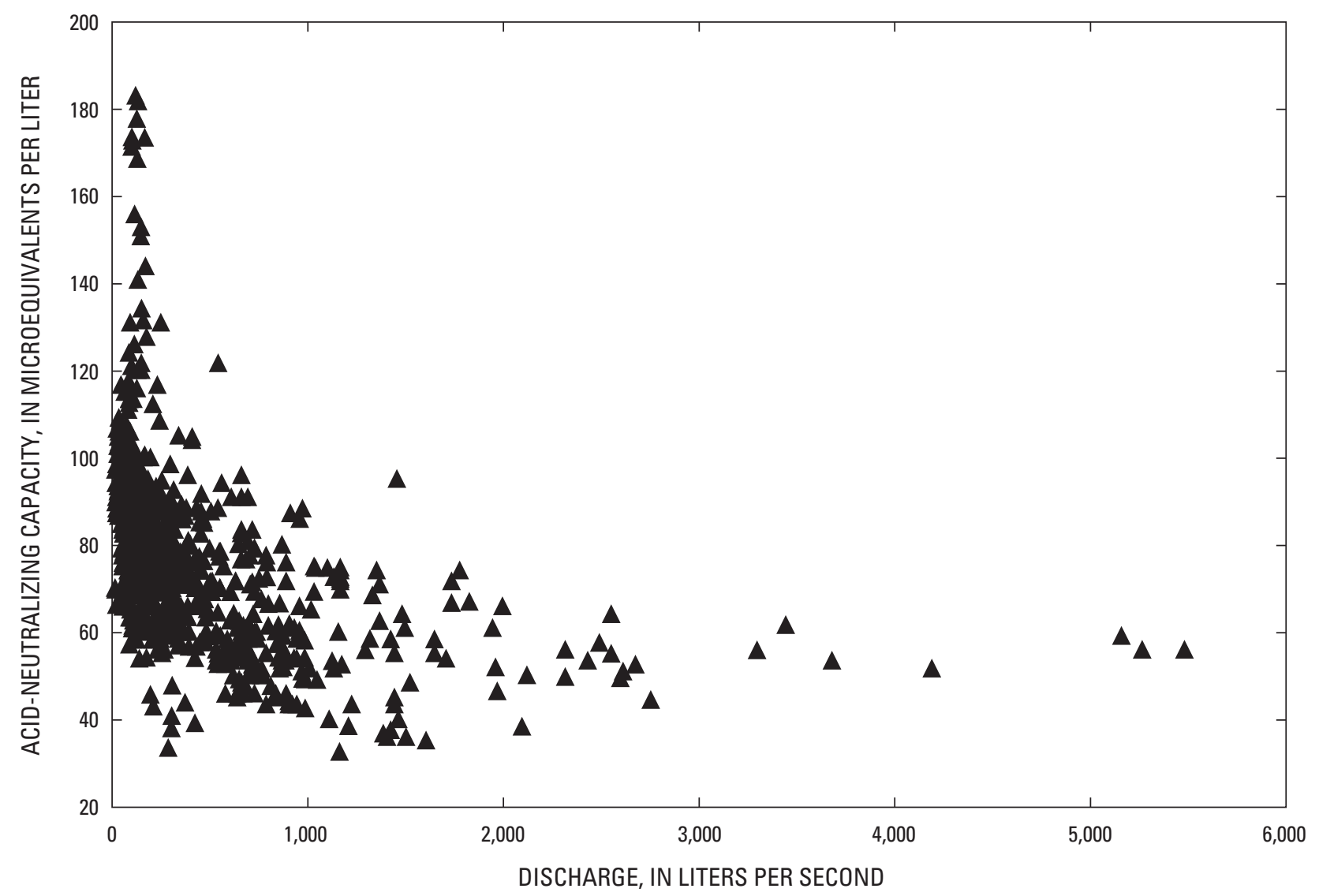

Figure 3. Relation between acid-neutralizing capacity and discharge in Staunton River in Shenandoah National Park, Virginia. 
Table 1. Response of brook trout to the average acid-neutralizing capacity of a stream (Bulger et al., 1995).

[ANC, acid-neutralizing capacity; $\mu \mathrm{eq} / \mathrm{L}$, microequivalents per liter; $>$, greater than; $\leq$, less than or equal to]

\begin{tabular}{clll}
\hline $\begin{array}{c}\text { Average } \\
\text { ANC } \\
\text { (peq/L) }\end{array}$ & \multicolumn{1}{c}{$\begin{array}{c}\text { Brook trout } \\
\text { response class }\end{array}$} & \multicolumn{1}{c}{ ANC response } & \multicolumn{1}{c}{$\begin{array}{c}\text { Effect on } \\
\text { brook trout }\end{array}$} \\
\hline$>50$ & Not acidic & Unlikely for ANC $<0$ & Little, if any \\
$>20-50$ & Indeterminate & ANC may or may not become $<0$ & Variable \\
$>0-20$ & Episodically acidic & Varying degrees of acidic episodes & Sublethal or lethal \\
$\leq 0$ & Chronically acidic & Will experience acidic episodes & Lethal effects likely \\
\hline
\end{tabular}

darter, and sculpin. Most, if not all, of these species are more sensitive to acidic conditions than are brook trout (Sullivan and others, 2003); therefore, these species are likely to respond differently than brook trout to decreases in streamwater ANC values.

The presence or absence of fish species in the Neversink River, New York, is related to average streamwater $\mathrm{pH}$ (Baldigo and Lawrence, 2000). Brook trout are not found where average $\mathrm{pH}$ is less than 4.77; slimy sculpin (Cottus cognatus) are not found where average $\mathrm{pH}$ is less than 5.26; longnose dace (Rhinichthys cataractae) are not found where average $\mathrm{pH}$ is less than 5.69; and blacknose dace (Rhinichthys atratulus) are not found where average $\mathrm{pH}$ is less than 6.36. In another study in the Neversink River watershed, caged brook trout had mortality in excess of 20 percent when exposed to inorganic monomeric aluminum concentrations greater than 200 micrograms per liter $(\mu \mathrm{g} / \mathrm{L})$ for periods of at least 48 hours (Baldigo and Murdoch, 1997). Total exposure time and frequency of events are important factors that determine survival rates.

Measures of fish species diversity are most highly related to streamwater chemistry and, to a lesser extent, to physical habitat characteristics in the Neversink River watershed (Baldigo and Lawrence, 2000). Number of fish per unit area is most related to streamwater chemistry, whereas weight of fish per unit area is most related to physical habitat characteristics. Fish are responsive to water temperature, $\mathrm{pH}, \mathrm{ANC}$, inorganic monomeric aluminum, calcium, potassium, magnesium, and silicon concentrations, and elevation, drainage area, and other physical habitat characteristics (Baldigo and Lawrence, 2000).

The bedrock geology underlying SNP indicates a chronic low-ANC condition in many watersheds. The vulnerability of streams throughout the park to episodic decreases in ANC values, however, has not been characterized or related to physicochemical and topographic properties of the watersheds. Geologic and topographic data are available for the entire park, whereas frequent ANC and discharge measurements are available only for a small number of the watersheds in the park.
Characterizing the magnitude, frequency, and duration of ANC decreases in streamwater requires a time series of ANC values at a time scale appropriate to the resources at risk from such decreases. For small watersheds, such as those found in SNP, ANC decreases on the order of hours-driven by short time-period hydrological events-may be critical. Hourly measurements of ANC, however, are expensive or difficult to obtain and generally are not available. By contrast, hourly observations of discharge are inexpensive to collect as compared to hourly measurements of ANC. Because ANC is inversely correlated with discharge (fig. 3; Pinol and Avila, 1992), statistical models can be developed that predict hourly ANC on the basis of measured hourly discharge. Time series models, such as those developed by Whitehead and others (1986), are examples of this type of statistical model. Measurements of ANC values over short time scales (for example, at 2-hour intervals) are required for the development of such models.

In 2002, the U.S. Geological Survey (USGS) and UVA, in cooperation with the National Park Service, began a study to characterize watersheds in the park in terms of the recurrence interval of low-ANC periods that can be expected to occur. This analysis modeled the magnitude, frequency, and duration of a water-quality parameter in streamwater using flood and low-flow methodology. Continuous discharge measurements and infrequent $\mathrm{ANC}$ measurements of park streams collected through September 30, 2003, were used to develop time series models that predict short-term ANC values. The predicted ANC values were used to develop ANC recurrence intervals. Maps summarizing the results of the analysis were created by use of regression and watershed attributes such as topography and geology to extrapolate results to ungaged watersheds. This approach is similar to that used by hydrologists in high-flow and low-flow frequency analysis of gaged watersheds and in regionalization, defined as the extrapolation of these analyses to ungaged watersheds (see, for example, Kite, 1977; Riggs, 1972; and Rao and Hamed, 2000). In the context of this work, recurrence interval is the inverse of frequency; period and 
duration are synonymous; and ANC decrease refers to the magnitude of the change in ANC value.

\section{Purpose and Scope}

This report describes the development of a mathematical model used to predict the vulnerability to episodic acidification of streams in Shenandoah National Park. Predictions made using the model are summarized on maps of watersheds in the park and the corresponding data are tabulated in appen$\operatorname{dix}$ A. The maps can be used for assessing the vulnerability of SNP watersheds to episodic acidification, ranking watershed vulnerability to future episodic acidification, assessing potential effects on aquatic biota, and identifying opportunities to improve the water-quality and aquatic biological monitoring programs in the park.

\section{Description of Study Area}

Shenandoah National Park is located in the Blue Ridge Physiographic Province in north-central Virginia (fig. 1). The park straddles the crest of the Blue Ridge Mountains along a 112-km-long segment from Front Royal in the north to Waynesboro in the south. The park consists of approximately 799 square kilometers $\left(\mathrm{km}^{2}\right)$.

\section{Geology}

Eleven geologic formations have been identified in the park (table 2). These formations were grouped into three "SWAS classes" on the basis of their capacity to neutralize acidic inputs. The SWAS classes are siliciclastic, granitic, and basaltic/carbonate (table 2) and are considered to group park streams with similar water quality (fig. 2). In general, the siliciclastic class is found in the westernmost portions of the park, the basaltic/carbonate class crops out in the middle of the park along the crest of the mountains, and the granitic class is found along the eastern margins of the park (fig. 4).

\section{Hydrology}

Park staff delineated 231 watersheds (SNP watersheds, numbered 0-230 in appendix A) whose areal extent covers almost the entire park. Watershed outlets were defined as the point at which the stream crosses the park boundary. Seventytwo of the watersheds are included in the park's fish-monitoring program (Vana-Miller and Weeks, 2004). Other watersheds are being added to the fish-monitoring program or being surveyed by electro-fishing crews.

SWAS maintains water-level (stage) recording stations on five streams in the park (fig. 4): North Fork of Dry Run (NFDR), since 1987; Paine Run (PAIN), since 1992; Piney River (PINE), since 1992; Staunton River (STAN), since 1992; and White Oak Run (WOR1), from 1979 until 1991 by USGS,
Table 2. Geologic formations in Shenandoah National Park, Virginia and associated Shenandoah Watershed Study (SWAS) class.

\begin{tabular}{ll}
\hline \multicolumn{1}{c}{ Formation or Lithology ${ }^{1}$} & \multicolumn{1}{c}{ SWAS class } \\
\hline Catoctin Formation & Basaltic/carbonate \\
Chilhowee Group & Siliciclastic \\
Waynesboro Formation & Basaltic/carbonate \\
Waynesboro Formation and & Basaltic/carbonate \\
Tomstown Dolomite & \\
Alkali Feldspar Leucogranite & Granitic \\
Charnockite & Granitic \\
Charnockite Gneiss & Granitic \\
Old Rag Granite & Granitic \\
Layered Pyroxene Granulite & Granitic \\
Swift Run Formation & Granitic \\
Mylonite, Mylonite Gneiss, and & Granitic \\
Cataclastic Rocks & \\
\hline
\end{tabular}

${ }^{1}$ From Virginia Division of Mineral Resources (2003)

and since 1991 by SWAS. Stage was recorded at hourly intervals, and the data were digitized and extrapolated to discharge using standard methods (Rantz, 1982a, 1982b). The watershed boundaries of these five watersheds were delineated by SWAS and differ slightly in extent from corresponding watersheds in the park that were delineated as described above. Streamgaging and data-analysis techniques used by SWAS are described in appendix B.

\section{Topography}

USGS 30-meter Digital Elevation Model (DEM) data for the 1:24,000 topographic quadrangles encompassing the park were obtained. The DEMs along with the watershed boundary overlay coverages were used to determine area, and maximum, minimum, and mean elevations, as well as elevation ranges for each of the park's watersheds.

\section{Streamwater Samples}

Streamwater samples are collected weekly as grab samples from the five streams with water-level recording stations: NFDR, since 1987; PAIN, PINE, and STAN, since 1992; and WOR1, since 1979. In addition, stormflow samples, which include samples collected on the rising and falling limbs of the hydrograph, are collected with an automated water sampler (ISCO model 2900) as frequently as every 2 hours during selected storm runoff events. Stormflow samples have been collected at PAIN (514 samples), PINE (717 samples), and STAN (669 samples) since 1992. Stormflow samples were 

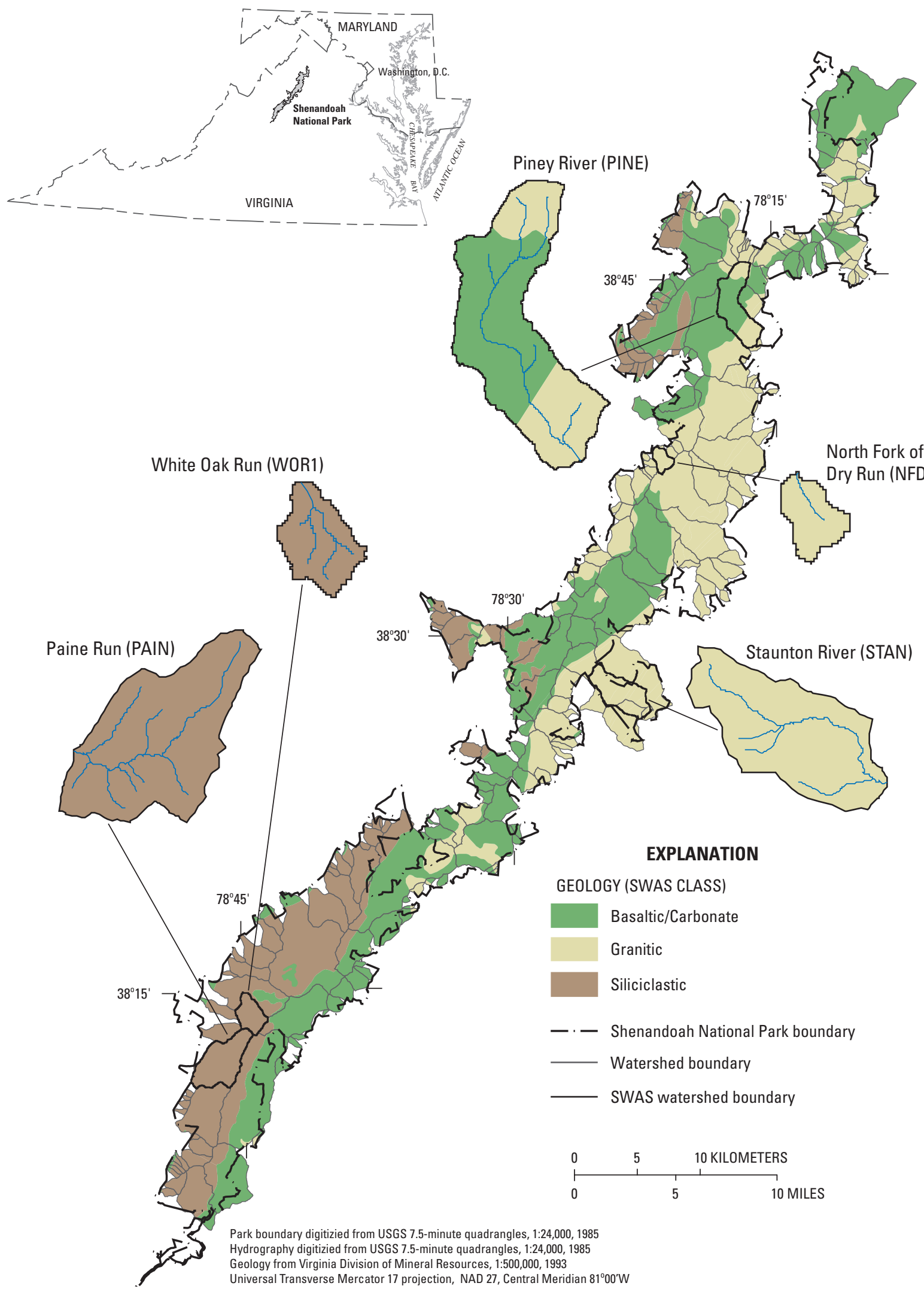

Figure 4. Generalized geology and location of the 5 Shenandoah Watershed Study (SWAS) watersheds and the 231 watersheds in Shenandoah National Park, Virginia. 
collected at NFDR (117 samples) and WOR1 (159 samples) by Marshall (1993) from 1991-92. Discharge and ANC data collected from the beginning of each record through September 30, 2003, were analyzed.

Streamwater samples, both grab and automated, were collected in 500-milliliter $(\mathrm{mL})$ low-density polyethylene bottles that were pre-washed with laboratory-grade detergent and hydrochloric acid $(\mathrm{HCl})$ and rinsed with de-ionized water. Prior to grab-sample collection, the bottle was rinsed three times with the sampled streamwater. After collection the samples were placed in insulated containers with refrigerant for delivery to the SWAS laboratory. Upon receipt at the laboratory, the samples were preserved by addition of chloroform $(0.5 \mathrm{~mL} / 500 \mathrm{~mL})$ and stored at ambient laboratory temperature (about $23^{\circ} \mathrm{C}$ ).

ANC of streamwater samples was determined by a modified Gran titration in the SWAS laboratory, using an Orion model $290 \mathrm{~A}+\mathrm{pH}$ meter and an Orion model 8102 Ross pH electrode. The procedure was Gran titration with a $100-\mathrm{mL}$ sample volume and 0.005 normal $\mathrm{HCl}$ titrant. Results are reported in $\mu \mathrm{eq} / \mathrm{L}$. Quality assurance and quality control of laboratory methods are documented in Rice and others (2001).

\section{Development of the Mathematical Models}

Although the same physical data are available for all watersheds in the park, the five SWAS watersheds can be termed data rich, because tens of thousands of hours of discharge data and roughly 1,000 water-quality samples have been collected from each watershed. By contrast, the rest of the SNP watersheds can be termed data poor, because no discharge data, no stormflow water-quality samples, and at most a relatively small number of base-flow water-quality samples (as compared to 1,000 samples) have been collected from each watershed. An objective of this analysis was to extrapolate information available only for the data-rich (SWAS) watersheds to the data-poor (SNP) watersheds using information commonly available for all. The first step in the development of the model was to compare the distributions of the physical attributes that are available for both the SWAS and the SNP watersheds. These physical attributes include watershed area, geology, and topography.

The SWAS watersheds comprise approximately 5 percent of the park area. There is a disparity in the distribution of watershed area between the SWAS and SNP watersheds (fig. 5). NFDR, the smallest SWAS watershed, is larger than almost 60 percent of the SNP watersheds, indicating that the SWAS watersheds over-represent the large watersheds. The largest SNP watersheds, however, cover a much greater percentage of the park than the small watersheds. Approximately 10 percent of the SNP watersheds are larger than PINE, the largest SWAS watershed. These disparities are a function of how the SNP watersheds were delineated and of how the
SWAS watersheds were selected. Large watersheds in parks typically have roads, campgrounds, and other facilities that have effects on water quality that would have confounded the initial purposes of setting up the SWAS watershed sites. Many of the smaller SNP watersheds are logistically inconvenient or hydrologically unsuitable (intermittent streams), making them poor candidates for long-term monitoring, given the expense of site instrumentation, maintenance, and data collection and analysis.

All major bedrock classes are represented in the SWAS watersheds. The SWAS watersheds, however, under-represent the fraction of SNP watersheds containing basaltic/carbonate bedrock and over-represent the fraction containing siliciclastic and/or granitic bedrock (fig. 6; table 3). Because the probability of episodic and, eventually, chronic acidification is higher in watersheds underlain by siliciclastic bedrock, it is appropriate for this analysis that this class is over-represented.

The SWAS watersheds have narrower distributions of topographic metric values than the SNP watersheds (fig. 7), as evidenced by steeper cumulative distribution functions (CDFs), indicating less variance. The SWAS and SNP watersheds have more similar minimum and mean elevations than maximum and range of elevation. These topographic differences are probably because the SWAS watersheds extend from or near park boundary elevations to the crest of the Blue Ridge. As the SNP watersheds were all delineated starting at the park boundary, their minimum and mean elevations should be similar to the SWAS watersheds; however, many of the SNP watersheds will have lower maximums and smaller ranges in elevation.

In summary, the SWAS watersheds are more representative of larger SNP watersheds in terms of the physiographic metrics area and topography. The SWAS watersheds also are more representative of the more sensitive watersheds in the park. These differences are not surprising given the practical constraints on site selection and the historical objectives of the SWAS program, as well as the larger number and variation in size of the SNP watersheds.

After comparing the physical attributes of the SWAS watersheds with the SNP watersheds, ANC values of the SWAS watersheds were compared. The distributions of ANC values of streamwater samples collected in the SWAS watersheds, across all flow regimes, vary between watersheds (fig. 8). Despite the small sample size, it was assumed that these differences were representative of those that would be present between other watersheds in SNP with similar geology and topography. NFDR and STAN, which have similar geology, appear to have similar streamwater ANC distributions, as do PAIN and WOR1, which also have similar geology (fig. 8). The distribution of sample ANC at PINE, which is the SWAS watershed underlain by the highest percentage of basaltic bedrock, differs substantially from the other four sites. Additional observations include that as the hourly mean ANC value of a watershed increases, in general, so does the variance. Within pairs of watersheds with similar geology (NFDR/STAN and WOR1/PAIN), the smaller watershed has greater ANC 


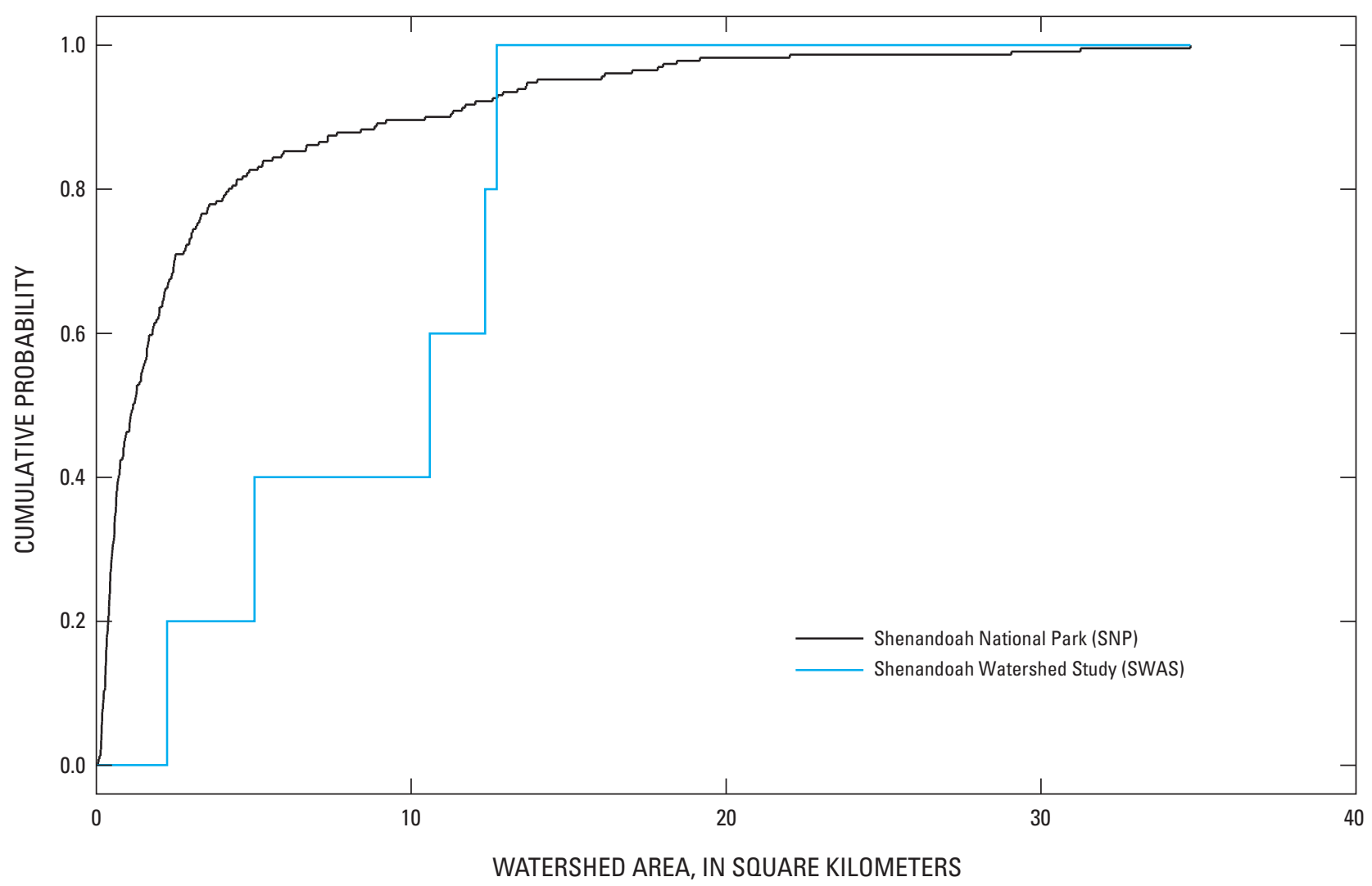

Figure 5. Distribution of watershed area among the Shenandoah Watershed Study (SWAS) and Shenandoah National Park (SNP) watersheds, Virginia. 

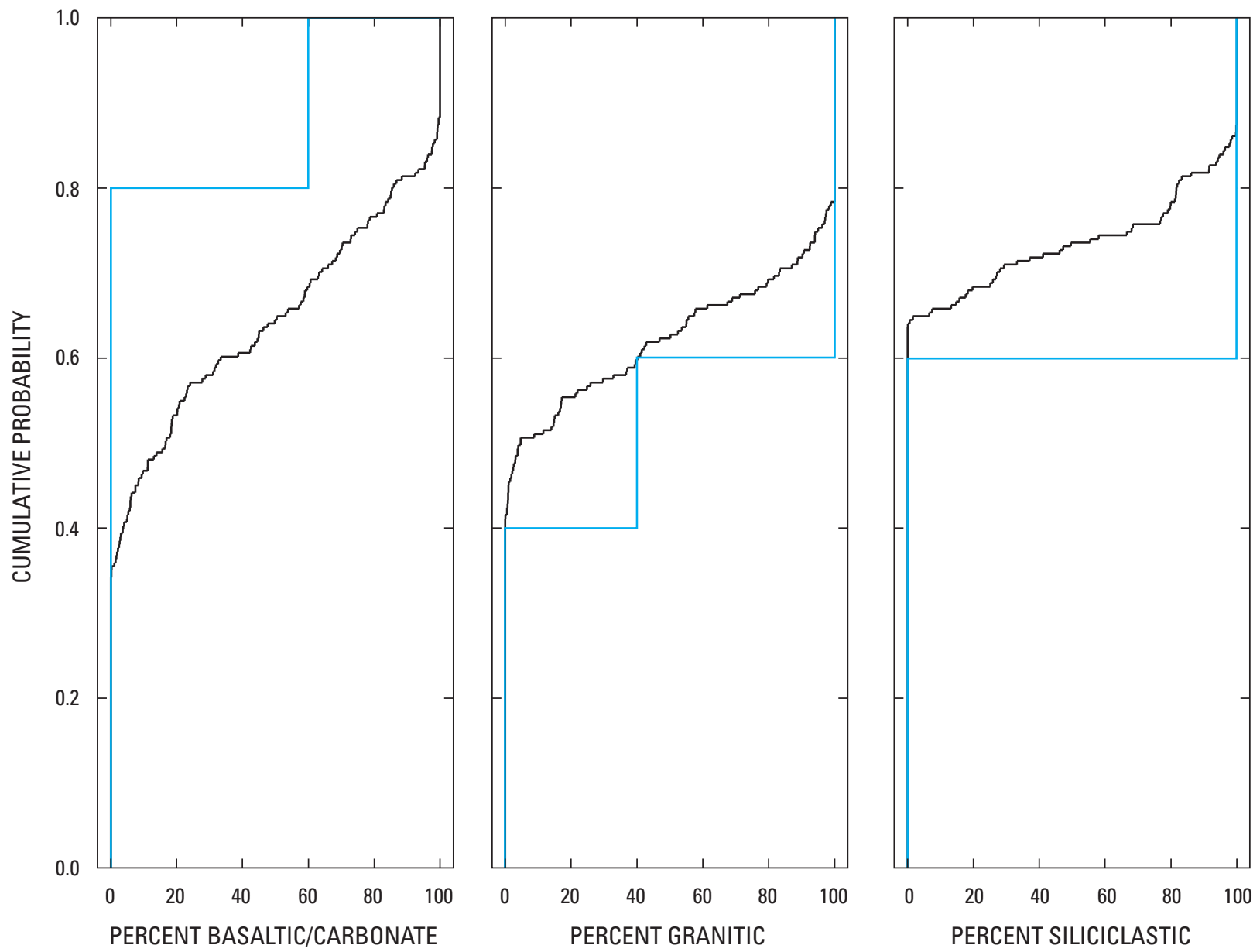

\section{EXPLANATION}

Shenandoah National Park (SNP)

Shenandoah Watershed Study (SWAS)

Figure 6. Distribution of geologic metrics among the Shenandoah Watershed Study (SWAS) and Shenandoah National Park (SNP) watersheds, Virginia. 

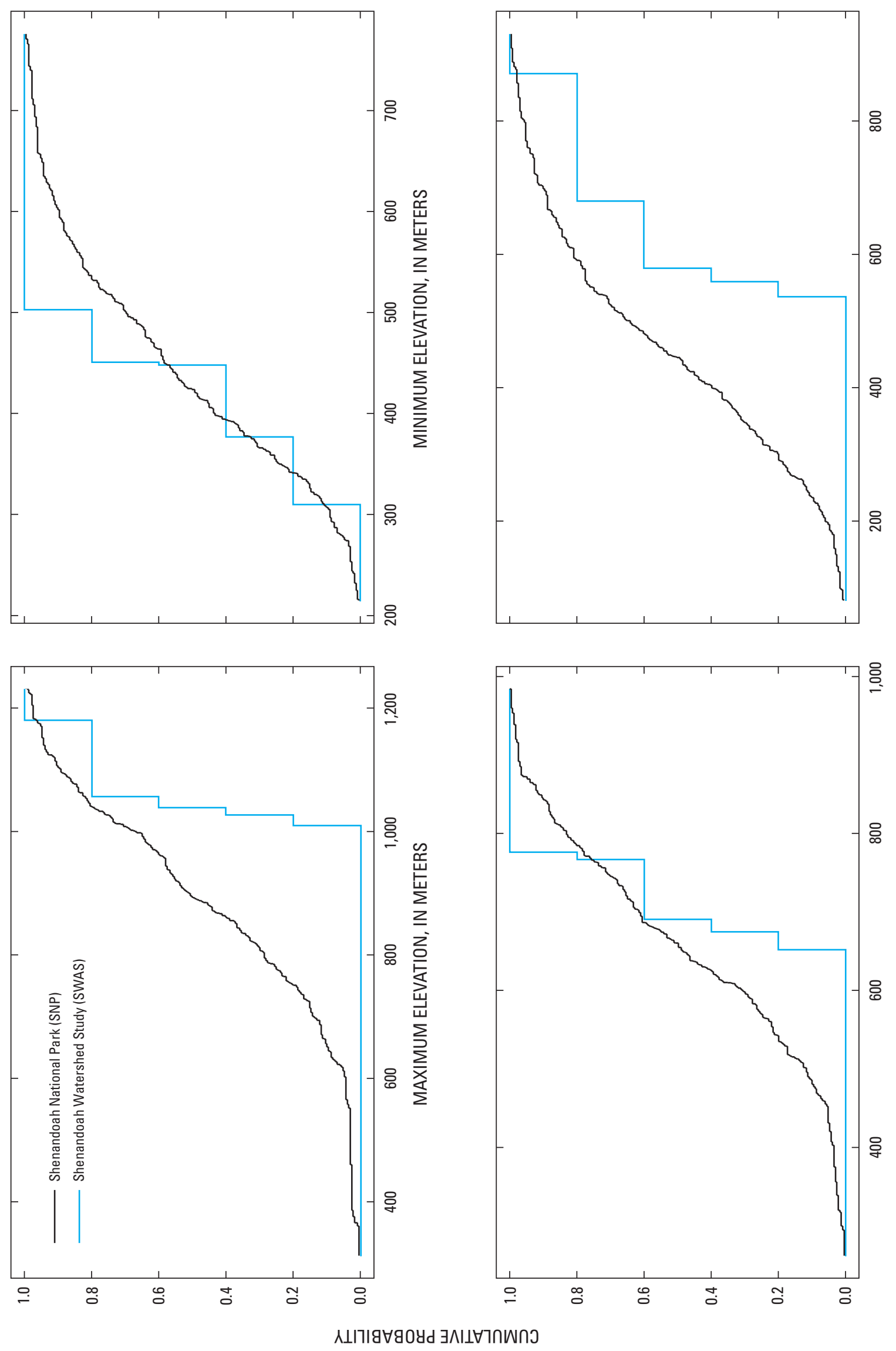

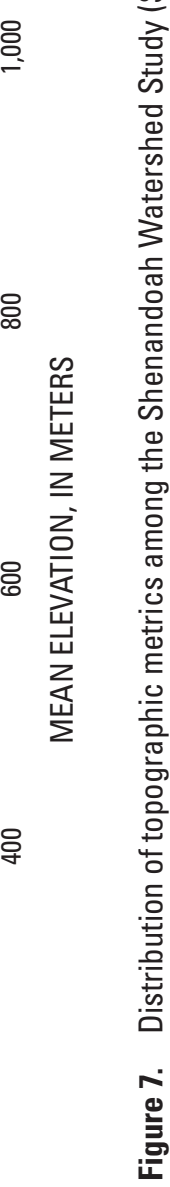


Table 3. Percentage of Shenandoah Watershed Study (SWAS) and Shenandoah National Park (SNP) watersheds, Virginia underlain by the three SWAS classes of bedrock (Vana-Miller and Weeks, 2004).

\begin{tabular}{lcc}
\hline \multicolumn{1}{c}{ SWAS class } & $\begin{array}{c}\text { SWAS watersheds } \\
\text { (percent) }\end{array}$ & $\begin{array}{c}\text { SNP watersheds } \\
\text { (percent) }\end{array}$ \\
\hline Siliciclastic & 41.3 & 29.0 \\
Granitic & 41.4 & 33.0 \\
Basaltic/carbonate & 17.3 & 38.0 \\
\hline
\end{tabular}

variance than the larger watershed. These observations are consistent with conceptual models of the effects of geology and water-soil interactions on streamwater ANC.

Discharge and runoff in millimeters ( $\mathrm{mm}$ ) (discharge divided by watershed area) for the SWAS watersheds for the period October 1, 1992, through September 30, 2003, were compared. Distributions of both discharge and runoff in $\mathrm{mm}$ are highly skewed, so the data were log-transformed before being plotted as CDFs. It was expected that raw discharge would be proportional to watershed size; however, this result was not observed. WOR1 has a lower median flow and greater flow variance than NFDR, even though WOR1 is approximately twice the size of NFDR. PAIN, one of the two largest SWAS watersheds, has discharge substantially less than either STAN or PINE. STAN and NFDR have less variance (that is, more vertical CDFs) than the other three sites. The median of hourly discharge in liters per second (L/s) for the period of record was WOR1, 21.1; NFDR, 28.1; PAIN, 64.1; PINE, 132; and STAN, 142 (fig. 9).

The distributions of runoff in mm for the SWAS watersheds diverge at low values (fig. 10). WOR1, which has been observed to dry up on occasion, has lower base-flow runoff in $\mathrm{mm}$ than PAIN. Low runoff in $\mathrm{mm}$ at PINE and NFDR are remarkably similar given the difference in watershed areas, and low runoff in mm is highest at STAN. As expected, there is a greater difference in discharge (fig. 9) than runoff in $\mathrm{mm}$ (fig. 10) among the SWAS watersheds. Mean annual runoff in $\mathrm{mm}$ for the five SWAS watersheds for the period of record was NFDR, 859; STAN, 711; PINE, 669; WOR1, 450; and PAIN, 435.

Information on the frequency, magnitude, and duration of ANC decreases in streamwater was extrapolated from the SWAS watersheds to the SNP watersheds in three steps (fig. 11): (1) time series models were constructed to predict hourly ANC for the five SWAS watersheds; (2) recurrence interval models were developed from the hourly ANC time series to predict the recurrence interval of designated episodic ANC decreases; and (3) the recurrence interval models were extrapolated to the SNP watersheds. The extrapolated models provided a basis for predicting recurrence intervals for SNP watersheds and for preparing maps showing the vulnerability of streams in the park to episodic acidification.

\section{Time Series Models}

Three models for hourly ANC predictions were considered (fig. 11). In the first model (hereafter referred to as Model 1), it is assumed that ANC can be predicted as the mean ANC of all samples. This assumption is not totally applicable, but this model serves as a benchmark for the more complicated candidate models. If a candidate model cannot outperform the mean model (Model 1), it is either a poor model, or a more complex model is not needed. The second model (hereafter referred to as Model 2) regresses ANC against the natural logarithm of discharge. The third model is a transfer function time series model.

Time series models for each SWAS watershed were developed using the available time series of hourly discharge and occasionally sampled ANC values. The purpose of the time series models was to predict hourly ANC values for the SWAS watersheds. An assumption of the basic time series model is that historical values of the time series can be used to predict future values. A transfer function model augments the basic time series model to take advantage of predictive relations between the dependent variables and the current and historical values of other time series (Brockwell and Davis, 1996). In this case, a basic model for hourly ANC based on historical values of ANC was augmented to include historical values of discharge. The addition of these discharge values was useful because (1) there are many missing values in the hourly times series of ANC values; (2) the hourly discharge record is complete; and (3) there is a strong correlation between ANC and discharge.

The natural logarithm of discharge (independent variable) in a simple regression with streamwater ANC (dependent variable) results in smaller error than using the untransformed discharge. In a simple regression, the magnitude of the slope indicates how much the dependent variable changes per change in unit of the independent variable (either discharge or the natural logarithm of discharge). The sign of the slope indicates whether increased flow concentrates (positive sign) or dilutes (negative sign) ANC.

The initial transfer function used to model ANC was

$C_{t}-\mu=\frac{\omega_{0}\left(1-\omega_{1} B-\omega_{2} B^{2}\right)}{\left(1-\nu_{1} B-\nu_{2} B^{2}\right)} Q_{t}^{\prime}+\frac{(1-\theta B)}{(1-\phi B)} \varepsilon_{t}$,

where

$C_{t}=$ hourly ANC time series $(\mu \mathrm{eq} / \mathrm{L})$,

$\mu=$ mean of ANC time series ( $\mu$ eq $/ \mathrm{L})$,

$Q_{t}^{\prime}=$ natural logarithm of hourly discharge $(\mathrm{L} / \mathrm{s})$,

$\omega_{0}, \omega_{l}, \omega_{2}, v_{l}, v_{2}=$ transfer function parameters,

$\varepsilon_{t}=$ innovation series, and

$\phi, \theta=$ autoregressive moving average parameters for the innovation series. 


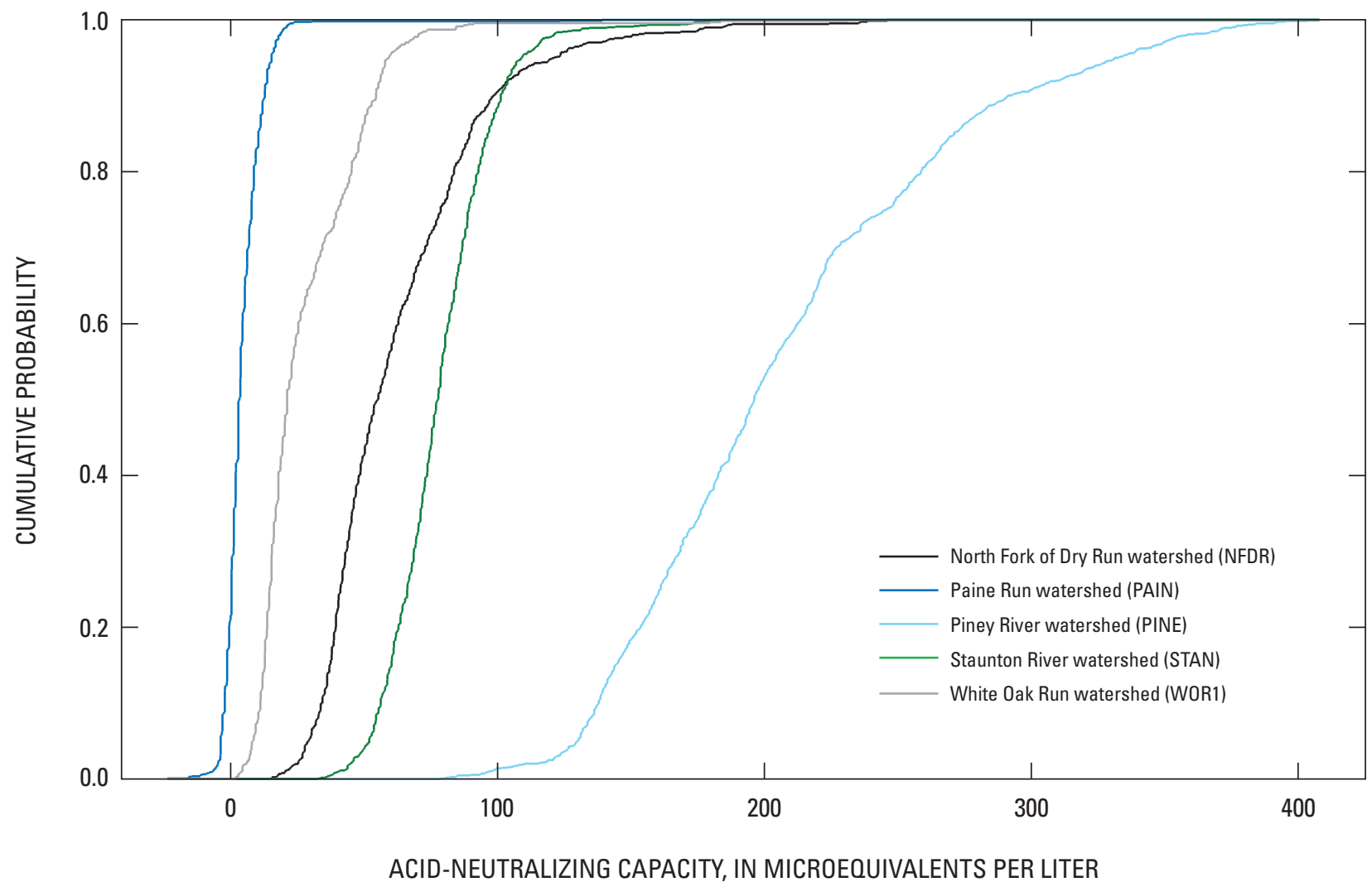

Figure 8. Distribution of streamwater acid-neutralizing capacity among the Shenandoah Watershed Study (SWAS) watersheds, Virginia. 


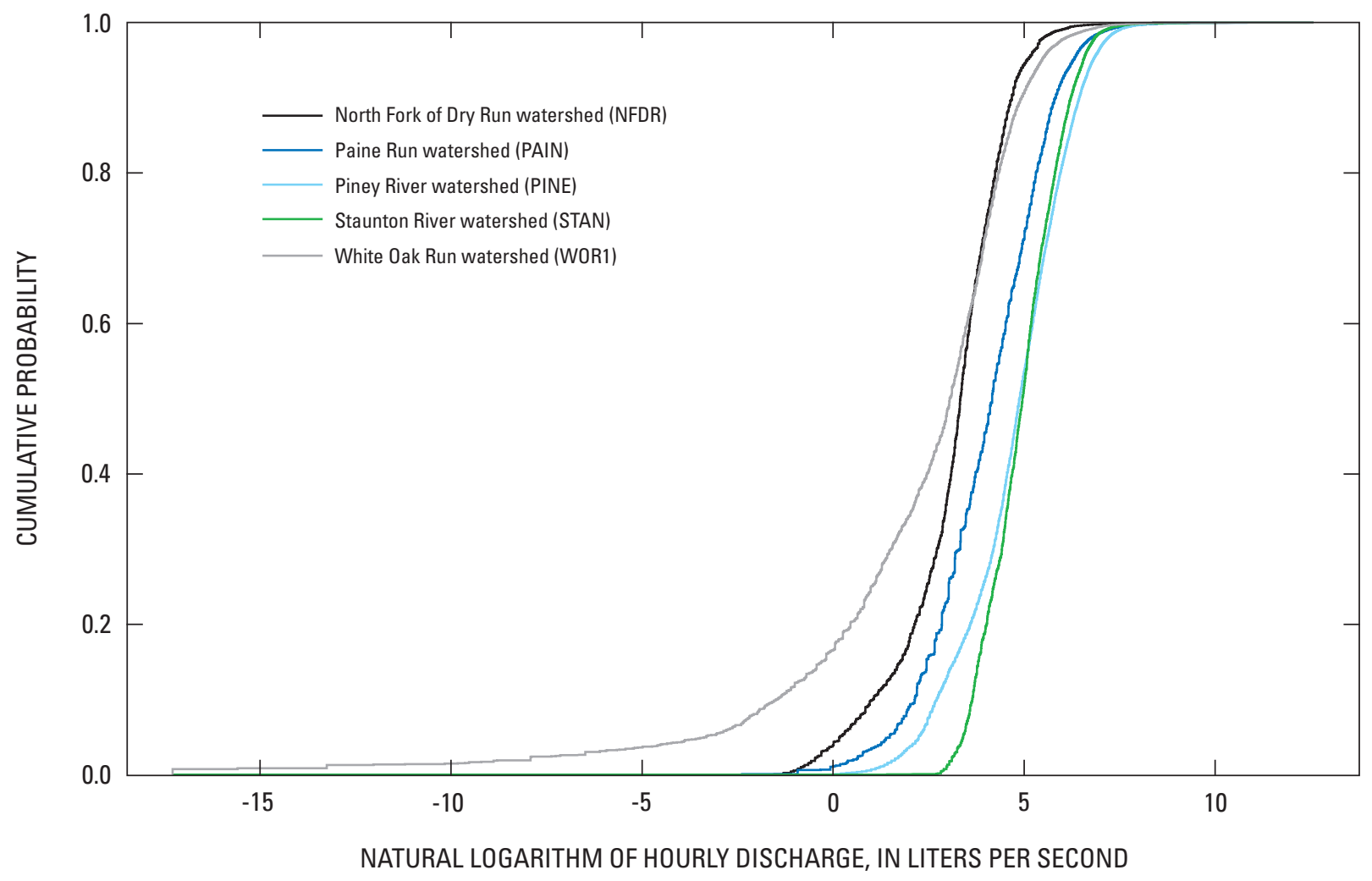

Figure 9. Distribution of natural logarithms of hourly discharge among the Shenandoah Watershed Study (SWAS) watersheds, Virginia. 


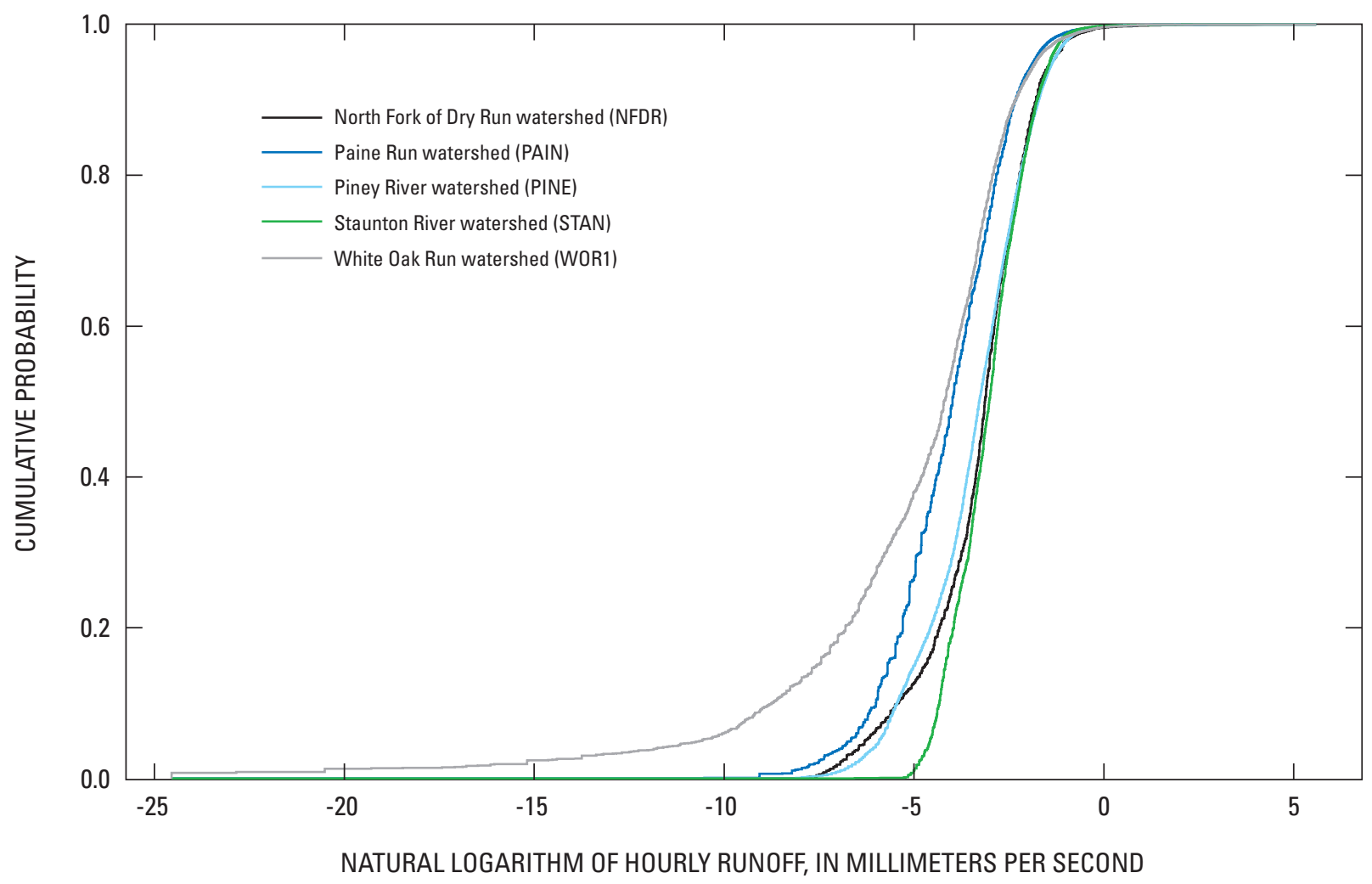

Figure 10. Distribution of natural logarithms of hourly runoff among the Shenandoah Watershed Study (SWAS) watersheds, Virginia. 

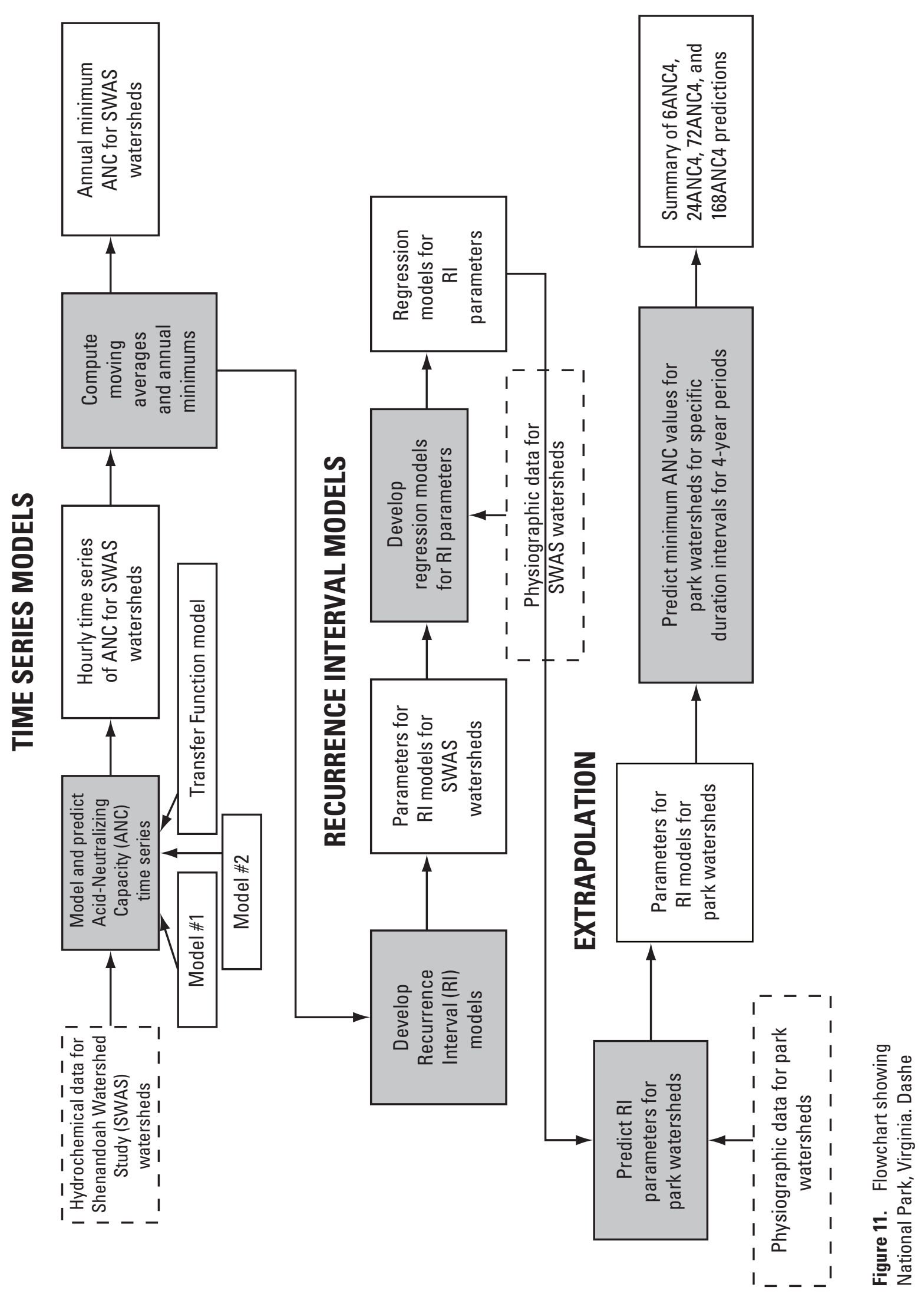
The two parenthetical terms of the transfer function (equation 1), which include the $\omega_{1}, \omega_{2}, v_{1}$, and $v_{2}$ parameters, provide a parsimonious means of specifying complex linear combinations of historical and current values of the input series $Q_{t}$ '. Because there are approximately 80,000 hourly discharge values but only about 1,000 hourly ANC values per site, the model parameters could not be estimated using SAS PROC ARIMA or PROC MODEL (SAS Institute, Inc., 2003). For transfer function models that depend on lagged values of the input series, SAS requires that there be no missing values. If, instead, values for $\omega_{1}, \omega_{2}, v_{1}$, and $v_{2}$ are assigned a priori, and letting

$Q_{t}^{\prime \prime}=\frac{\left(1-\omega_{1} B-\omega_{2} B^{2}\right)}{\left(1-\nu_{1} B-\nu_{2} B^{2}\right)} Q_{t}^{\prime}$,

and letting

$\eta_{t}=\frac{(1-\theta B)}{(1-\phi B)} \varepsilon_{t}$

then

$C_{t}-\mu=\omega_{0} Q_{t}^{\prime \prime}+\eta_{t}$,

which has the form of a simple regression. $Q_{t}$ ” is the result of filtering $Q_{t}$ ' with a backshift polynomial resulting from polynomial division (Brockwell and Davis, 1996). Filtering is accomplished by taking a weighted sum of the current and historical values of $Q_{t}$ ' to obtain $Q_{t}$ ”. The weights result from the values assigned to $\omega_{1}, \omega_{2}, v_{1}$, and $v_{2}$. The assumption to be tested was that an appropriate filter might yield lower error in a simple regression than using $Q_{t}$, alone, given appropriate values of $\omega_{1}, \omega_{2}, v_{1}$, and $v_{2}$.

The procedure was to iterate over the 19 values in the set $\{-0.9,-0.8,-0.7, \ldots, 0.7,0.8,0.9\}$ for each of $\left\{\omega_{1}, \omega_{2}, v_{1}\right.$, and $\left.v_{2}\right\}$ and record the mean square error (MSE) for each combination and site. As such, there were $19^{4}=130,321$ combinations; however, combinations were used only if the resulting filter was both causal and invertible (Brockwell and Davis, 1996). In the range considered, this restriction resulted in 73,441 combinations. For this step, data from only PAIN, PINE, and STAN were used, because of the relative lack of stormflow sample data for NFDR and WOR1. This step was performed prior to the addition of data from another year (October 1, 2002-September 30, 2003) and was not repeated afterwards.

The primary advantage to following the procedure described above was that once $\omega_{1}, \omega_{2}, v_{1}$, and $v_{2}$ were specified, the parameters $\omega_{0}, \phi, \theta$, and $\mu$ could be estimated simultaneously using SAS PROC ARIMA. Another advantage was that the MSE data could be used to select a model that was globally best for all three sites, even if it was not locally best for any one site. Each combination of parameters was ranked on its performance by site, and the average and maximum ranks of each combination were examined.

Parameter estimation in time series models can be affected significantly by the presence of outliers. Removing outliers from a time series by deleting them, however, only worsens the parameter-estimation problem. To avoid these problems, outliers were modeled using methods described by Chen and Liu (1993). They describe four basic types of univariate time series outliers: additive, innovational, level shift, and temporary change. Conceptually, an additive outlier results from some unknown cause that persists for only one time period. Given the amount of missing ANC data, it was appropriate to restrict identification to additive outliers, with the exception of a period at STAN. Missing discharge and water-quality data at STAN, from approximately mid-June through the end of October 1995, were related to a large flood in 1995 (Smith and others, 1996). Discharge previously had been estimated from other nearby gages, and ANC was modeled as an intervention (similar to a level shift).

Each additive outlier can be modeled by adding to the right-hand-side of the transfer function model (equation 1) a term of the form

$\delta_{T} I_{t}^{T}$

where $\delta_{T}$ is the outlier effect for outlier $T$, and $I_{t}^{T}$ is an indicator series whose value is 1 at the time of the outlier and 0 otherwise. After identification of a set of outliers, parameters were re-estimated, which often caused new outliers to appear because the error variance usually decreased significantly after outliers were modeled. The identification and re-estimation process was repeated iteratively until no new outliers were identified.

Hourly ANC values for the period of record for discharge were predicted, and the results were evaluated using error analysis of predicted and observed ANC concentrations. Lastly, the predicted ANC time series was adjusted to remove outlier effects.

The basic transfer function time series model was selected using data from PAIN, PINE, and STAN, because these watersheds have the best combination of discharge, and base-flow and stormflow chemistry data among the five SWAS watersheds. For each of the three sites, each combination of $\omega_{1}, \omega_{2}, v_{1}$, and $v_{2}$ was ranked on its associated MSE. The sum of ranks for each combination and the maximum rank among the three sites for each combination were evaluated. The $\left(\omega_{1}=\right.$ $\left.0, \omega_{2}=0, v_{1}=0, v_{2}=-0.6\right)$ combination was selected, because it ranked first on sum of ranks and second on maximum rank.

This combination simplified the transfer function model to

$C_{t}-\mu=\frac{\omega_{0}}{\left(1-0.6 B^{2}\right)} Q_{t}^{\prime}+\frac{(1-\theta B)}{(1-\phi B)} \varepsilon_{t}$, 
which corresponds to a filter (described previously) equivalent to

$$
Q_{t}^{\prime \prime}=Q_{t}^{\prime}+0.6 Q_{t-2}^{\prime}+0.6^{2} Q_{t-4}^{\prime}+\cdots+0.6^{n} Q_{t-2 n}^{\prime},
$$

which is a linear combination of historical $\ln$ (discharge) values two hours apart, with exponentially declining weights. Essentially, it is an AR(1) process on 2-hour data. This process was considered to be appropriate- as opposed to an AR(1) process on 1-hour data-because approximately 75 percent of the chemistry data were collected on or assigned to an even hour because of the protocol used for automated sampling.

The number of outliers identified in the ANC time series for each of the SWAS watersheds was as follows: 20 for NFDR, 11 for PAIN, 21 for PINE, 8 for STAN, and 5 for WOR1. All parameters for each site were statistically significant at the $\mathrm{p} \leq 0.0001$ level (table 4); parameters for the 65 outliers were statistically significant at the $p \leq 0.01$ level and most were significant at the $\mathrm{p} \leq 0.0001$ level.

All $\phi$ values were essentially equal to 1 (table 4 ). These $\phi$ values indicate that the ANC and $\ln$ (discharge) series should be differenced. Differencing, however, is impractical because of the high frequency of missing values in the ANC series; differencing would result in almost all missing values. The $\phi$ values also indicate that the errors resulting from the transfer function portion of the model are equivalent to an integrated moving average $\operatorname{IMA}(1,1)$ filter of the innovations. The $\operatorname{IMA}(1,1)$ model is equivalent to an exponentially weighted moving average function with smoothing parameter $\lambda=1-\theta$. The resulting small value of $\lambda$ indicates that the error resulting from the transfer function part of the model is relatively constant over a short time period, for example, during a storm (although over all events the expected value of the error is zero), and indicates that factors other than discharge control ANC during an event.

Such a factor described above might have a seasonal characteristic. For example, leaf fall occurs at approximately the same time every year and temporarily affects streamwater quality. Soil temperatures vary seasonally and may affect soil microbial activity that may, in turn, affect streamwater quality in ways that vary seasonally. No attempt was made, however, to introduce a seasonal component to the model. To introduce

Table 4. Transfer function parameter values ( $p$ less than or equal to 0.0001 ) for the Shenandoah Watershed Study (SWAS) watersheds, Virginia.

\begin{tabular}{lrrrr}
\hline Watershed & \multicolumn{1}{c}{$\boldsymbol{\mu}$} & \multicolumn{1}{c}{$\omega_{\mathbf{0}}$} & \multicolumn{1}{c}{$\phi$} & \multicolumn{1}{c}{$\theta$} \\
\hline NFDR & 60.89011 & -4.18853 & 0.99662 & 0.51970 \\
PAIN & 8.86667 & -0.89931 & .99891 & .93478 \\
PINE & 258.00627 & -8.01027 & .99956 & .82710 \\
STAN & 100.70228 & -4.36271 & .99732 & .86778 \\
WOR1 & 26.21063 & -1.53964 & .99915 & .89760 \\
\hline
\end{tabular}

seasonality in a stochastic manner using seasonal differencing would result in a loss of additional ANC data for the reasons mentioned previously. Depending on the method, modeling seasonality deterministically could risk model parsimony.

Floods are dynamic events that cause temporary disturbances such as trees falling into the water, stream banks sloughing off, and gravel bars and their contents being re-distributed. These types of disturbances could affect streamwater quality immediately downstream for hours or over 1-4 days in ways that would present themselves as temporary constant or slowly changing errors in predicted concentrations.

MSE was used as the criterion for model evaluation, because it is easily calculated for a wide variety of models and because it rewards models for good performance, whereas penalizing them for complexity. Such a statistic is desirable in model selection rather than a statistic such as $R^{2}$, which can always be improved by adding more variables without regard to the increased complexity. In practice, overly complex models do not perform well on new data (that is, data other than those used to develop the model, but that result from the same process). MSE is defined as

$M S E=\frac{S S E}{n-p}$,

where SSE is the sum of squares for error, $n$ is the total number of error observations, and $p$ is the number of parameters in the model. Generally, MSE initially decreases with increasing $p$ (increasing model complexity) up to a point, after which MSE begins to increase again.

Model 1 is written as

$C_{t}=\mu+\varepsilon_{t}$,

where $C_{t}$ is ANC at time $t, \mu$ is the mean ANC, and $\varepsilon_{t}$ is the error (the difference between the observed ANC and the mean ANC) at time $t, p=1$, and the MSE is equivalent to the unbiased sample variance,

$\operatorname{Var}\left(C_{t}\right)=\frac{1}{n-1} \sum_{i=1}^{n}\left(C_{t}-\mu\right)^{2}=\frac{1}{n-1} \sum_{i=1}^{n} \varepsilon_{t}^{2}$.

Model 2 is written as

$C_{t}-\mu=\omega_{0} Q_{t}^{\prime}+\varepsilon_{t}$,

where $Q_{t}^{\prime}$ is the natural logarithm of discharge, $\omega_{0}$ is a parameter relating a change in ANC to a change in $Q_{t}$, there are two parameters $(p=2)$, and the MSE is 
$M S E=\frac{S S E}{n-p}=\frac{1}{n-2} \sum_{i=1}^{n} \varepsilon_{t}^{2}$.

The transfer function model is written as

$C_{t}-\mu=\frac{\omega_{0}}{\left(1-0.6 B^{2}\right)} Q_{t}^{\prime}+\frac{(1-\theta B)}{(1-\phi B)} \varepsilon_{t}+\sum_{i=1}^{T} \delta_{i} I_{t}^{i}$,

where $\mu, \omega_{0}, \theta, \phi$, and $\delta_{l}, \delta_{2}, \ldots, \delta_{T}$ are parameters described previously, $T$ is the number of outliers, and $I_{t}^{1}, I_{t}^{2}, \ldots, I_{t}^{T}$ are special time series that indicate the locations of outliers, and there are $4+T$ parameters $(p=4+T)$. For this model, the MSE is

$$
M S E=\frac{1}{n-(4+T)} \sum_{i=1}^{n} \varepsilon_{t}^{2} .
$$

For all models to have the same MSE, the transfer function model must have smaller SSE than Model 2, which must have smaller SSE than Model 1. Although outliers were not chosen so as to minimize MSE, the transfer function model performed better on the basis of MSE than did either of the other candidate models (table 5).

The results shown in table 5 are not unexpected. The time series analysis indicated that errors are positively correlated and that discharge alone, especially during storm events, is insufficient to predict ANC. The positively correlated errors are important because the next step, development of the recurrence interval model, was to calculate moving averages of ANC values (fig. 11). If errors from simple regression were uncorrelated, their effect would be minimized by the averaging, whereas positively correlated errors would tend to propagate through to the moving averages. Using time series models instead of simple regression resulted in uncorrelated errors, which resulted in unbiased moving averages.

Table 5. Mean square error for Model 1, Model 2, and the transfer function model for the Shenandoah Watershed Study (SWAS) watersheds, Virginia.

\begin{tabular}{lrrc}
\hline & \multicolumn{3}{c}{ Mean Square Error } \\
\cline { 2 - 4 } Watershed & \multicolumn{1}{c}{ Model 1 } & \multicolumn{1}{c}{ Model 2 } & $\begin{array}{c}\text { Transfer } \\
\text { function model }\end{array}$ \\
\hline NFDR & 980.8605 & 742.8085 & 13.6547 \\
PAIN & 63.6641 & 41.8244 & 4.1455 \\
PINE & 3786.9168 & 1687.3276 & 73.2624 \\
STAN & 369.7289 & 236.0557 & 38.0814 \\
WOR1 & 414.5442 & 147.7422 & 17.4878 \\
\hline
\end{tabular}

\section{Recurrence Interval Models}

"Recurrence interval" refers to the expected time between events of a prescribed magnitude and duration. Recurrence interval models were developed to relate the magnitude, frequency, and duration of low-ANC events in the SWAS watersheds. Hydrologists characterize flood or low-flow frequencies by accumulating observations of extreme events and then fitting parametric distributions that permit estimation of magnitude and frequency for any desired duration. A number of related methods and distributions have been used successfully (for example, Riggs, 1968). It is not clear that any one method or distribution is superior, and the field of floodfrequency analysis is one of active research (Rao and Hamed, 2000 , and references therein).

Flood or low-flow frequencies for ungaged watersheds have been estimated by use of a regionalization process whereby results for data-rich (gaged) watersheds are extrapolated to data-poor (ungaged) watersheds using physical and topographic characteristics available for all and a variety of statistical procedures (for example, Kite, 1977; Rao and Hamed, 2000; Waltemeyer, 2002). Often, it is assumed that results extrapolated to a gaged site using data from all gaged sites are superior to those that would be obtained using data from the gaged site alone.

The annual 6-, 24-, 72-, and 168-hour-duration minimumANC values were extracted from the hourly ANC predictions for the five SWAS watersheds (fig. 11). For each hour and duration period, the moving average ANC centered on the current hour was calculated. The minimum moving average value for each water year was recorded as that year's statistic. Pearson Type III distributions (Riggs, 1968) were fitted to the annual water-year minimums. Although other more complicated distributions often are used in flood- frequency analysis (for example, Kite, 1977; Rao and Hamed, 2000), the Pearson Type III was chosen because of its simplicity and the lack of similar frequency analysis of a water-quality parameter in streamwater in the literature. The Pearson Type III distribution has three parameters: scale, shape, and threshold, and is characterized by the following equation:

$$
p(x)=\frac{1}{\sigma \Gamma(\alpha)}\left(\frac{x-\theta}{\sigma}\right)^{\alpha-1} \exp \left(-\left(\frac{x-\theta}{\sigma}\right)\right),
$$

where $\sigma$ is the scale parameter, $\alpha$ is the shape parameter, $\theta$ is the threshold parameter, and $\Gamma(\cdot)$ is the gamma function. Shape $(\alpha)$ was fixed to predetermined values, whereas the other two parameters for each combination of $\alpha$, site, and duration period were estimated. In regionalization it is common to assume that some homogeneous property is present across the watershed population. In this analysis, it was assumed that the shape of recurrence interval distributions would be constant across the park.

The hourly predictions of ANC, corrected for outlier and post-1995 flood effects at STAN, were used to calculate mov- 
ing averages of ANC for duration periods of 6, 24, 72, and 168 hours. That is,

$$
A N C_{t}^{d}=\frac{1}{d}\left(\frac{1}{2}\left(X_{t-\frac{d}{2}}+X_{t+\frac{d}{2}}\right)+\sum_{i=1-\frac{d}{2}}^{\frac{d}{2}-1} X_{t+i}\right),
$$

where $d$ is the duration period for which the moving average is calculated, and $X_{t}$ is the hourly prediction of ANC. For each site and duration period, the minimum value for each water year was selected and ranked (fig. 12). Streams with chronically low ANC values, such as PAIN and WOR1, have little variation in annual minimum ANC compared to higher ANC streams such as PINE (fig. 12).

Pearson Type III distributions for recurrence intervals for annual minimum ANC values were fitted for each site and duration period for various values of $\alpha$. The best results were obtained for $\alpha=1$. The resulting distributions indicate that high- and low-variance ANC streams such as PAIN, WOR1, and PINE do not often cross the brook trout response categories of Bulger and others (1995), and ANC in STAN is predicted to remain above $50 \mu \mathrm{eq} / \mathrm{L}$ for years at a time (fig. 13). Among the SWAS watersheds, only NFDR appears to have ANC decreases that might affect brook trout populations differently from year to year (fig. 13). These response categories were developed for acid-tolerant brook trout, but the response of the 27 other fish species in SNP is unknown. The developed distributions allow estimation of recurrence intervals for any ANC value and duration.

\section{Extrapolation}

The objective of the extrapolation was to estimate recurrence interval model parameters for the SNP watersheds. This objective was achieved by regressing the Pearson Type III distribution parameters scale and threshold against geologic and topographic watershed attributes for each of the four duration periods $(6,24,72$, and 168 hours). In order to produce estimated distributions that were conceptually correct (distributions for longer duration periods should predict higher minimum ANC values for the same period of recurrence), the shape parameter was held constant. For the same purpose, the scale parameter was constrained to be positive through selection of the independent variables in the regression. To make a final selection for shape, all parameters for each SWAS watershed and duration period were estimated freely, followed by the regression, followed by an examination of the adjusted coefficient of determination $\left(R^{2}\right)$ values for the other two parameters. A shape parameter value that resulted in optimal adjusted $R^{2}$ values for both scale and threshold was selected.

The distribution parameters scale and threshold were regressed against duration period, watershed area, elevation (minimum, maximum, range, and mean), and proportion of the watershed underlain by each of the three SWAS classes of bedrock (table 3 ) for each watershed. The duration period was treated as a categorical variable and the proportional variables were transformed using a logit transformation. All possible subsets of variables were tested using SAS PROC REG (SAS Institute, Inc., 2003), and the model and $\alpha$ value that provided the highest adjusted $R^{2}$ value (equivalent to the minimum MSE) and minimum number of independent variables was chosen (tables 6-8). The best results were obtained for $\alpha=1$. The best regression models for scale and threshold yielded adjusted $R^{2}$ values over 0.98 and statistically significant Fstatistics. A number of alternate models, however, yielded adjusted $R^{2}$ values almost as high. If additional discharge and water-quality data were to be collected, a different model might be selected. Similar prediction results, however, likely would occur.

Model equation for parameter scale:

$$
\begin{aligned}
& \text { Scale }=\begin{array}{l}
\beta_{0}+\beta_{1} \text { lp_BACA }+\beta_{2} \text { lp_GRAN }+\beta_{3} \operatorname{span}_{6}+ \\
\beta_{4} \operatorname{span}_{24}+\beta_{5} \operatorname{span}_{72}+\text { error }
\end{array} \\
& \text { lp_BACA }=\begin{array}{l}
\text { transformed proportion of basaltic } / \\
\text { carbonate rocks }
\end{array} \\
& \operatorname{span}_{6}= \begin{cases}1 & 6-\text { hour duration } \\
0 & \text { otherwise }\end{cases} \\
& \operatorname{span}_{24}= \begin{cases}1 & \text { 24- hour duration } \\
0 & \text { otherwise }\end{cases} \\
& \operatorname{span}_{72}= \begin{cases}1 & 72-\text { hour duration } \\
0 & \text { otherwise }\end{cases}
\end{aligned}
$$

Model equation for parameter threshold:

Threshold $=\beta_{0}+\beta_{1} \mathrm{MIN}+\beta_{2} \mathrm{MEAN}+\beta_{3}$ lp_BACA + $\beta_{4} \operatorname{span}_{6}+\beta_{5} \operatorname{span}_{24}+\beta_{6} \operatorname{span}_{72}+$ error

MIN = minimum elevation in meters

MEAN $=$ mean elevation in meters

By choosing $\alpha=1$, the Pearson Type III distribution simplifies to the exponential distribution 
Table 6. Analysis of variance of regression model for distributional parameters scale and threshold for the Shenandoah Watershed Study (SWAS) watersheds, Virginia.

$[<$, less than; DF, degress of freedom; n.a., not applicable $]$

\begin{tabular}{lccccc}
\hline \multicolumn{1}{c}{ Source } & DF & $\begin{array}{c}\text { Sum of } \\
\text { squares }\end{array}$ & $\begin{array}{c}\text { Mean } \\
\text { square }\end{array}$ & $\begin{array}{c}\text { F- } \\
\text { value }\end{array}$ & $\begin{array}{c}\text { p- } \\
\text { value }\end{array}$ \\
\hline \multicolumn{7}{c}{ Scale } \\
\hline Model & 5 & 4096.18560 & 819.23712 & 211.93 & $<0.0001$ \\
Error & 14 & 54.11951 & 3.86568 & n.a. & n.a. \\
Corrected total & 19 & 4150.30511 & n.a. & n.a. & n.a. \\
\hline \multicolumn{7}{c}{ Threshold } \\
Model & 6 & 20624 & 3437.33607 & 150.75 & $<0.0001$ \\
Error & 13 & 296.41161 & 22.80089 & n.a. & n.a. \\
Corrected total & 19 & 20920 & n.a. & n.a. & n.a. \\
\hline
\end{tabular}

Table 7. Fit statistics of regression model for distributional parameters scale and threshold for the Shenandoah Watershed Study (SWAS) watersheds, Virginia.

\begin{tabular}{lcc}
\hline \multicolumn{1}{c}{ Statistic } & \multicolumn{1}{c}{ Scale } & Threshold \\
\hline Root mean square error & 1.96613 & 4.77503 \\
Dependent mean & 15.69302 & 24.79674 \\
Coefficient of variance & 12.52871 & 19.25668 \\
$\mathrm{R}^{2}$ & .9870 & .9858 \\
Adjusted $\mathrm{R}^{2}$ & .9823 & .9793 \\
\hline
\end{tabular}

Table 8. Parameter estimates of regression model for distributional parameters scale and threshold for the Shenandoah Watershed Study (SWAS) watersheds, Virginia. Degrees of freedom for all variables equals one.

$[<$, less than]

\begin{tabular}{crrrr}
\hline Variable & $\begin{array}{c}\text { Parameter } \\
\text { estimate }\end{array}$ & $\begin{array}{c}\text { Standard } \\
\text { error }\end{array}$ & t-value & p-value \\
\hline & \multicolumn{1}{c}{ Scale } \\
\hline$\beta_{0}$ & 37.92969 & 1.21136 & 31.31 & $<0.0001$ \\
$\beta_{1}$ & 3.39510 & .11433 & 29.70 & $<.0001$ \\
$\beta_{2}$ & .71922 & .05337 & 13.48 & $<.0001$ \\
$\beta_{3}$ & 3.12908 & 1.24349 & 2.52 & .0247 \\
$\beta_{4}$ & 3.50849 & 1.24349 & 2.82 & .0136 \\
$\beta_{5}$ & 3.61143 & 1.24349 & 2.90 & .0115 \\
\hline & & $T h r e s h o l d$ & & \\
\hline$\beta_{0}$ & 53.83705 & 18.40794 & 2.92 & .0118 \\
$\beta_{1}$ & -.17566 & .01718 & -10.23 & $<.0001$ \\
$\beta_{2}$ & .14421 & .02239 & 6.44 & $<.0001$ \\
$\beta_{3}$ & 6.75074 & .30338 & 22.25 & $<.0001$ \\
$\beta_{5}$ & -13.18038 & 3.01999 & -4.36 & .0008 \\
$\beta_{6}$ & -8.53632 & 3.01999 & -2.83 & .0143 \\
\hline & & & &
\end{tabular}



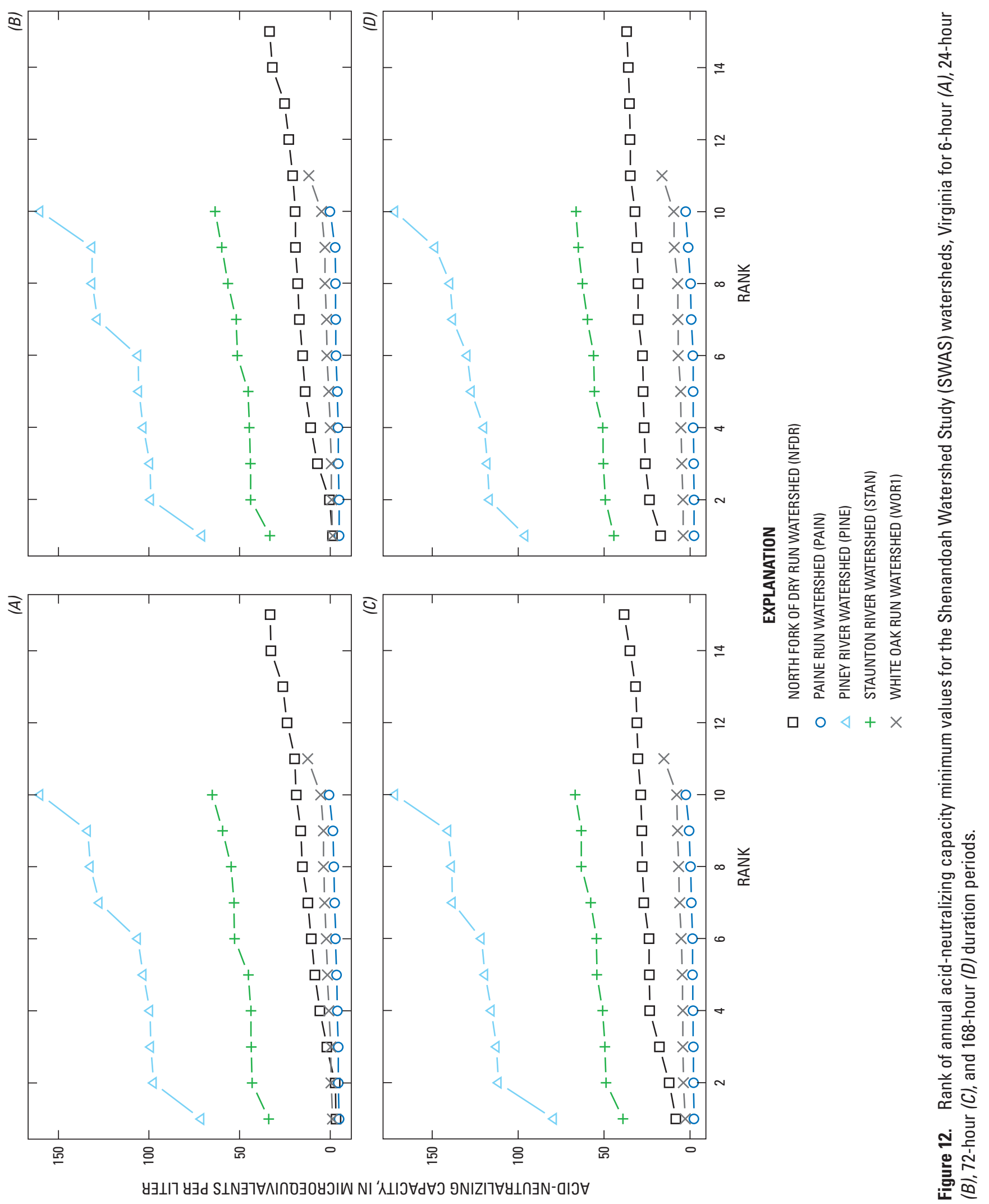


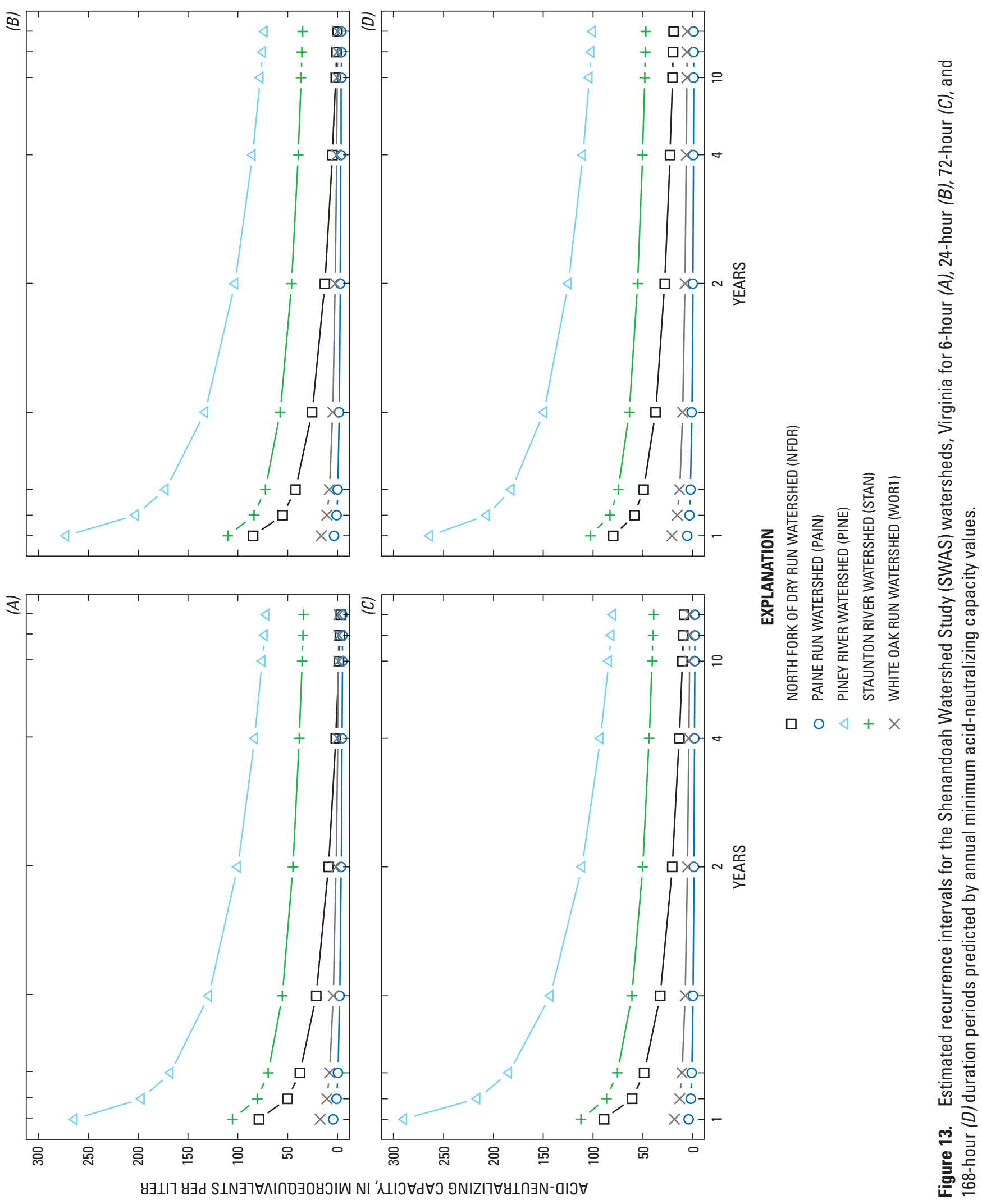


$p(x)=\frac{1}{\sigma} \exp \left[-\left(\frac{x-\theta}{\sigma}\right)\right]$,

where to repeat, $\sigma$ is the scale parameter and $\theta$ is the threshold parameter.

\section{Predictions of Stream Acidification}

The results of the mathematical model developed in this analysis are summarized on four maps (figs. 14-17). The maps indicate the predicted range of low-ANC values on a 4-year recurrence interval for 6- (fig. 14), 24- (fig. 15), 72- (fig. 16), and 168- (fig. 17) hour duration periods for the 231 SNP watersheds. The terminology used, for example, 168ANC4, indicates the minimum average ANC value predicted to occur for 168 consecutive hours about once every 4 years. During the 168 hours, ANC values might increase or decrease, but the average ANC for that period will be lower than any other 168hour period. Another interpretation of the terminology is that there is a 25-percent probability in any one year that the minimum ANC would be maintained for the designated number of hours. The choice of 4 years for the recurrence interval was arbitrary but corresponds to the maximum expected lifespan of a brook trout. In general, shorter recurrence intervals would result in higher low-ANC values, and longer recurrence intervals would result in lower low-ANC values.

To create the 6ANC4 map (fig. 14), for example, the value on the $y$-axis of the point on the 6-hour extrapolated curve corresponding to the 4-year value on the $\mathrm{x}$-axis was identified for each of the 231 SNP watersheds (see figure 18 for the curves for the SWAS watersheds). That is, for each watershed, the scale and threshold parameters were calculated using the scale and threshold parameter model equations and the desired recurrence interval. Then using equation (3) and setting $p(x)$ to the inverse of the desired recurrence interval (for example, 0.25 for a 4 -year recurrence interval), the expected low-ANC value was calculated. To generate the map, each watershed was color-coded to represent the range within which this value fell.

Model results indicate that a large percentage of SNP's total land and watershed area has episodic acidification on 4-year recurrence intervals to levels associated with negative effects on aquatic biota, as defined by Bulger and others (1995). On the basis of a 4-year recurrence interval, approximately 23 percent of SNP's land area (44 percent of the watersheds) can be expected to have conditions classified as "Indeterminate," "Episodically acidic," or "Chronically acidic" for 72 continuous hours (table 9). For 6 continuous hours, approximately 27 percent of the land area (51 percent of the watersheds) can be expected to have conditions classified as "Indeterminate," "Episodically acidic," or "Chronically acidic." Nine percent of delineated SNP watersheds have acidic episodes for 168 hours (1 week's duration) at 4-year recurrence intervals (table 9 ).

These estimates are dependent on the way that watershed boundaries were delineated, as predictions are for the most downstream point in the watershed. Had additional subwatersheds been defined farther upstream in the watersheds, larger portions of the park would be predicted to be vulnerable to episodic acidification; therefore, these estimates are considered conservative.

Comparison of the recurrence intervals predicted by regression for the SWAS watersheds indicates that the differences in expected minimum ANC values for a given recurrence interval are greater between watersheds than between duration periods (fig. 18). Lower ANC watersheds such as WOR 1 are predicted to have the same episodic conditions year after year, whereas higher ANC watersheds, such as PINE, are predicted to have significantly different (in terms of the raw concentrations and not standardizing for relative ANC values in the respective streams) annual episodic ANC extremes over time. This difference indicates that the number of aquatic species present would be more stable over time, although lower, in low-ANC streams than in high-ANC streams.

The regression equations and recurrence interval models developed from the SWAS watershed data allow visualization of the effect of geology and topography on episodic ANC

Table 9. Percentage of land area in Shenandoah National Park, Virginia subject to defined levels of episodic acidification on a 4-year recurrence interval. Percentages of Shenandoah National Park watersheds are given in parentheses.

[ANC, acid-neutralizing capacity; $\mu \mathrm{eq} / \mathrm{L}$, microequivalents per liter; >, greater than; <, less than or equal to]

\begin{tabular}{llcccc}
\hline \multirow{2}{*}{$\begin{array}{c}\text { Average ANC } \\
\text { ( } \boldsymbol{\mu e q} / \mathbf{L})\end{array}$} & \multicolumn{1}{c}{$\begin{array}{c}\text { Brook trout response } \\
\text { class }^{1}\end{array}$} & \multicolumn{1}{c}{ Duration interval } \\
\cline { 3 - 6 } & Not acidic & $\begin{array}{c}\mathbf{6} \\
\text { hours }\end{array}$ & $\begin{array}{c}\mathbf{2 4} \\
\text { hours }\end{array}$ & $\begin{array}{c}\mathbf{7 2} \\
\text { hours }\end{array}$ & $\begin{array}{c}\mathbf{1 6 8} \\
\text { hours }\end{array}$ \\
\hline 50 & Indeterminate & $73.5(49.4)$ & $73.8(50.6)$ & $77.0(55.8)$ & $81.8(61.9)$ \\
$>20-50$ & Episodically acidic & $12.9(16.9)$ & $12.6(15.6)$ & $12.4(13.0)$ & $9.0(9.5)$ \\
$>0-20$ & Chronically acidic & $6.1(10.0)$ & $6.2(10.4)$ & $6.0(10.8)$ & $8.0(19.5)$ \\
$\leq 0$ & $7.5(23.8)$ & $7.4(23.4)$ & $4.6(20.3)$ & $1.1(9.1)$ \\
\hline
\end{tabular}

${ }^{1}$ From Bulger and others (1995) 

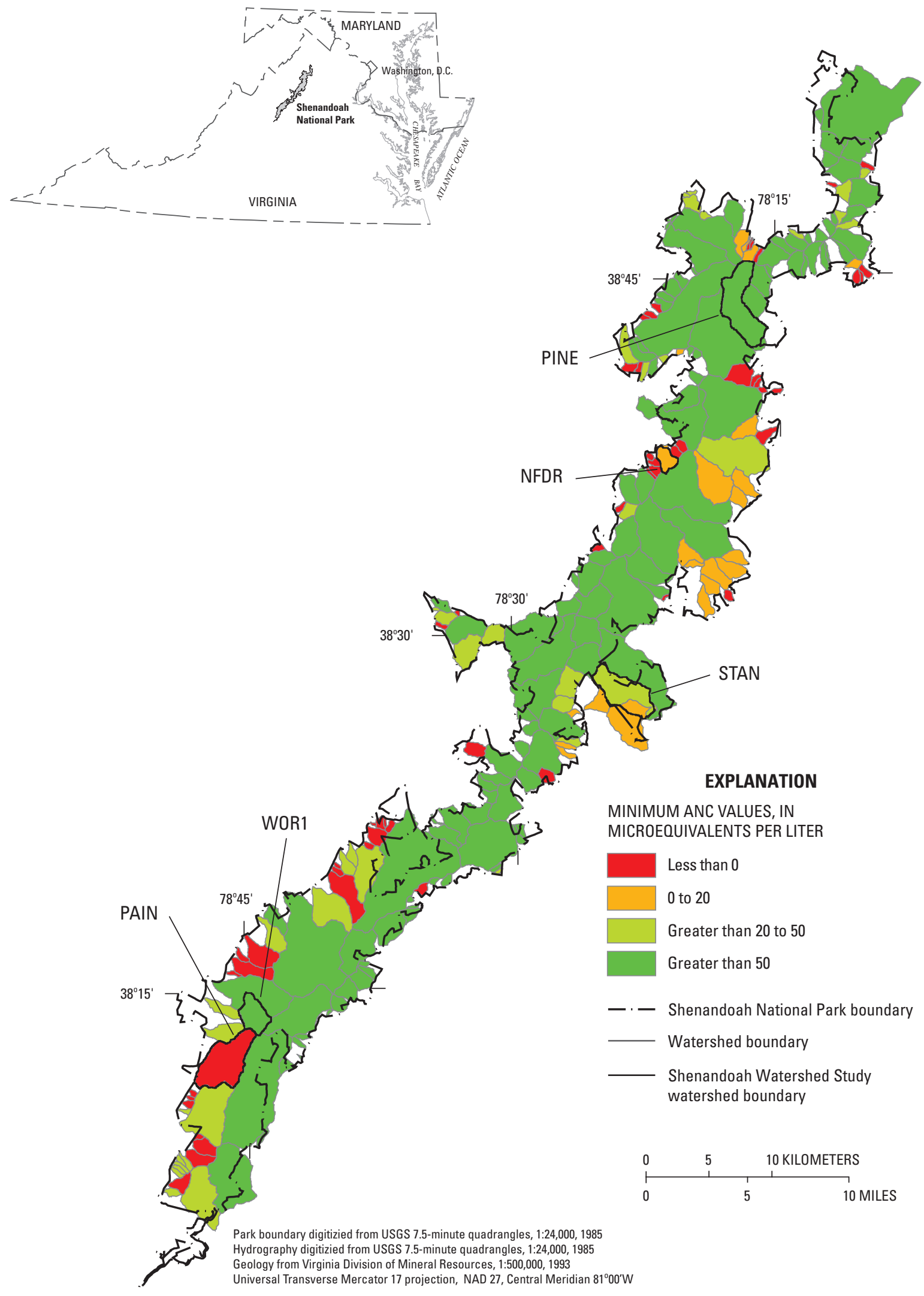

Figure 14. Predicted range of minimum values of acid-neutralizing capacity (ANC) on a 4-year recurrence interval for 6-hour duration periods (6ANC4) in watersheds in Shenandoah National Park, Virginia. 

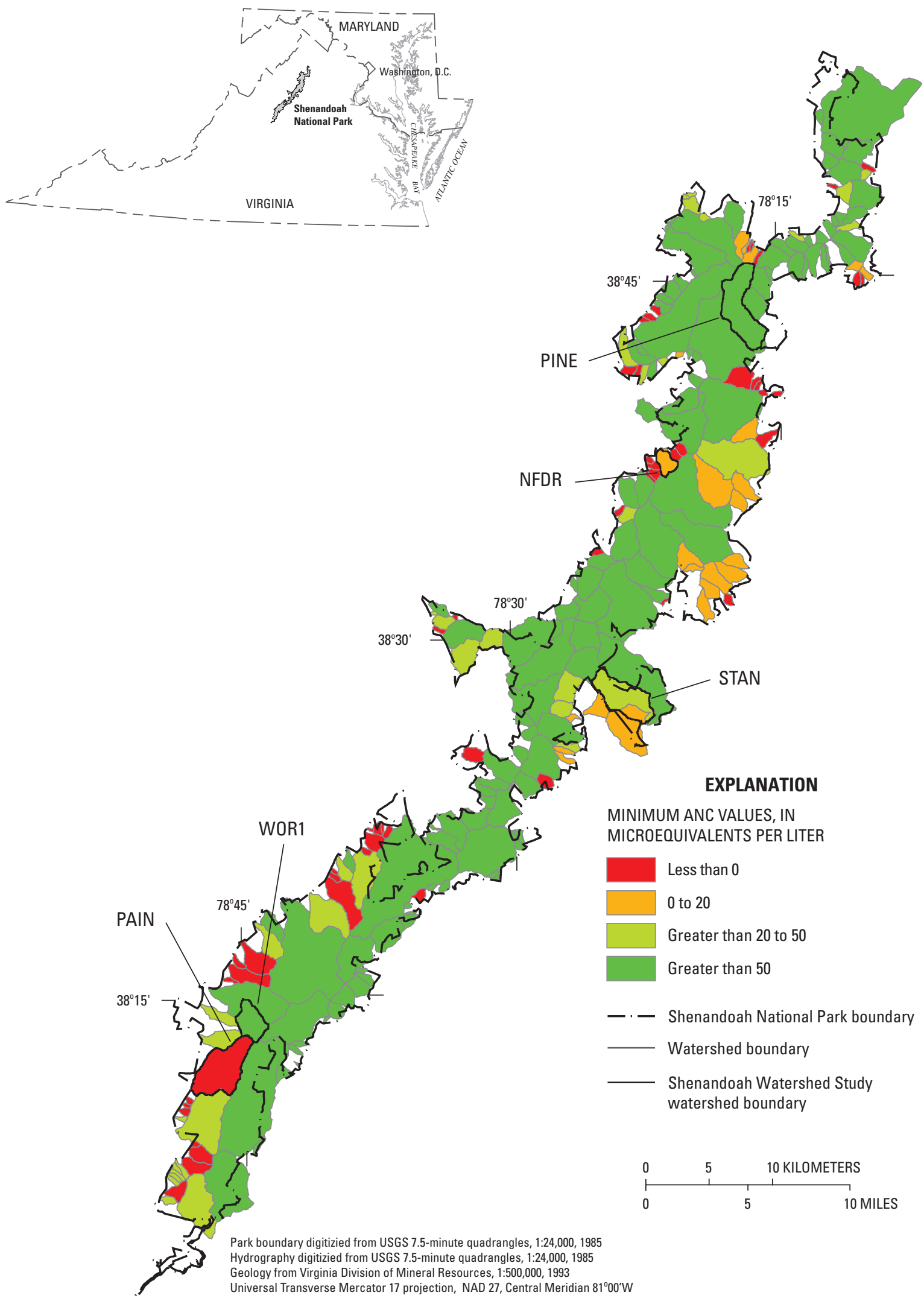

Figure 15. Predicted range of minimum values of acid-neutralizing capacity (ANC) on a 4-year recurrence interval for 24-hour duration periods (24ANC4) in watersheds in Shenandoah National Park, Virginia. 

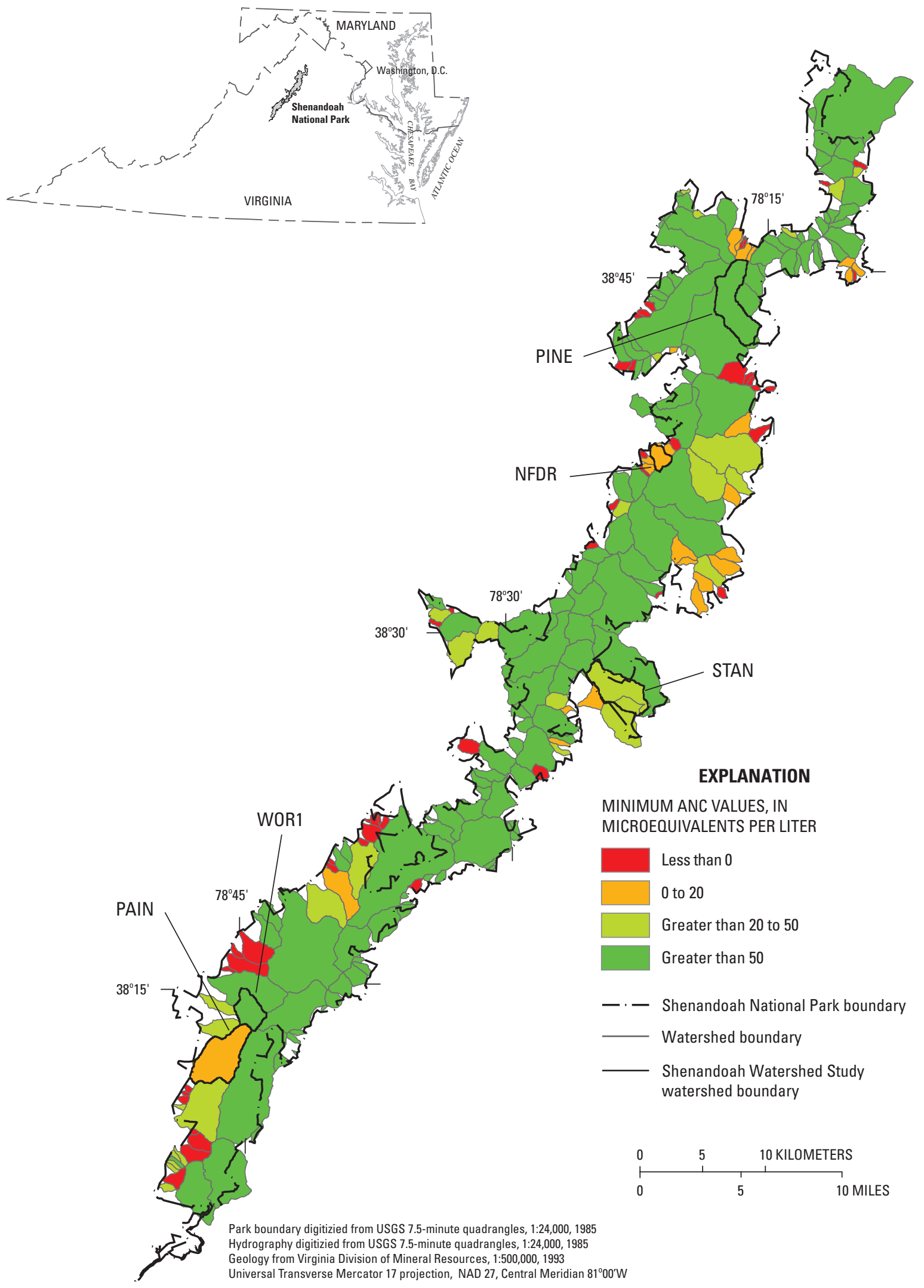

MINIMUM ANC VALUES, IN MICROEQUIVALENTS PER LITER

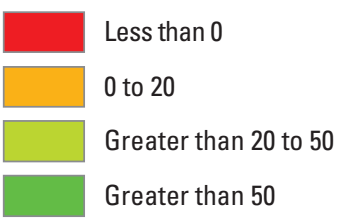

- - Shenandoah National Park boundary

Watershed boundary

Shenandoah Watershed Study watershed boundary

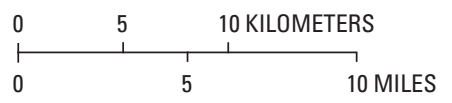

Park boundary digitized from USGS 7.5-minute quadrangles, 1.24,000, 1985

Universal Transverse Mercator 17 projection, NAD 27, Central Meridian 8100' W

Figure 16. Predicted range of minimum values of acid-neutralizing capacity (ANC) on a 4-year recurrence interval for 72-hour duration periods (72ANC4) in watersheds in Shenandoah National Park, Virginia. 

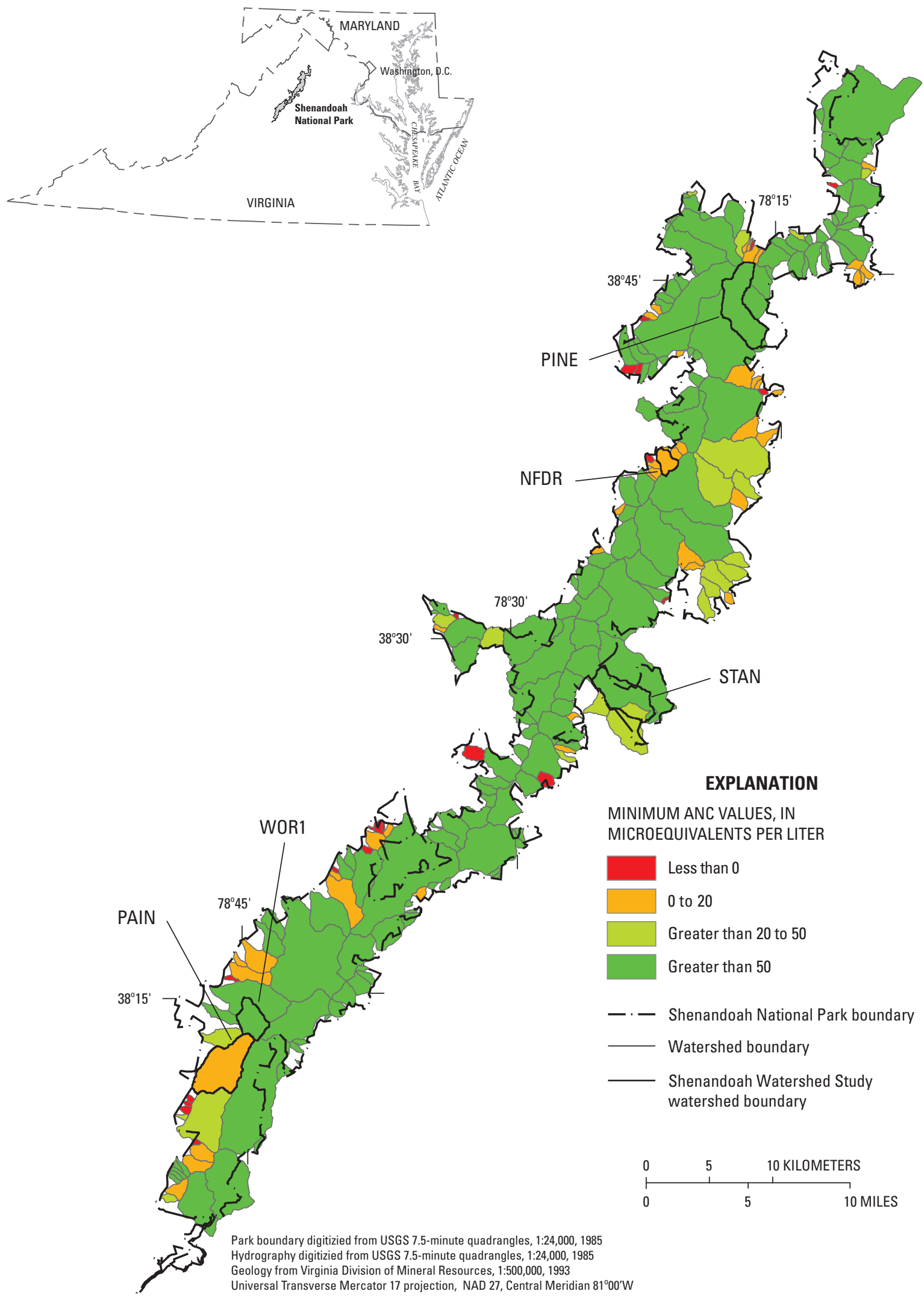

Figure 17. Predicted range of minimum values of acid-neutralizing capacity (ANC) on a 4-year recurrence interval for 168-hour duration periods (168ANC4) in watersheds in Shenandoah National Park, Virginia. 


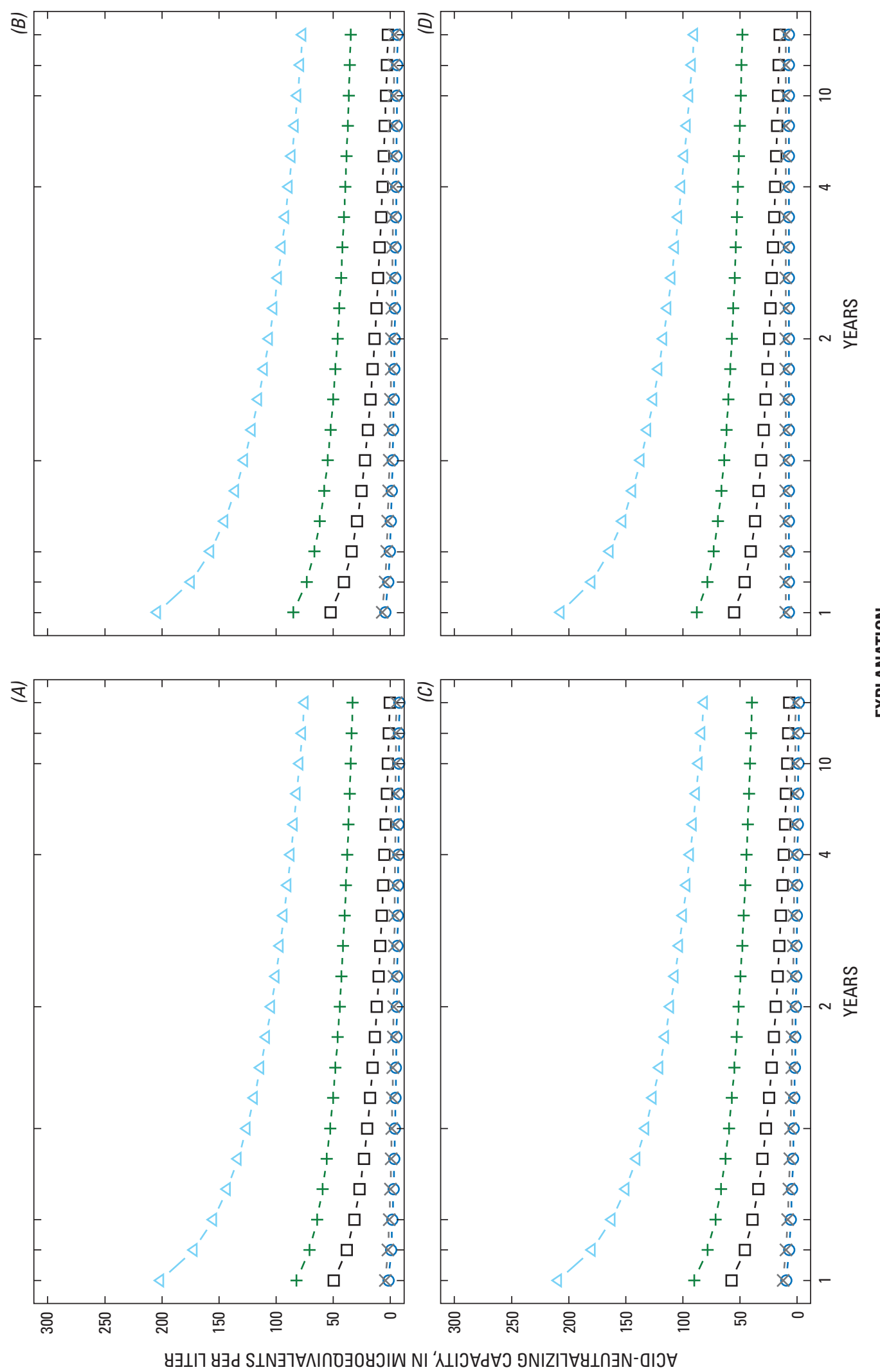

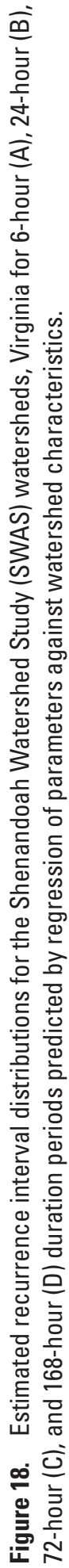


values. Contours of ANC values for selected duration and recurrence intervals were plotted against topographic metrics (fig. 19). For watersheds underlain by similar percentages of basaltic/carbonate bedrock, higher ANC values are predicted to be associated with higher mean and lower minimum elevations, which tend to be the larger watersheds. Lower episodic ANC values are predicted to be associated with smaller watersheds, which have mean elevations similar to their minimum elevations. Given the same minimum elevation, a watershed with greater mean elevation generally will be larger than a watershed with smaller mean elevation, and larger watersheds generally will have less severe ANC decreases than smaller watersheds, other factors being equal. Watersheds with similar topographic metrics are predicted to have more severe ANC decreases if they also are underlain by less basaltic/carbonate bedrock. It is clear that the SWAS watersheds represent watersheds underlain by a relatively low percentage of basaltic/carbonate bedrock (fig. 19).

\section{Potential Effects on Aquatic Biota}

An isolated event of magnitude and duration sufficient to have a negative effect on fish populations is of concern. A sequence of events of magnitude and duration sufficient to eliminate the more-sensitive young-of-year class, occurring over a period of successive years equal to the maximum lifespan of the species, theoretically could extirpate a population. Let an event of concern have recurrence interval $T$. Over a long time period and assuming independence from year-to-year of the occurrence of the event, the probability $p$ of experiencing at least one sequence of $k$ years in a row of the event within a management period of $N$ years is

$p=1-\left(1-\left(\frac{1}{T}\right)^{k}\right)^{N}$.

Recurrence intervals for SNP's watersheds for 72-hour durations of average ANC less than -20, 0, 20, and $50 \mu \mathrm{eq} / \mathrm{L}$ were estimated (fig. 20a). These ANC values are associated roughly with $\mathrm{pH}$ values in the range where various species of fish were not observed in the Neversink River watershed (Baldigo and Lawrence, 2000). Only two park watersheds were predicted to have 72 -hour periods of ANC less than $-20 \mu \mathrm{eq} / \mathrm{L}$, which is roughly equivalent to the $\mathrm{pH}$ level below which brook trout were not found in the Neversink River watershed. Brook trout are the most common species represented at monitoring stations in the SNP fish-monitoring program (Vana-Miller and Weeks, 2004), but are considered to be the least sensitive fish species to acidification effects in the park (Sullivan and others, 2003).
About one-fifth of SNP's 231 delineated watersheds were predicted to have 72 -hour periods of ANC less than $0 \mu \mathrm{eq} / \mathrm{L}$ at least occasionally. Of these watersheds, roughly two-thirds, or approximately 14 percent of the delineated watersheds, were predicted to have recurrence intervals of these conditions of less than 2 years. A recurrence interval of less than 2 years indicates that with near certainty (probability greater than 0.90 ) a watershed will have 4 continuous years of these conditions at least once in the next 40-100 years (fig. 20b).

Because various park fish species, including brook trout, have maximum life spans of less than 4 years, these results are of concern. In addition, ANC decreases are concurrent with natural cycles of floods and droughts, which also can have deleterious effects on fish populations. Whereas geologic maps alone can provide a qualitative measure of the relative risk of acidification, the probability calculations included in this report provide quantitative information that can be more useful in management decision models that incorporate risk.

Whereas a relation between minimum observed ANC and species diversity has been reported in park streams (Bulger and others, 2000), the tolerances of individual species, with the exception of brook trout and blacknose dace, to ANC decreases are largely unknown. In the Neversink River watershed, Baldigo and Murdoch (1997) found that exposure to inorganic aluminum concentrations in excess of $200 \mu \mathrm{g} / \mathrm{L}$ for more than 48 hours would produce mortality in brook trout. These conditions have not been observed in the SWAS watersheds. Baldigo and Murdoch (1997) also found, however, that frequency of the occurrence of events was important, and that effects were cumulative. This result indicates that lower exposure magnitudes, occurring either over a longer duration or at a sufficient frequency, also could be lethal.

\section{Management Implications and Future Directions}

This modeling effort was possible because of the extensive record of discharge and water quality available for five watersheds in the park, and because of the placement of these sites across a range of geologic and physiographic conditions. Improvements in the models would result from additional sites and/or additional years of data collection from the present sites, in particular, water-quality data during stormflow. The SWAS record is considered "long-term" when compared to other watershed research efforts; however, in time series modeling, 15 years is considered short.

From a natural resource management perspective, the results of this study indicate that: 1) some of the focus of water-quality monitoring and research should be shifted to smaller and higher-elevation watersheds; 2) geology alone is not an adequate surrogate for predicting the complicated hydrochemical environment and associated fish distributions; 3) discharge and water-quality monitoring need to be done on a wider range of watershed sizes; and 4) modeling of fish 

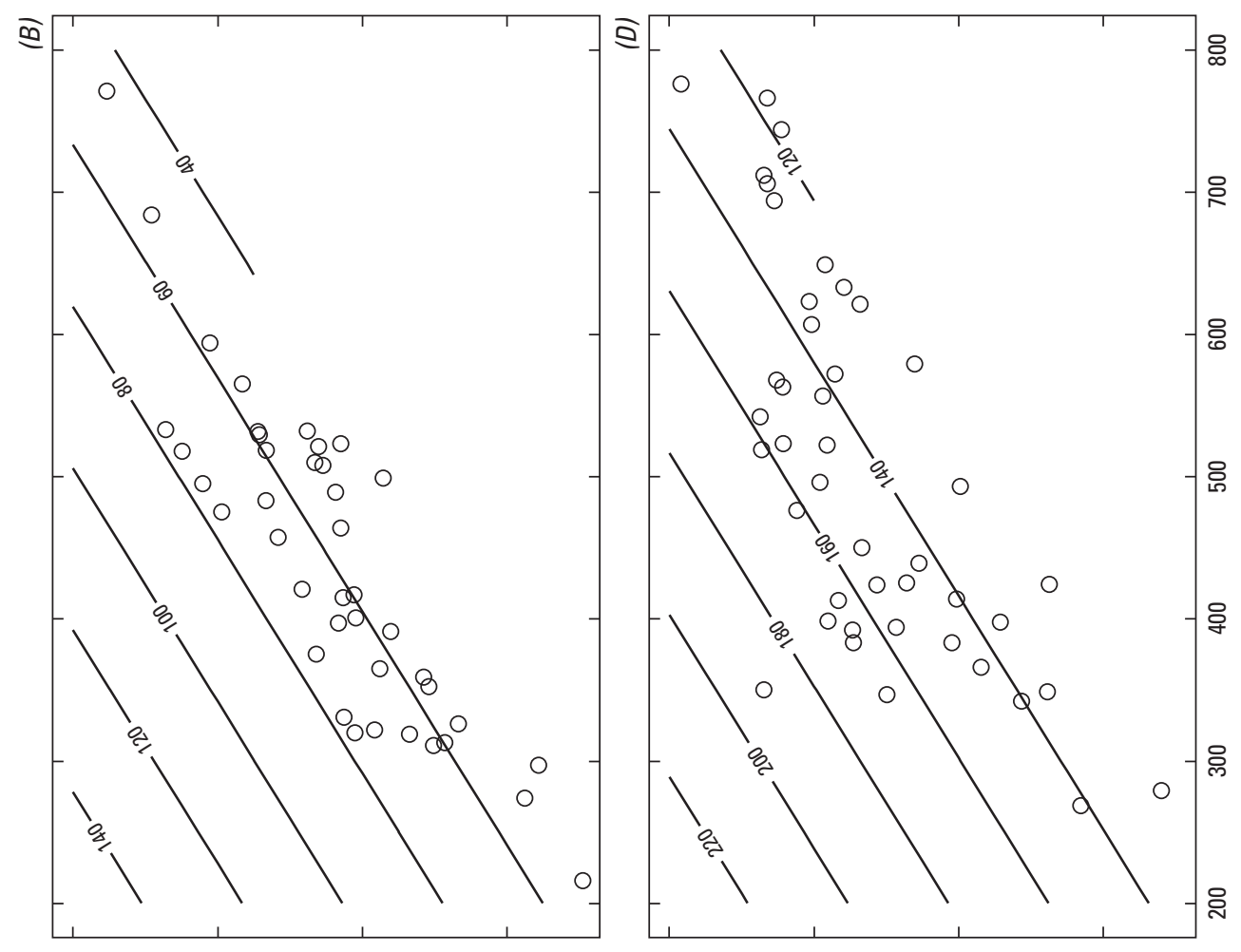

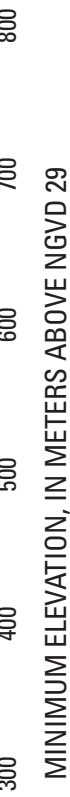
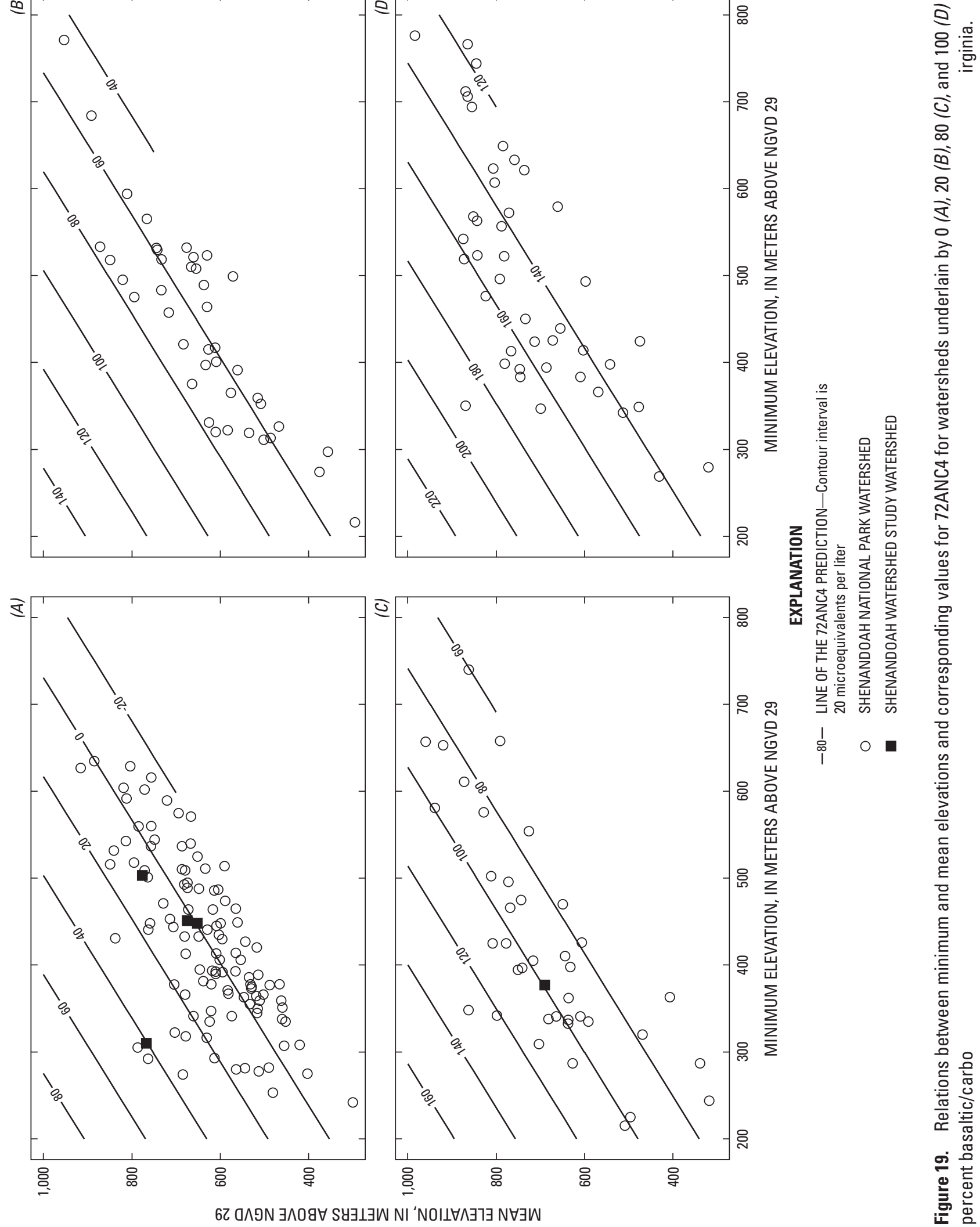
(A)
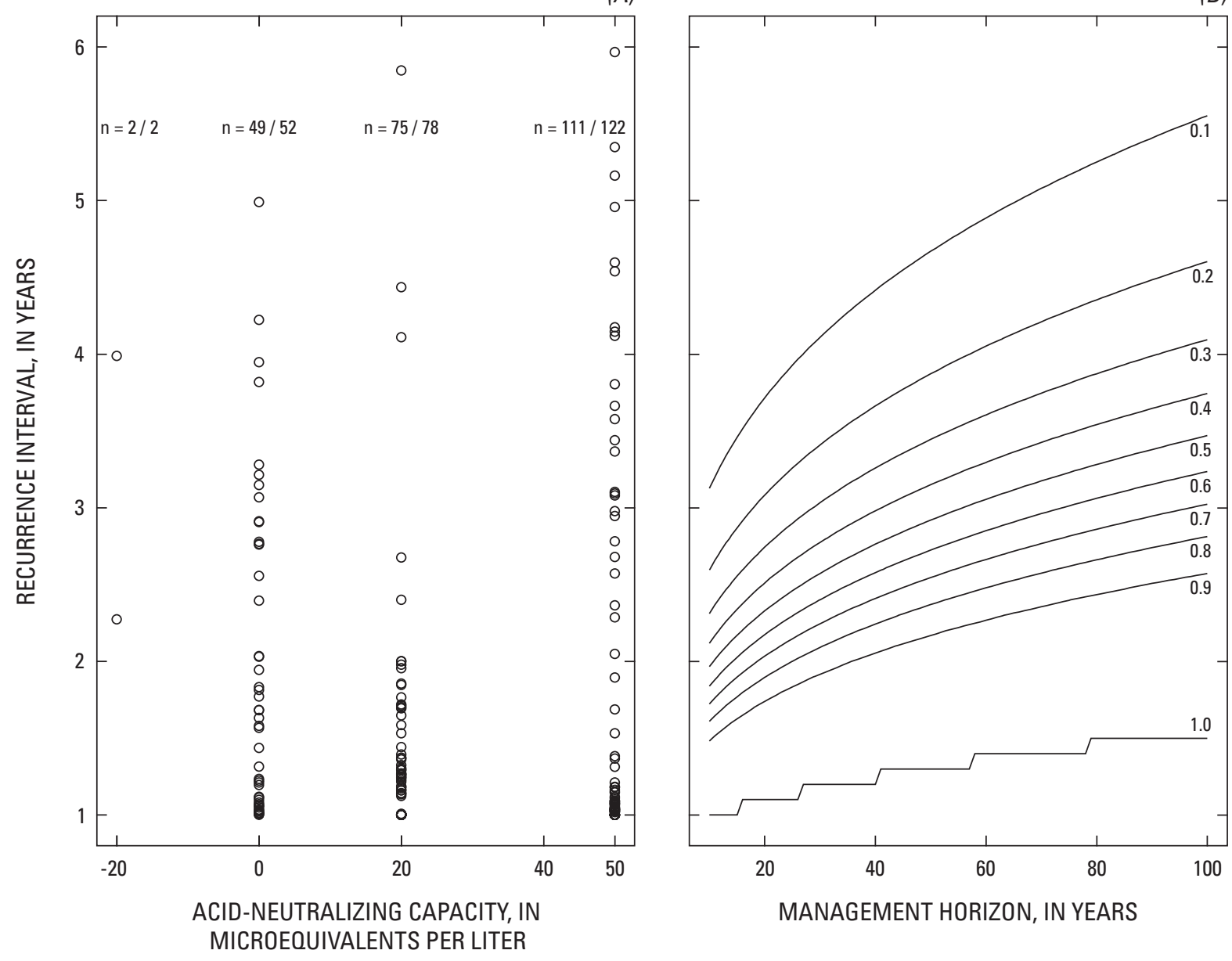

Figure 20. Distribution of Shenandoah National Park, Virginia watersheds that are predicted to have 72-hour low-acid-neutralizing capacity periods of less than $-20,0,20$, and 50 microequivalents per liter, at least once every 6 years. Watersheds with recurrence intervals greater than 6 years are not plotted $(n=n$ plotted $/ n$ total) $(A)$, and probability of a watershed having at least one sequence of 4 years of an event (such as 72 successive hours of acid-neutralizing capacity less than 0 ) given the recurrence interval of the event and a management horizon of 20 to 100 years $(B)$, in Shenandoah National Park, Virginia 
distributions relative to hydrochemical and physical environments needs to be done. The models developed through this analysis allow estimation of recurrence intervals for any ANC value and duration.

Additional results provide a mechanism for identifying SNP watersheds that should be high priority for investigations that might lead to impairment designation. Investigations that might lead to impairment designation can be prioritized in watersheds where the risk analysis identified in figure 20 indicates a high probability of species loss within the next 3 years. (A 3-year time frame corresponds to a category that is being used in the Mid-Atlantic Network water-quality monitoring assessment, which describes streams that have not yet been designated but which NPS managers believe to be in imminent danger of experiencing water-quality problems). $\mathrm{As} \mathrm{pH}$ is one indicator that can lead to impairment designation, this study could be repeated to estimate the probability of a stream experiencing $\mathrm{pH}$-impaired conditions in the near future.

This work generated a number of questions:

(1) Do predicted ANC values explain the pattern of fish distributions observed in SNP? Clearly other factors may be responsible for the pattern, but a longstanding theory of acid rain research is that aquatic organisms are affected by episodic conditions long before a water body becomes chronically acidified (Bulger and others, 1995). The "average" or baseflow chemical conditions usually measured are indicative only of the episodic conditions resulting in a watershed. Although not definitive, this body of research indicates that to understand the observed distributions of fish species in SNP, it is necessary to better understand water-quality variations at all watershed scales.

(2) How accurate are the ANC predictions? To answer this question definitively, stream gages and autosamplers would need to be installed in a number of other watersheds in the park and operated over long time periods. If fish do respond to ANC decreases (or other water-quality metrics), however, then a form of indirect validation of the predictive models is achieved without additional long-term monitoring.

(3) Which water-quality indicator, or indicators, best link(s) episodic acidification to fish response? The analysis presented in this report assumed that ANC is integrative of other water-quality indicators and, thus, sufficient to explain fish population attributes. One study, however, concluded that ANC alone is not a sufficient predictor (Baldigo and Lawrence, 2000). Inorganic monomeric aluminum concentrations for the SWAS watersheds are not available in sufficient quantity for a modeling effort of a similar scope as this analysis. Either additional water-quality indicators need to be explored or an aluminum monitoring program initiated.

(4) To what degree are the low fish populations and species counts in watersheds underlain by siliciclastic bedrock a function of flow regime and to what degree a function of ANC decreases? Among the SWAS watersheds, the siliciclastic watersheds have lower discharge given similar topography, as well as lower ANC values, than watersheds on the other bedrock types. Streams that dry up are not likely to support fish populations. Data are available so that an analysis similar to that presented in this report could be performed for streamwater discharge alone.

\section{Summary and Conclusions}

Acid rain is a worldwide problem. In the United States, the problem is particularly acute in the Mid-Atlantic and Northeastern States because of the downwind drift of contaminants emitted primarily by power plants in the Ohio River Valley. Acid-neutralizing capacity (ANC) is the capacity of natural waters to neutralize acidic inputs, and the standard unit of measurement of ANC is microequivalents per liter ( $\mu \mathrm{eq} / \mathrm{L}$ ). Acid rain affects streams by temporarily decreasing the ANC of the water to less than $0 \mu \mathrm{eq} / \mathrm{L}$, a process termed episodic acidification. During episodic acidification, the increase in acidic components in streamwater can have deleterious effects on aquatic biota. After the rain stops and the excess runoff subsides, ANC of streamwater eventually returns to its normal level, generally greater than $0 \mu \mathrm{eq} / \mathrm{L}$. ANC of streamwater is strongly affected by the underlying bedrock in a watershed: rocks that weather relatively easily (for example, limestone) yield streams with higher ANC relative to rocks that are resistant to weathering (for example, quartzite).

Shenandoah National Park in north-central Virginia is one of the three most contaminated parks in the national park system because of the deposition of acid rain. Episodic acidification is thought to be a controlling factor on fish populations in the park. Although acidic deposition to the park is relatively uniform across its land area, the water-quality response of streamwater during rain events varies substantially. This response is a function of the underlying geology and topographic attributes of watersheds. The park has three main types of bedrock - basaltic/carbonate, granitic, and siliciclastic - that yield streams with higher, medium, and lower ANC values, respectively. The U.S. Geological Survey and the University of Virginia, in cooperation with the National Park Service, conducted a study of the response of Shenandoah National Park streams to acid rain input. The purpose of the study, which began in 2002, was to develop a tool that can predict the vulnerability of streams in the park to changes in streamwater chemistry caused by acid rain input. Although qualitative assessments can be made on the basis of geology alone, a quantitative tool can provide more useful information for decision makers.

The University of Virginia's Shenandoah Watershed Study (SWAS) has been monitoring hourly discharge and weekly and occasionally hourly water quality of five streams in the park for up to 15 years. Although geologic and topographic data for the park's 231 watersheds are readily available, equivalent measurements of streamwater ANC and accompanying discharge are not and would be prohibitively expensive to collect. Modeled predictions of the vulnerability of the park's streams to episodic acidification are an alterna- 
tive to long-term water-quality monitoring; these predictions can aid park officials in making management decisions.

Transfer function time series models were developed to predict hourly ANC from discharge for the five SWAS watersheds that have long-term records of water quality and discharge. Hourly ANC predictions over short time periods $(6,24,72$, and 168 hours) were averaged and distributions of the recurrence intervals of annual water-year minimum ANC values were modeled for the same periods. Prediction error was reduced substantially by use of a time series transfer function model that included outlier identification and modeling. Models for the recurrence of episodes of a given magnitude and duration were related to physical characteristics of watersheds, specifically, bedrock geology and elevation metrics such as minimum and average elevation. Regression equations were developed that predict the parameters of the recurrence interval models from geologic and topographic metrics. These equations allowed recurrence interval models to be developed for other watersheds in the park; these extrapolations to other park watersheds were done on the basis of watershed geology and topography. Finally, maps were created that show the vulnerability of park streams to episodic acidification at selected recurrence intervals.

The models and resulting maps indicate that large portions of the park are vulnerable to episodic acidification. That is, large areas have from 6- to 168-hour periods of low-ANC values that are associated with deleterious effects on resident brook trout and other fish populations. The results indicate that smaller watersheds and higher elevation watersheds are more vulnerable to episodic acidification than larger and lower elevation watersheds on the same bedrock. This difference in vulnerability among watersheds may reflect thinner or younger soils at higher elevations, and/or a greater effect of short-term acidic deposition. Because of these additional factors, and the way the park watersheds were delineated, the estimates of vulnerability probably are considered conservative.

Additional results of the modeling effort indicate that substantial areas of the park are vulnerable to ANC decreases that could preclude the presence of some fish species. For example, approximately 14 percent of the park watersheds are predicted to have 72-hour periods of average ANC less than $0 \mu \mathrm{eq} / \mathrm{L}$ at least once every 2 years. At this frequency, these watersheds can be expected, with a probability greater than 90 percent, to have 4 continuous years of 72-hour periods of average ANC less than $0 \mu \mathrm{eq} / \mathrm{L}$ at least once in the next 40-100 years.

Precise relations between episodic acidification and fish populations are still unknown. This analysis modeled the magnitude, frequency, and duration of a water-quality parameter in streamwater using flood and low-flow frequency methods. Although ANC is a commonly used water-quality indicator, additional indicators, such as inorganic monomeric aluminum concentrations, may need to be explored to ensure that predictions of fish population distributions are as accurate as possible. Studies of water-quality variations at all watershed scales within the park and of the effect of geology relative to flow regime would also help elucidate the effects of acid rain on park streamwater and on aquatic biota.

\section{Acknowledgments}

The authors acknowledge the NPS/USGS Water-Quality Partnership Program and the U.S. Environmental Protection Agency for SWAS program support. The authors acknowledge Michael J. Focazio and Earl A. Greene, USGS, for providing technical reviews of the report, and Robert B. Banks, USGS, for graphics support.

\section{References Cited}

Appalachian Voices and National Parks Conservation Association, 2004, Code Red-America's five most polluted national parks, available online and accessed on June 29, 2005, at http://www.npca.org/across_the_nation/visitor_experience/ clear_air/code_red/default.asp

Baadecker, P.A., Edney, E.O., Moran, P.J., Simpson, T.C., and Williams, R.S., 1990, Effects of acidic deposition on materials, NAPAP Report 19, in Acidic deposition: State of science and technology: Washington, D.C., National Acid Precipitation Assessment Program, 279 p.

Baker, J.P., and Christensen, S.W., 1991, Effects of acidification on biological communities in aquatic ecosystems, in Charles, D.F. ed., Acid deposition and aquatic ecosystems: Regional case studies: New York, Springer-Verlag, 747 p.

Baker, L.A., Herlihy, A.T., Kaufmann, P.R., and Eilers, M.J., 1991, Acidic lakes and streams in the United States-The role of acidic deposition: Science, v. 252, p. 1151-1154.

Baldigo, B.P., and Murdoch, P.S., 1997, Effect of stream acidification and inorganic aluminum on mortality of brook trout in the Catskill Mountains, New York: Canadian Journal of Fisheries and Aquatic Sciences, v. 54, p. 603-615.

Baldigo, B.P., and Lawrence, G.B., 2000, Composition of fish communities in relation to stream acidification and habitat in the Neversink River, New York: Transactions of the American Fisheries Society, v. 129, p. 60-76.

Bricker, O.P., and Rice, K.C., 1989, Acidic deposition to streams-A geology-based method predicts their sensitivity: Environmental Science and Technology, v. 23, no. 4, p. 379-385.

Bricker, O.P., and Rice, K.C., 1993, Acid rain: Annual Review of Earth and Planetary Sciences, v. 21, p. 151-174.

Brockwell, P.J., and Davis, R.A., 1996, Introduction to time series and forecasting: New York, Springer-Verlag, 420 p. 
Bulger, A.J., Dolloff, C.A., Cosby, B.J., Eshleman, K.N., Webb, J.R., and Galloway, J.N., 1995, The "Shenandoah National Park: Fish in Sensitive Habitats (SNP: FISH)" project-An integrated assessment of fish community responses to stream acidification: Water, Air, and Soil Pollution, v. 85 , p. 309-314.

Bulger, A.J., Webb, J.R., and Cosby, B.J., 2000, Current and projected status of coldwater fish communities in the southeastern U.S. in the context of continued acid deposition: Canadian Journal of Fisheries, v. 57, p. 1515-1523.

Chen, Chung, and Liu, Lon-mu, 1993, Joint estimation of model parameters and outlier effects in time series: Journal of the American Statistical Association, v. 88, no. 421, Theory and Methods, p. 284-297.

Davies, T.D., Tranter, Martyn, Wigington, Jr., P.J., and Eshleman, K.N., 1992, 'Acidic episodes' in surface waters in Europe: Journal of Hydrology, v. 132, p. 25-69.

Driscoll, C.T., Lawrence, G.B., Bulger, A.J., Butler, T.J., Cronan, C.S., Eagar, C., Fallon-Lambert, K., Likens, G.E., Stoddard, J.L., and Weathers, K.C., 2001, Acidic deposition in the northeastern U.S.-Sources and inputs, ecosystem effects, and management strategies: BioScience, v. 51, p. 180-198.

Graham, J.A., Grant, L.D., Folinsbee, L.J., Garner, D.E., Schlesinger, R.B., Overton, J.H., Lounsbury, S.W., McCurdy, T.R., Hasslelblad, V., McKee, D.J., Richmond, H.M., Polkowsky, B.V., and Marcus, A.H., 1990, Direct health effects of air pollutants associated with acidic precursor emissions, NAPAP Report 22, in Acidic deposition: State of science and technology: National Acid Precipitation Assessment Program, Washington, D.C., 133 p.

Grant, E.H.C., Jung, R.E., and Rice, K.C., 2005, Stream salamander species richness and abundance in relation to environmental factors in Shenandoah National Park: American Midland Naturalist, v. 153, p. 155-163.

Grant, L.D., Elias, R., Nicholson, W., Goyer, R., and Olem, H., 1990, Indirect health effects associated with acidic deposition, NAPAP Report 23, in Acidic deposition: State of science and technology: National Acid Precipitation Assessment Program, Washington, D.C., 173 p.

Huntington, T.G., 2000, The potential for calcium depletion in forest ecosystems of southeastern United States-Review and analysis: Global Biogeochemical Cycles, v. 14, no. 2, p. 623-638.

Kite, G.W., 1977, Frequency and risk analyses in hydrology: Fort Collins, Colo., Water Resources Publications, 224 p.
Lawrence, G.B., Burns, D.A., Baldigo, B.P., Murdoch, P.S., and Lovett, G.M., 2001, Controls of stream chemistry and fish populations in the Neversink Watershed, Catskill Mountains, New York: U.S. Geological Survey WaterResources Investigation Report 00-4040, 16 p.

Lynch, D.D., and Dise, N.B., 1985, Sensitivity of stream basins in Shenandoah National Park to acid deposition: U.S. Geological Survey Water-Resources Investigation Report 85-4115, $61 \mathrm{p}$.

Marshall, Lisa, 1993, Mechanisms controlling variation in stream chemical composition during hydrological episodes in the Shenandoah National Park, Virginia: Charlottesville, University of Virginia, Master's thesis, 166 p.

Pinol, Josep, and Avila, Anna, 1992, Streamwater pH, alkalinity, $\mathrm{pCO}_{2}$ and discharge relationships in some forested Mediterranean catchments: Journal of Hydrology, v. 131, p. 205-225.

Rantz, S.E., 1982a, Measurement and computation of streamflow: Volume 1. Measurement of stage and discharge: U.S. Geological Survey Water-Supply Paper 2175, 284 p.

Rantz, S.E., 1982b, Measurement and computation of streamflow: Volume 2. Computation of discharge: U.S. Geological Survey Water-Supply Paper 2175, p. 285-631.

Rao, A.R., and Hamed, K.H., 2000, Flood Frequency Analysis: Boca Raton, Fla., CRC Press, 349 p.

Rice, K.C., Maben, S.W., and Webb, J.R., 2001, Water-quality data of soil water from three watersheds, Shenandoah National Park, Virginia, 1999-2000: U.S. Geological Survey Open-File Report 01-236, 17 p. Available on-line at http://va.water.usgs.gov/online_pubs/OFR/01-236.pdf.

Riggs, H.C., 1968, Frequency curves: Techniques of waterresources investigations of the U.S. Geological Survey, chapter A2, book 4, Arlington, Va., 15 p.

Riggs, H.C., 1972, Low-flow investigations, Techniques of water-resources investigations of the U.S. Geological Survey, chapter B1, book 4, Washington, D.C., 18 p.

SAS Institute, Inc., 2003, SAS OnlineDoc® 9.1., Cary, NC: SAS Institute Inc.

Smith, J.A., Baeck, M.L., Steiner, M., and Miller, A.J., 1996, Catastrophic rainfall from an upslope thunderstorm in the central Appalachians: The Rapidan storm of June 27, 1995: Water Resources Research, v. 32, no. 10, p. 3099-3113.

Smith, R.A., 1872, Air and rain-the beginnings of a chemical climatology: London, Longmans \& Green, 600 p. 
Sullivan, T.J., Cosby, B.J., Laurence, J.A., Dennis, R.L., Savig, K., Webb, J.R., Bulger, A.J., Scruggs, M., Gordon, C., Ray, J., Lee, E.H., Hogsett, W.E., Wayne, H., Miller, D., and J.S. Kern, 2003, Assessment of Air Quality and Related Values in Shenandoah National Park: NPS/NERCHAL/NRTR03/090, U.S. Department of the Interior, Philadelphia, Pennsylvania. (On-line at www.nps.gov/shen/air_quality.htm)

Vana-Miller, D.L., and Weeks, D.P., 2004, Shenandoah National Park, Virginia water resources scoping reportTechnical report NPS/NRWRS/NRTR-2004/320: United States Department of the Interior, National Park Service, $138 \mathrm{p}$.

Virginia Division of Mineral Resources, 2003, Digital representation of the 1993 geologic map of Virginia: Virginia Division of Mineral Resources Publication 174 [CD-ROM; 2003, December 31]. Adapted from Virginia Division of Mineral Resources, 1993, Geologic map of Virginia: Virginia Division of Mineral Resources, scale 1:500,000.

Waltemeyer, S.D., 2002, Analysis of the magnitude and frequency of the 4-day annual low flow and regression equations for estimating the 4-day, 3-year low-flow frequency at ungaged sites on unregulated streams in New Mexico: U.S. Geological Survey Water- Resources Investigation Report 01-4271, $22 \mathrm{p}$.

Webb, J.R., Deviney, F.A., Galloway, J.N., Rinehart, C.A., Thompson, P.A., and Wilson, S., 1994, The acid-base status of native brook trout streams in the mountains of VirginiaA regional assessment based on the Virginia Trout Stream Sensitivity Study: Report to the Virginia Department of Game and Inland Fisheries, 75 p.

Webb, J.R., 1999, Synoptic stream water chemistry, in Bulger, A.J., and others, Shenandoah National Park-Fish in sensitive habitats: Project Final Report Volume II for U.S. National Park Service, p. 1-50.

Webb, J.R., Deviney, F.A., Cosby, B.J., and Galloway, J.N., 2001, Regional trends in the acid-base status of western Virginia stream waters: 1988-1999: Report to the National Park Service, 49 p.

Whitehead, P.G., Neal, Colin, Seden-Perriton, S., Christophersen, Nils, and Langan, S., 1986, A time-series approach to modelling stream acidity: Journal of Hydrology, v. 85, p. 281-303.

Wigington, Jr., P.J., Davies, T.D., Tranter, Martyn, and Eshleman, K.N., 1990, Episodic acidification of surface waters due to acidic deposition, NAPAP Report 12, in Acidic deposition: State of science and technology: National Acid Precipitation Assessment Program, Washington, D.C., $200 \mathrm{p}$. 

Appendix A and B 


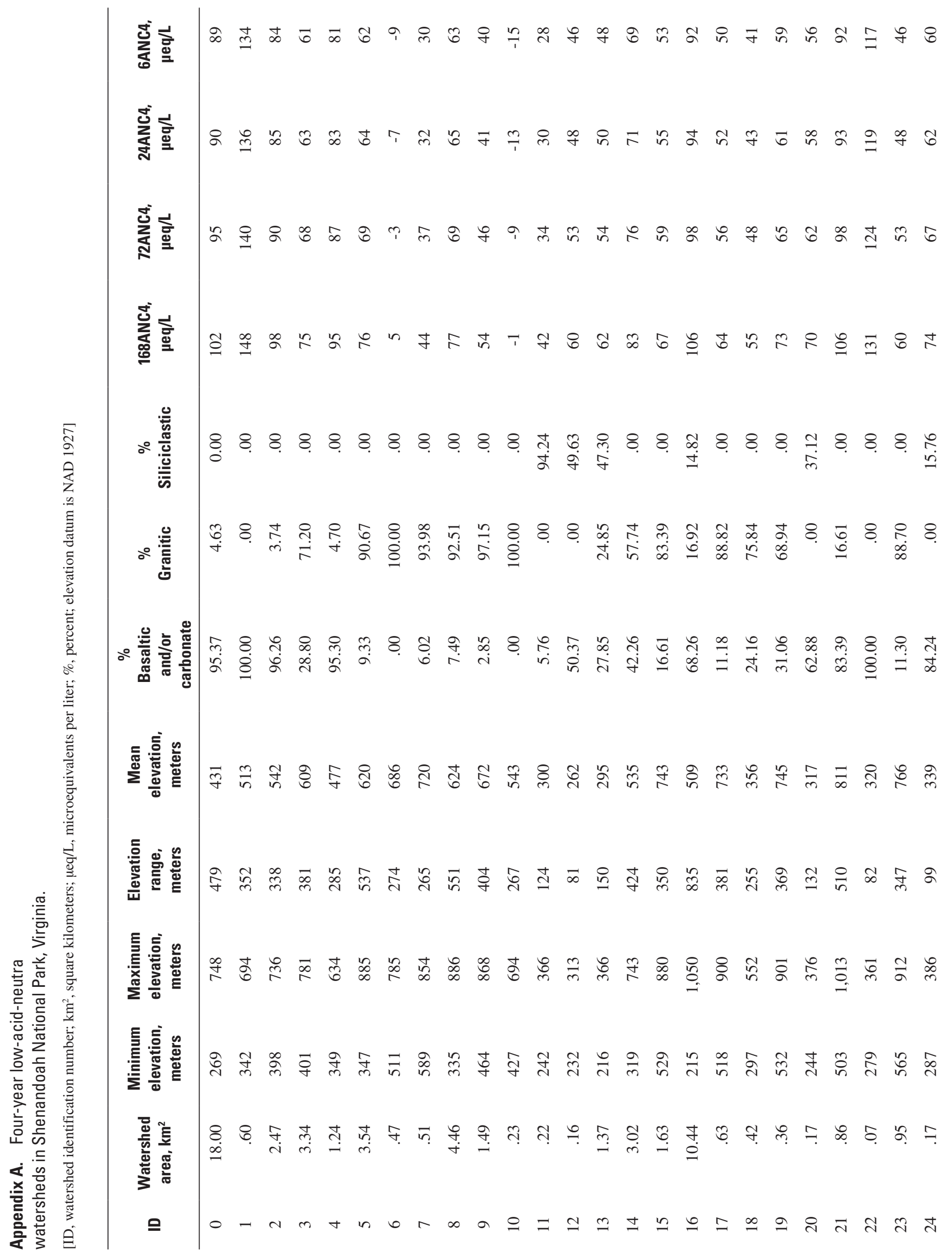




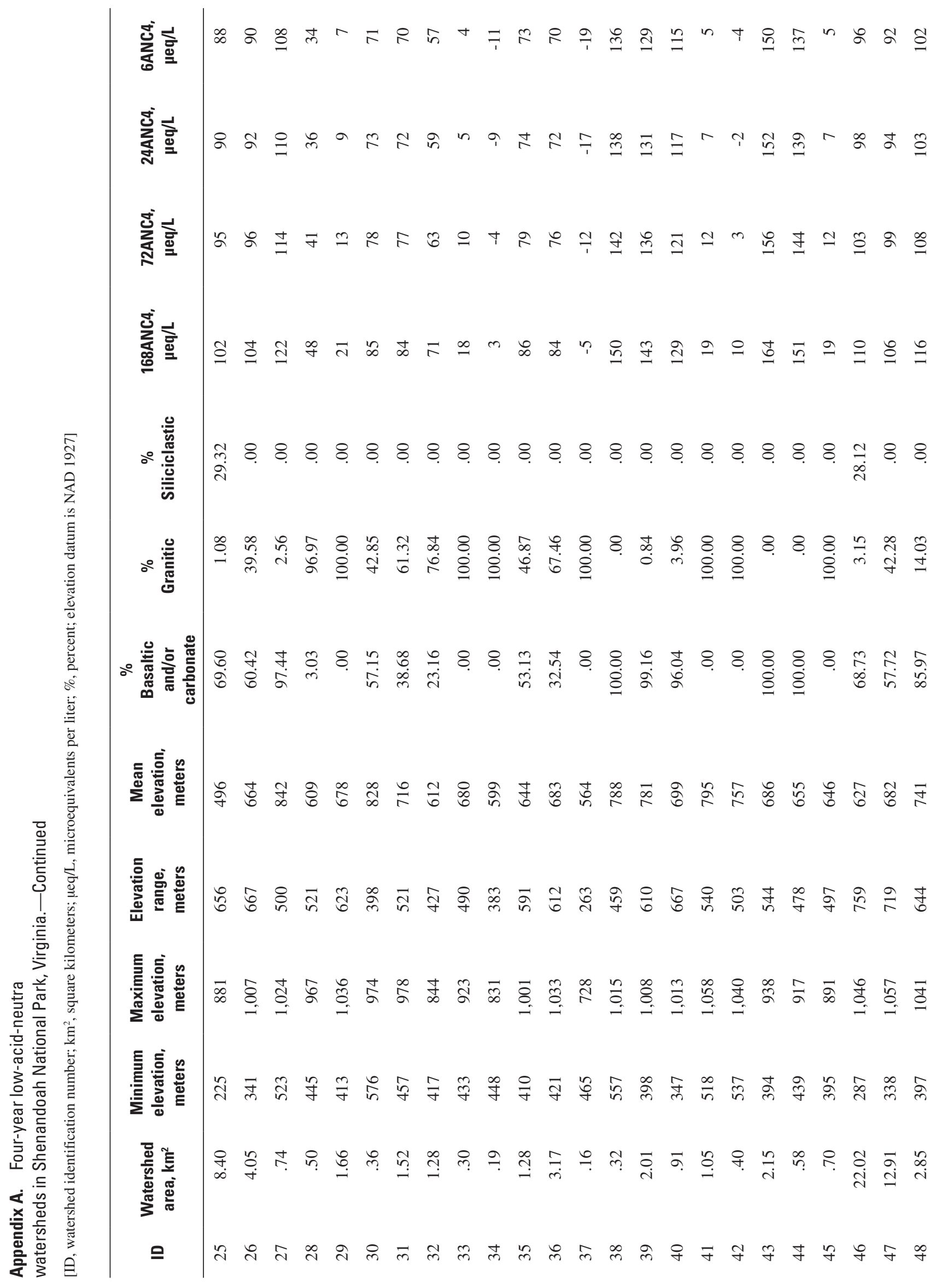




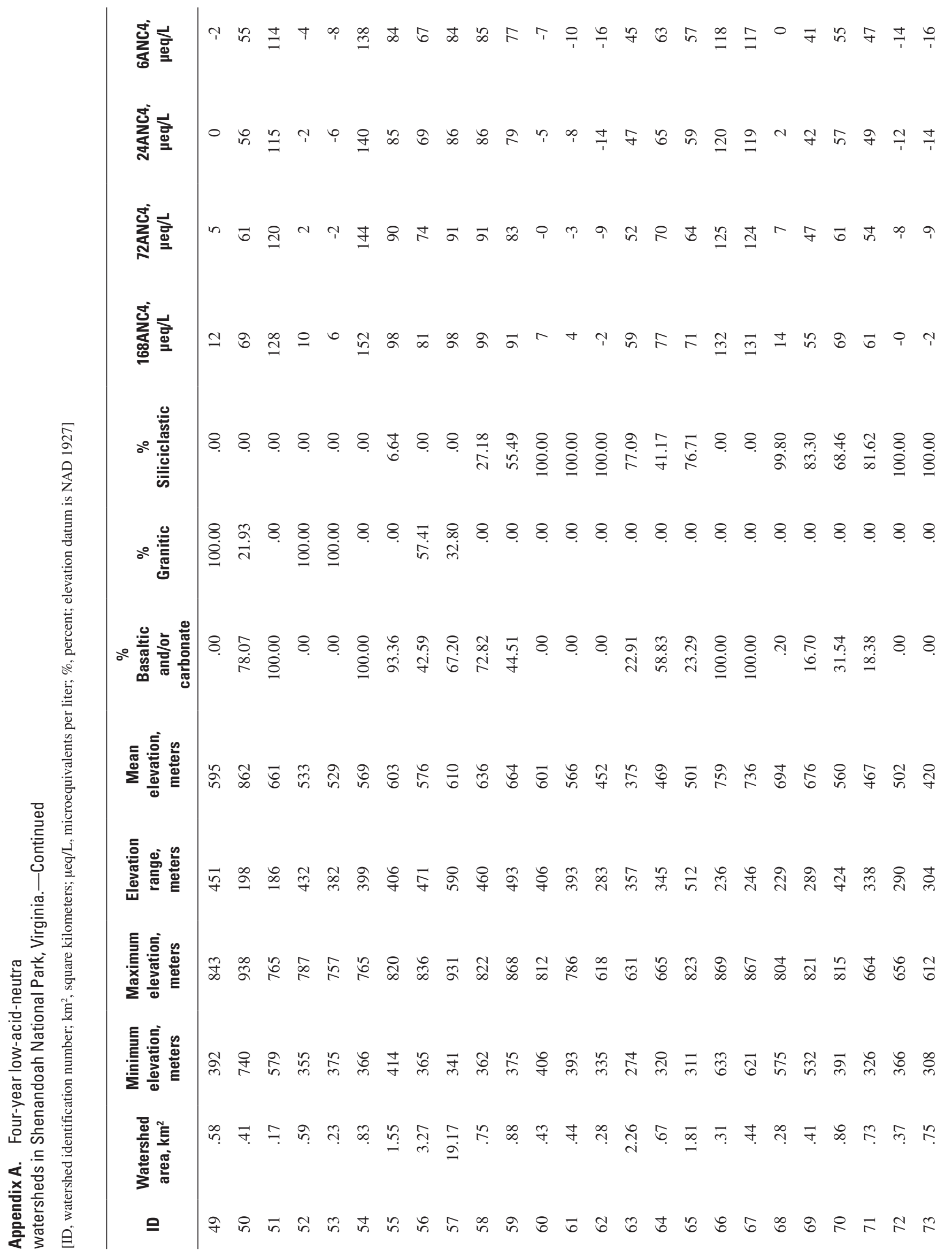




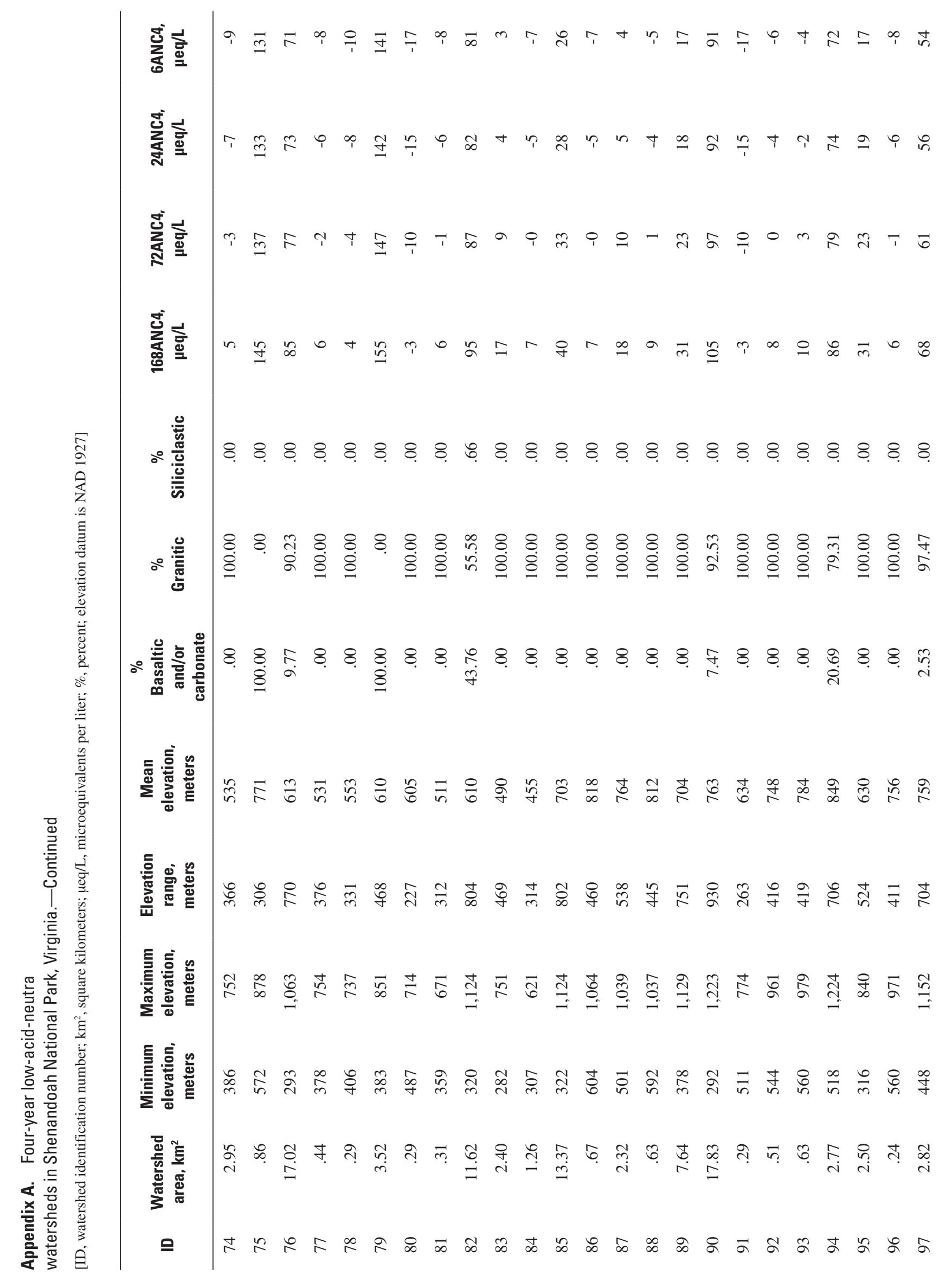




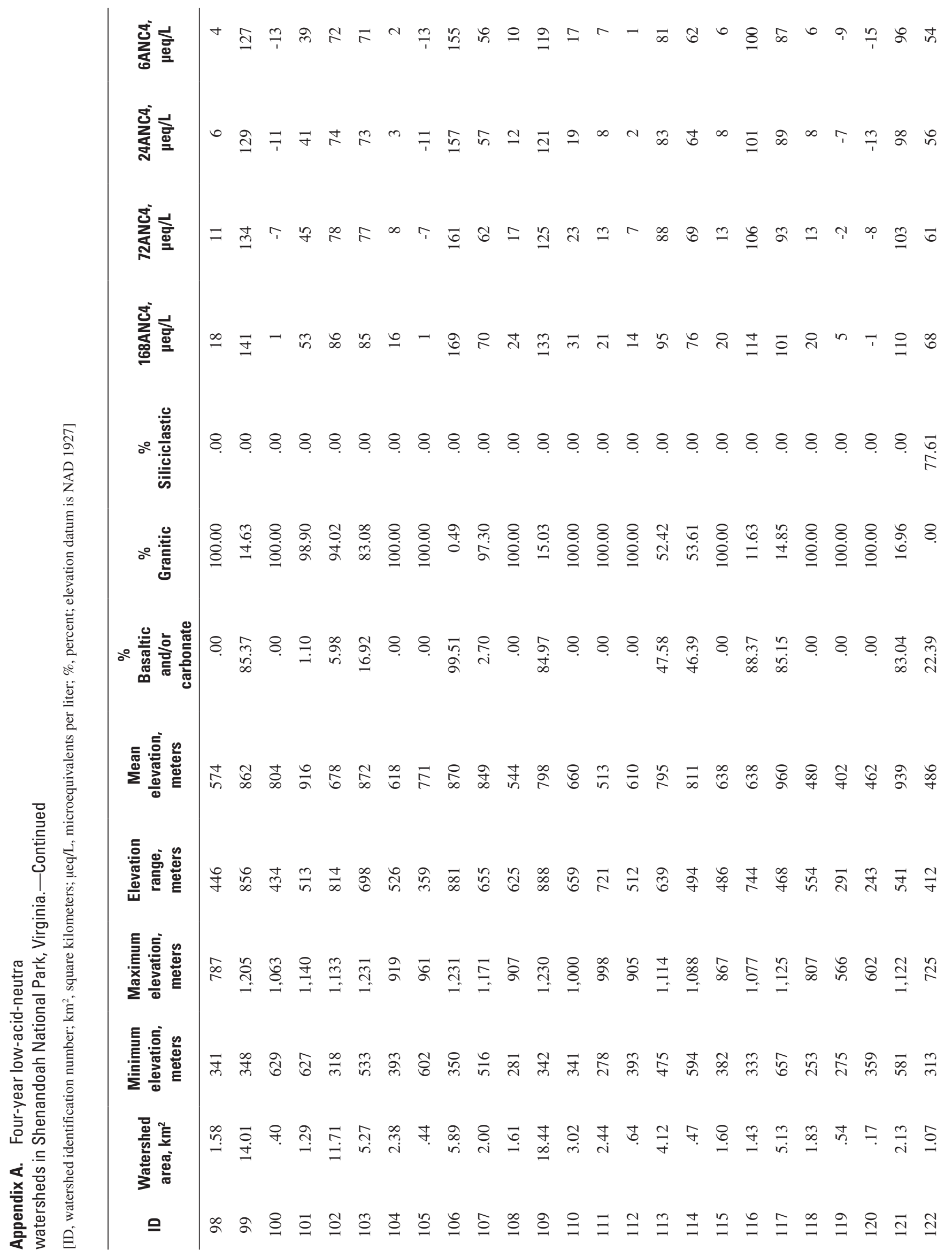




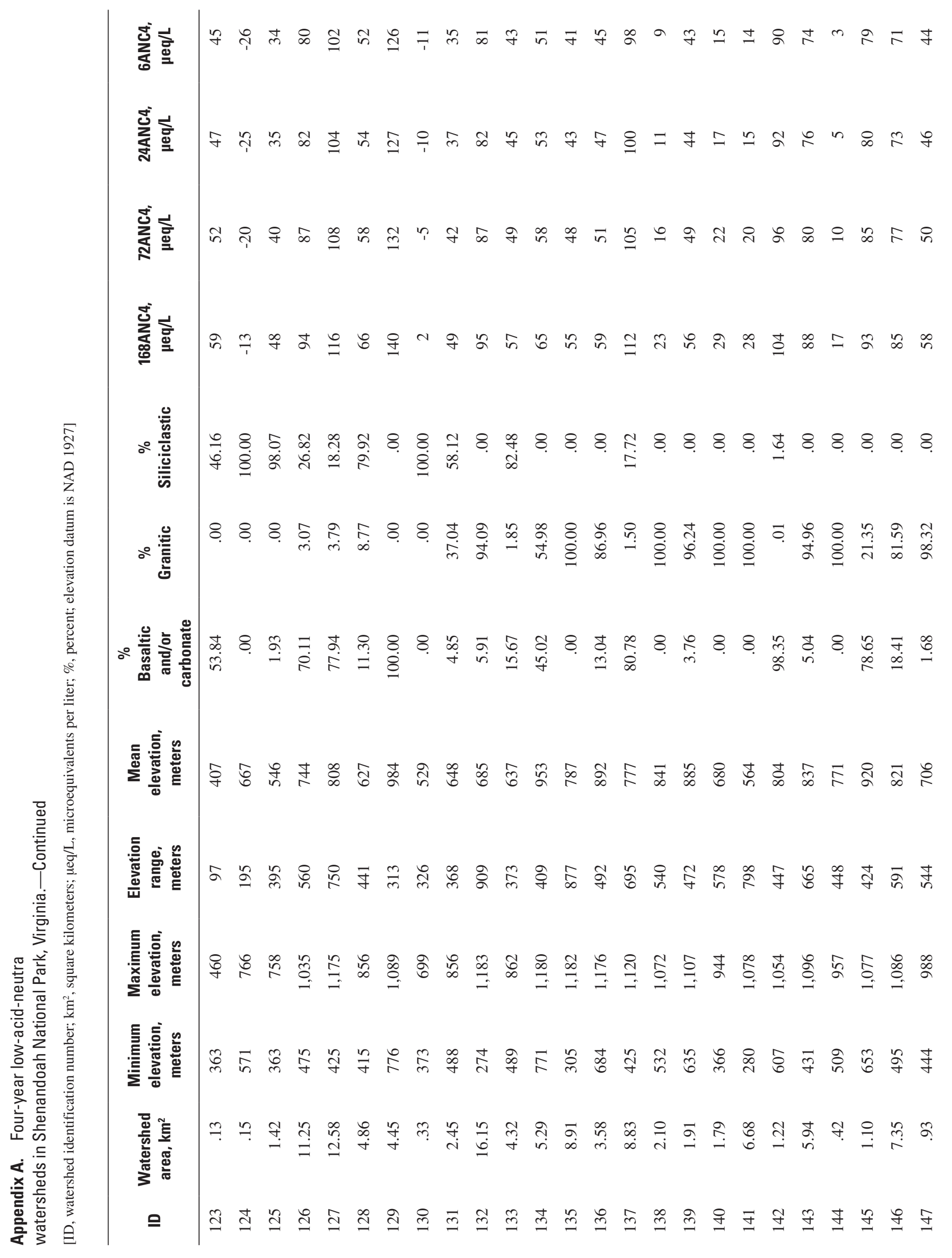




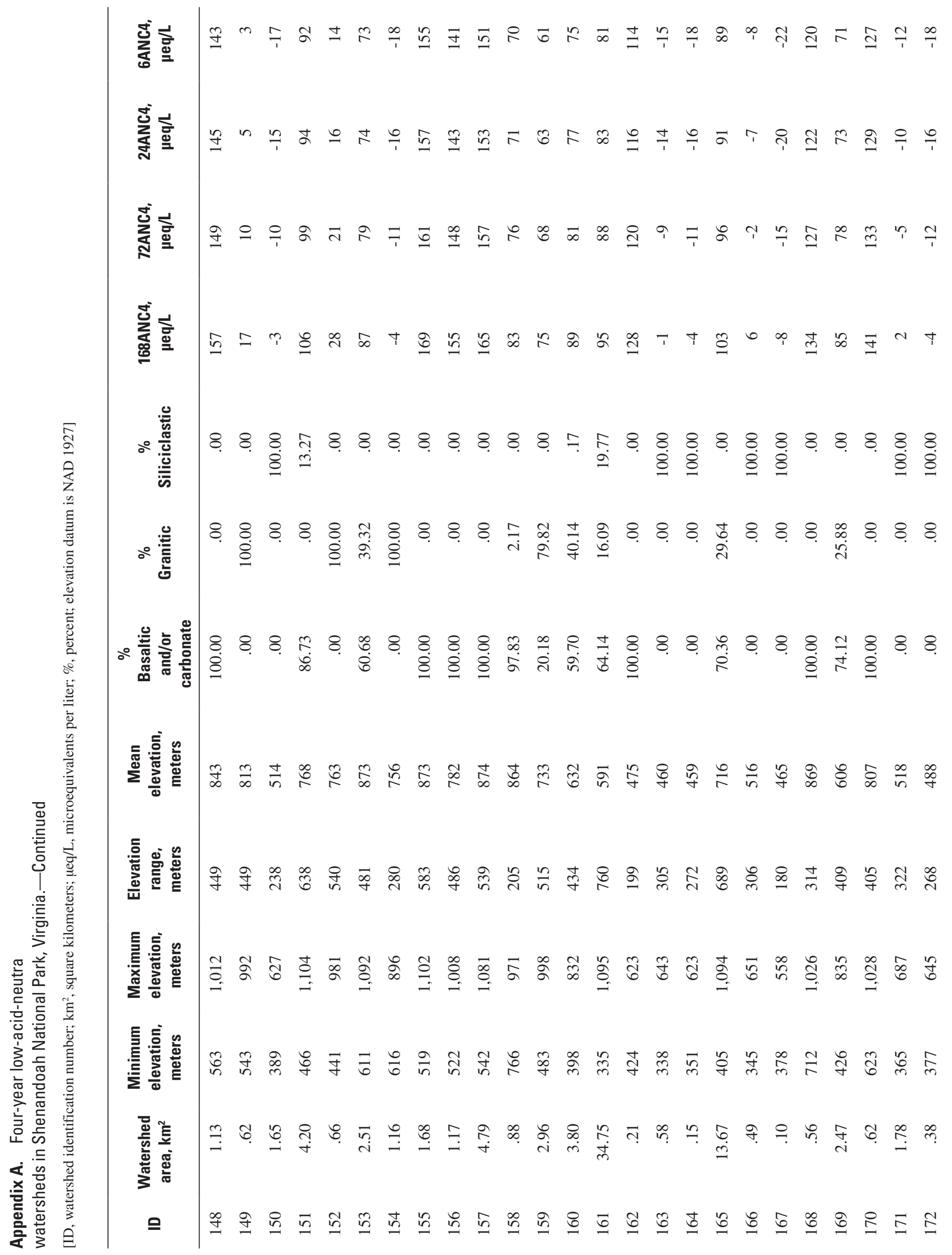




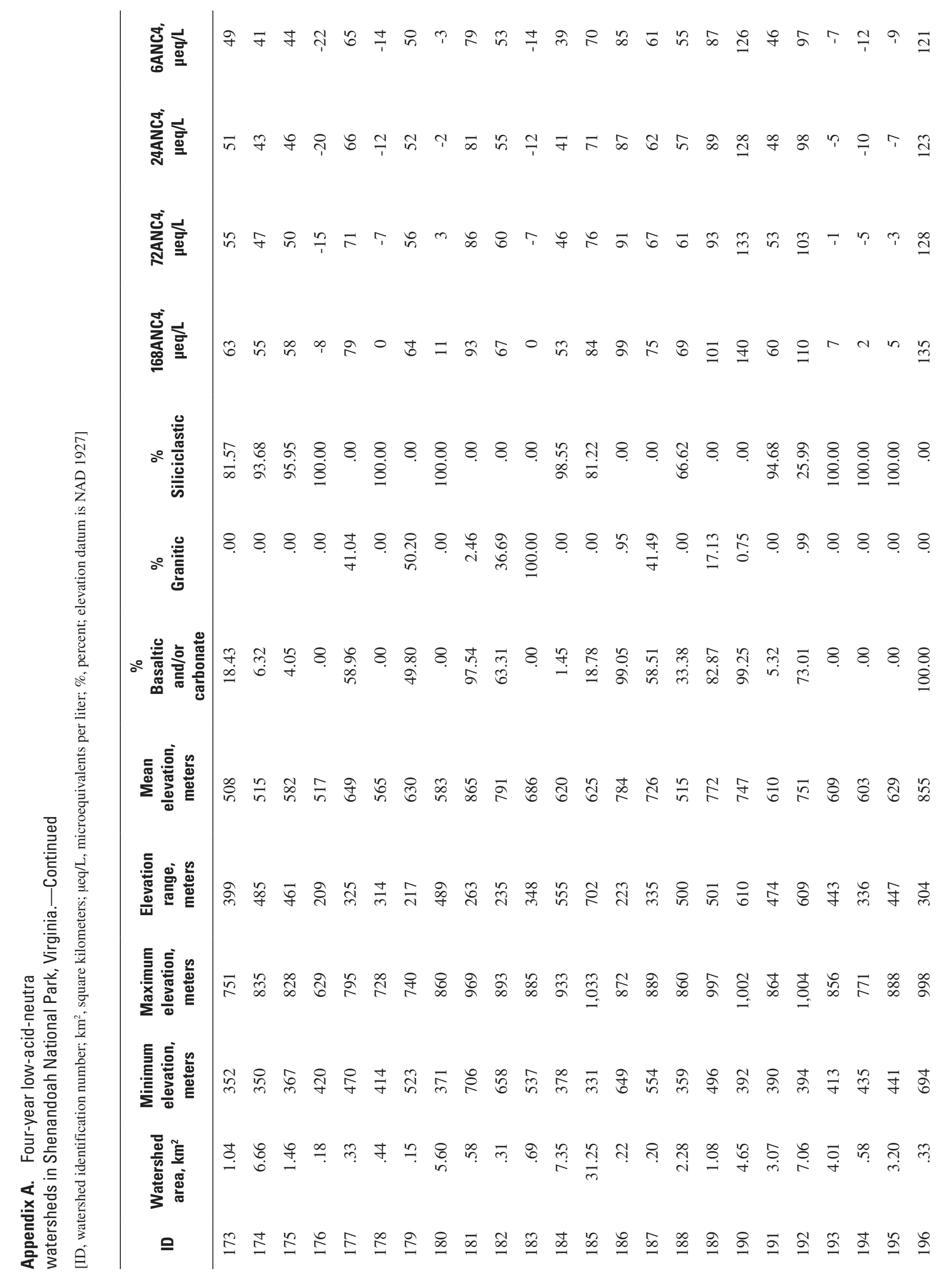




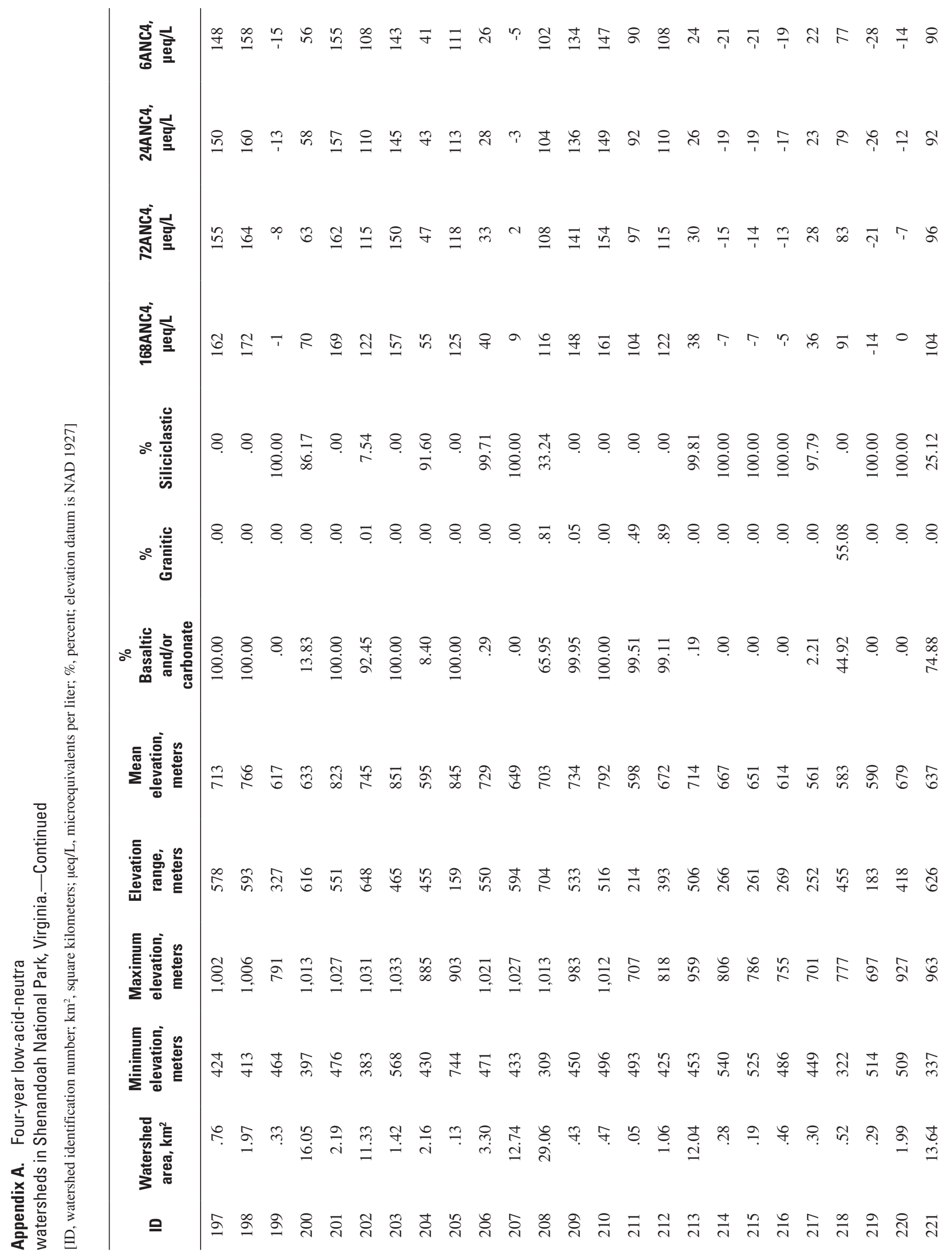




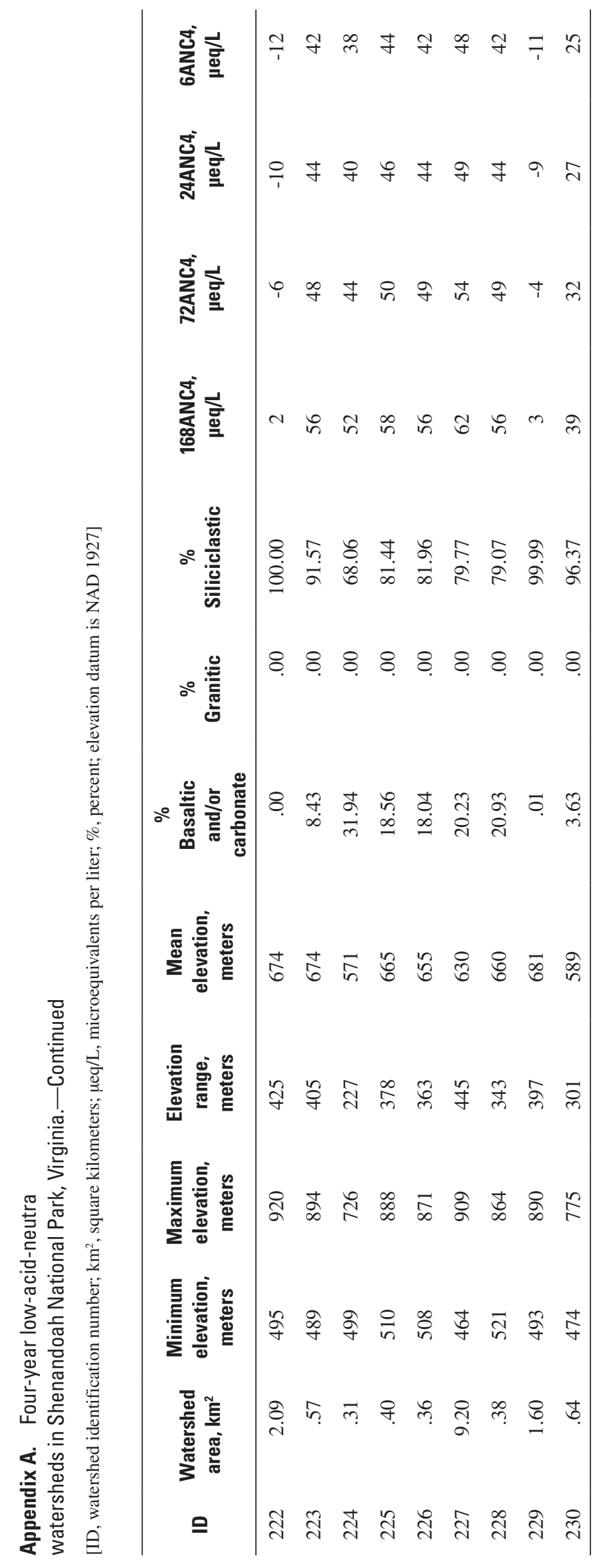




\section{Appendix B. Streamgaging techniques used by the Shenandoah Watershed Study (SWAS), Virginia.}

Approximately 5-10 discharge measurements are made at each site per year using a Marsh-McBirney Flomate 2000 flow meter; previous Marsh-McBirney models were used in the past. Field technicians follow procedures described in Harrelson and others (1994) and record measurements on waterproof paper. Two discharge measurements are taken during each site visit. The stream is divided into approximately 25 equal-width segments, although at low flow there may be fewer segments and/or the technician may decide to concentrate segments in the high-flow segment of the stream. Each segment measurement is taken at a depth equal to 60 percent of the total depth at the point (except at very shallow depths), using a 20 -second average. In the office, the segment measurements are entered into a computerized form, which calculates the total discharge for each of the two discharge measurements. Discharge measurements can be rated as "good," "fair," or "poor." Poor measurements are excluded from rating curve determination. The discharge measurements and stage heights are stored in an electronic database.

During initial site set up, rating curves were determined at least annually. Discharge measurements taken since the last rating curve were used to generate the new rating curve, and the new curve was used to estimate discharge from stage height for a period determined by the analyst.

Currently (2005), all available and acceptable discharge measurements are used for rating curve determination, but more recent measurements are given greater weight than previous measurements. The assumption is that the channel is continuously changing, but that the error in measurement is great enough that confidence in the most recent measurement is not great enough to justify radical changes in the rating curve. A new rating curve is generated each time a flow measurement is taken, and that curve is applied to stage heights observed since the last rating curve. Rating curves are uniquely identified and stored in an electronic database. Each observation in the discharge record includes a link to the rating curve used to estimate it.

The rating curve is assumed to be a linear relation between the natural logarithms of discharge and stage. That is,

$\ln (Q)=a \ln (s-e)+b+\varepsilon$,

where $Q$ is discharge, $s$ is stage height, $a$ is the slope, $b$ is the intercept, $e$ is the theoretical stage height of zero flow, and $\varepsilon$ is the error. Values for $a, b$, and $e$ are estimated using PROC NLP (SAS Institute, Inc., 2003) to minimize the weighted sum of squared errors between predicted discharge and measured discharge. That is, the idea is to minimize

$W S S E=\sum_{i=1}^{N} w_{i}\left(\ln \left(Q_{i}\right)-(a \ln (s-e)+b)\right)^{2}$,

where $w_{i}$ is the weight applied to the squared error associated with observation $i$. The weight for each observation was set equal to

$w_{i}=\lambda(1-\lambda)^{N-i}$,

and $\lambda$ was set equal to 0.05 (prior to October 1,2003) or 0.10 (beginning October 1,2003). The result is a set of weights that decline exponentially back in time from the most recent observation. Note that the sum of weights equals 1 in the limit. For $\mathrm{N}<\infty$, the sum will be less than one. Increasing the weights proportionally so that the sum equals 1 , however, does not result in different values of $a, e$, and $b$, because the adjustment can be made by multiplying the right-hand side by a constant.

Plots of the rating curve parameters are examined, with particular emphasis on $e$. Because the parameters are correlated, however, a $\mathrm{T}^{2}$ control chart provides the primary means for detecting an out-of-control measurement process. 
Ideally, discharge measurements should be taken across a range of flows. Histograms of the percentile ranks of discharge measurements taken at each site were plotted and compared visually to a theoretical uniform distribution (fig. B-1). Little, if any, bias exists in measurements towards either low or high flows at all sites (fig. B-1).
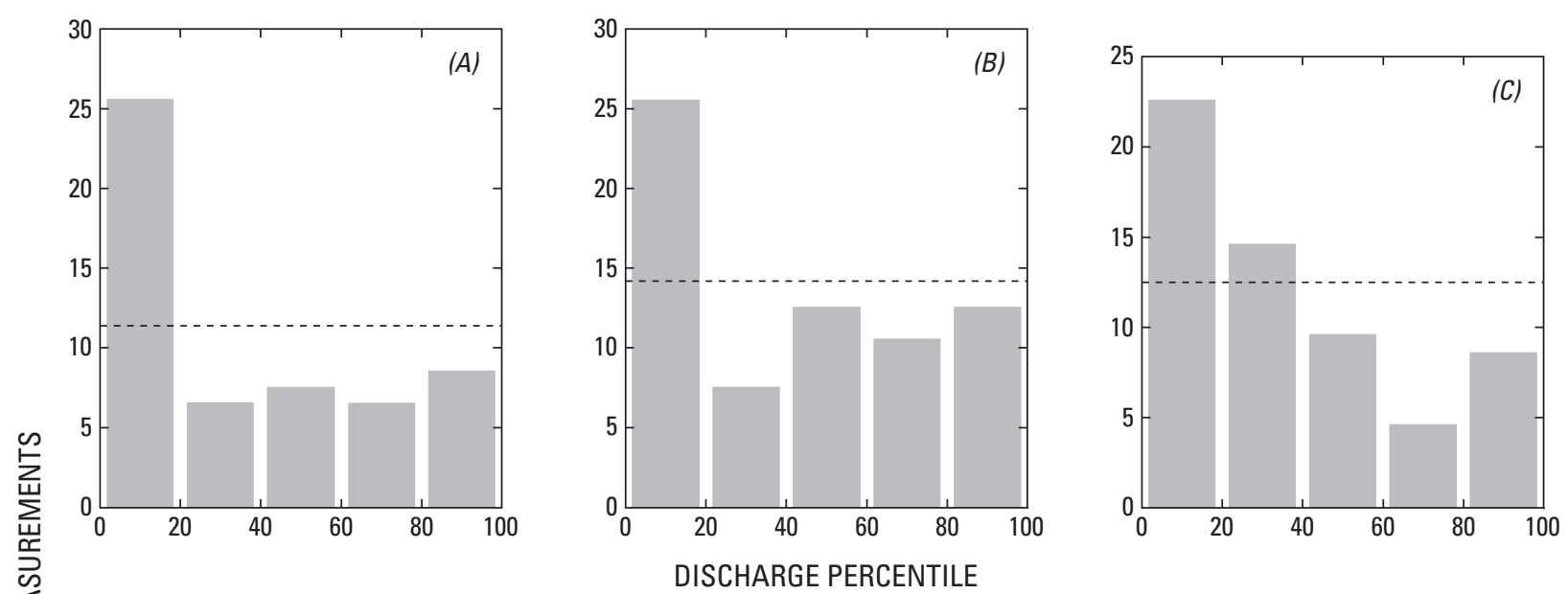

DISCHARGE PERCENTILE
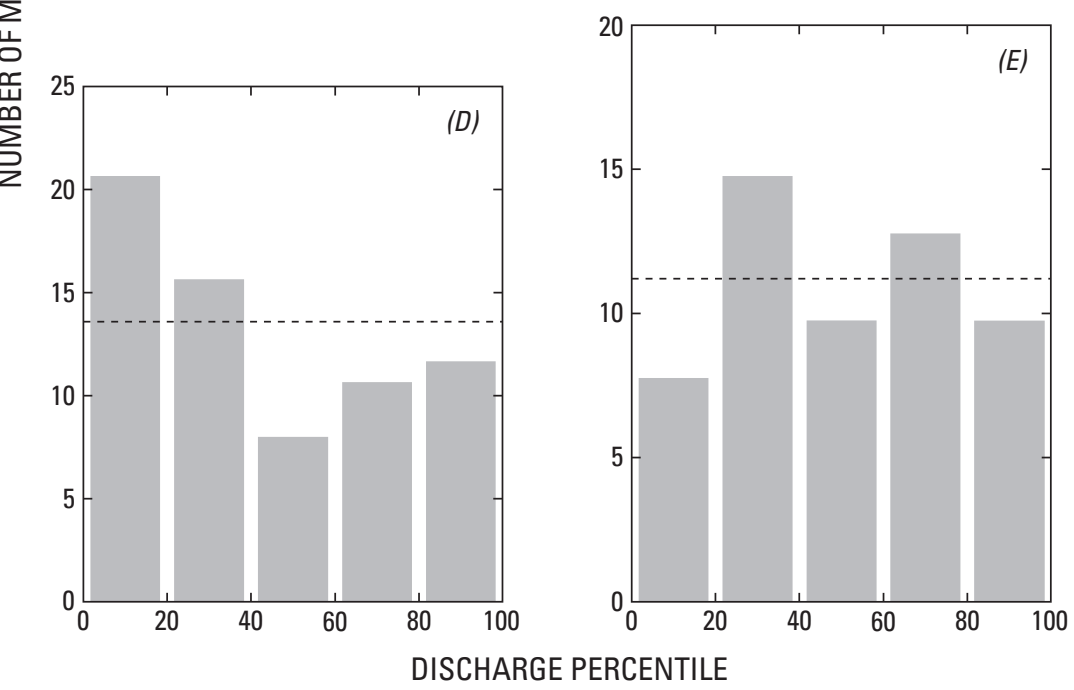

Figure B-1. Histograms of percentile of discharge measurements taken at North Fork of Dry Run (A), Paine Run (B), Piney River (C), Staunton River (D), and White Oak Run (E) for the Shenandoah Watershed Study (SWAS) watersheds, Virginia.

\section{References Cited}

Harrelson, C.C., Rawlins, C.L., and Potyondy, J.P., 1994, Stream channel references sites-An illustrated guide to field techniques, Gen. Tech. Rep. RM-245: Fort Collins, Colo., U.S. Department of Agriculture, Forest Service, Rocky Mountain Forest and Range Experiment Station, 61 p.

SAS Institute, Inc., 2003, SAS OnlineDoc® 9.1., Cary, NC: SAS Institute Inc. 